Marcos Thiago Graciani

Axiomatic choice under uncertainty: a history of von Neumann and Morgenstern's Theory of Games

Escolha sob incerteza axiomática: uma história do Theory of Games de von Neumann e Morgenstern

São Paulo 


\author{
Prof. Dr. Vahan Agopyan \\ Reitor da Universidade de São Paulo \\ Prof. Dr. Fábio Frezatti
}

Diretor da Faculdade de Economia, Administração e Contabilidade

Prof. Dr. José Carlos de Souza Santos

Chefe do Departamento de Economia

Prof. Dr. Ariaster Baumgratz Chimeli

Coordenador do Programa de Pós-Graduação em Economia 
Marcos Thiago Graciani

\title{
Axiomatic choice under uncertainty: a history of von Neumann and Morgenstern's Theory of Games
}

\section{Escolha sob incerteza axiomática: uma história do Theory of Games de von Neumann e Morgenstern}

\author{
Dissertação de Mestrado apresentada ao \\ Departamento de Economia da Faculdade de \\ Economia, Administração e Contabilidade \\ da Universidade de São Paulo (FEA-USP) \\ como requisito parcial à obtenção do título \\ de Mestre em Ciências. \\ Área de Concentração: Teoria Econômica.
}

Universidade de São Paulo — USP

Faculdade de Economia, Administração e Contabilidade

Programa de Pós-Graduação

Orientador: Pedro Garcia Duarte

\section{Versão Corrigida}

(A versão original está disponível na biblioteca da Faculdade de Economia, Administração e Contabilidade.)

São Paulo 


\section{FICHA CATALOGRÁFICA}

Elaborada pela Seção de Processamento Técnico do SBD/FEA com dados inseridos pelo autor.

Graciani, Marcos Thiago.

Axiomatic choice under uncertainty: a history of von Neumann and Morgenstern's Theory of Games / Marcos Thiago Graciani. - São Paulo, 2019.

$133 p$.

Dissertação (Mestrado) - Universidade de São Paulo, 2019.

Orientador: Pedro Garcia Duarte.

1. História da teoria dos jogos 2. Axiomática 3. Incerteza 4. Von Neumann e Morgenstern I. Universidade de São Paulo. Faculdade de Economia, Administração e Contabilidade. II. Título. 


\section{ACKNOWLEDGEMENTS}

This dissertation evolved directly from the support my parents gave me: I fully appreciate how they assisted me even if they disapproved many of my decisions so they could see me fulfill my dreams. Further, I fully acknowledge that my dissertation is not an individual accomplishment - it is undoubtedly a natural unfolding of opportunities generously placed at my hands by my parents. I wish they feel proud (even if they are not sure about what I do).

Many people helped me during my graduate studies. I am most indebted to my advisor, Pedro. He offered me unbounded assistance by sharing his experiences and encouraging me whenever difficulties arose. Besides, it gratifies me that I have him as a dear friend who I long to keep throughout the years. I should also manifest my gratitude towards professors Marcos and Roberta who so carefully read preliminary versions of my dissertation. I hope my final work can measure up for how helpful they were for me. I fell grateful to them and Catherine for participating in my defense committee and providing me great insights for future research. Naturally, many other professors participated in my still short academic journey-I should thank them in person, in any hallway we eventually meet.

The University awarded me many friends whom I should mention here: I thank Felipe for being such an excellent companion even if misfortune set us apart; Isabella for always being available to watch underestimated (some would unjustly say "low-quality") movies and TV shows; Lucas for being on my side as we overcame the daily difficulties of life as graduate students; Mariana for giving me reasons to laugh constantly (even if she didn't intend to); Tainá for encouraging me now when my future path is everything but certain. Most importantly, I thank Rafael for his love. To say I have been happy beside him would be minimizing my feelings; I hope I can convey to him how I value our relationship through different means (as I am not skilled in choosing and arranging words). I further thank our beloved Mufasa and Zazu: cats and cockatiels are great listeners (I would confidently bet they understand my research more than I do).

Finally, I should thank CAPES for financially supporting me. In full compliance to their rules, I add gratefully: "This study was financed in part by the Coordenação de Aperfeiçoamento de Pessoal de Nível Superior-Brasil (CAPES)-Finance Code 001". 



\section{RESUMO}

GRACIANI, M. T. Escolha sob incerteza axiomática: uma história do Theory of Games de von Neumann e Morgenstern. Dissertação (Mestrado) - Faculdade de Economia, Administração e Contabilidade, Universidade de São Paulo, São Paulo, 2019.

Esta dissertação estuda a recepção imediata do Theory of Games and Economic Behavior, de von Neumann e Morgenstern. Seu foco reside em como economistas (e outros cientistas, tais como matemáticos) reagiram à axiomatização da teoria de utilidade esperada composta por von Neumann e Morgenstern. Tal estudo se vale de resenhas do Theory of Games, artigos autorados por leitores proficientes em matemática que seguiram a deixa dos autores de axiomatizar teoria de escolha sob incerteza e, por fim, artigos cujas citações incluem trabalhos destes leitores habilidosos. Há três conclusões principais. Primeiro, para entender a história de recepção do Theory of Games, é importante considerar que fontes secundárias agiram como disseminadores de premissas, resultados e o próprio método do Theory of Games. Segundo, muitos leitores capazes refletiram sobre o livro de von Neumann e Morgenstern. A maioria dos que usaram tal literatura a fizeram de acordo com o método axiomático, citanto aqueles artigos para reproduzir ou adaptar hipóteses. Dentre os que os citaram para aplicar seus resultados diretamente usaram ferramentas matemáticas menos sofisticadas e não tinham como objetivo a produção de demonstrações formais, em geral. Terceiro, enquanto o axioma de independência é uma condição necessária para a teoria de utilidade esperada, economistas tiveram dificuldades em compreender como von Neumann e Morgenstern usaram-no. Não estava claro para eles onde o Theory of Games o havia escondido. Uma vez que os economistas descobriram o axioma, não encontraram uso imediato para ele.

Palavras-chave: história da teoria dos jogos; axiomática; incerteza; Von Neumann; Morgenstern. 



\section{ABSTRACT}

GRACIANI, M. T. Axiomatic choice under uncertainty: a history of von Neumann and Morgenstern's Theory of Games. Dissertation (Master) - School of Economics, Administration, and Accounting, University of São Paulo, São Paulo, 2019.

This dissertation studies the immediate reception of von Neumann and Morgenstern's Theory of Games and Economic Behavior. It focuses on how economists (and other scientists, such as mathematicians) reacted to von Neumann and Morgenstern's axiomatization of expected utility theory. Such study employs book reviews the Theory of Games received, articles authored by mathematically-proficient readers who followed von Neumann and Morgenstern's lead of axiomatizing choice under uncertainty, and articles that cited the later. The main conclusions are threefold. First, to understand the history of the Theory of Games' reception it is unavoidable to consider how secondary sources acted as disseminators of its premises, results, and method. Second, many skilled authors reflected on von Neumann and Morgenstern's book. Most economists who used that literature in an axiomatic framework cited such contributions to borrow and adapt assumptions. Those who applied results directly generally used less-sophisticated mathematical tools and were not proof-driven. Third, while the independence axiom is a necessary condition for expected utility theory, economists struggled to understand how von Neumann and Morgenstern used it. It was not clear where the Theory of Games hid that assumption. After economists discovered the independence axiom, they did not find an immediate use for it.

Keywords: history of game theory; axiomatics; uncertainty; Von Neumann; Morgenstern. 



\section{LIST OF FIGURES}

Figure 1 - Column Maxima and Row Minima . . . . . . . . . . . . . . . 49

Figure 2 - Mixed Strategies and Saddle-Points . . . . . . . . . . . . . . 52

Figure 3 - Visual Approach to Intransitivity . . . . . . . . . . . . . . . 56

Figure 4 - Graphical Model of One Seller and Two Buyers . . . . . . . . . . . 57

Figure 5 - Cowles' Logo: "Science is Measurement" . . . . . . . . . . . . . 67

Figure 6 - Marschak's "Domain" and "Feasible Set" . . . . . . . . . . . . . . 82

Figure 7 - Marschak's "Postulate $\mathrm{IV}_{1}$ " and "Postulate $\mathrm{IV}_{2}$ " . . . . . . . . . . . 83

Figure 8 - The "Theorem of Mixtures" . . . . . . . . . . . . . . 97 



\section{LIST OF TABLES}

Table 1 - The Theory of Games' Book Reviews . . . . . . . . . . . . . . . . 22

Table 2 - Cowles Commission Seminars, January 1, 1949-June 30, 1949 . . . . . . 71

Table 3 - Cowles Commission Seminars, July 1, 1950-February 15, 1951 . . . . . 72 



\title{
LIST OF SYMBOLS
}

\author{
The negation operation. \\ The set of natural numbers (zero excluded). \\ $\mathbb{R} \quad$ The set of real numbers. \\ $\mathbb{R}_{+} \quad$ The set $\{x \in \mathbb{R}: x>0\}$. \\ $n \quad$ An element of $\mathbb{N}$ representing a number of commodities or outcomes. \\ $\mathscr{X} \quad$ A commodity space or a set of outcomes (a subset of $\mathbb{R}_{+}^{n} \cup\{0\}$ ). \\ $\mathscr{L} \quad$ A space of simple lotteries (a subset of $\left\{\left(p_{1}, \ldots, p_{n}\right) \in \mathbb{R}_{+}^{n} \cup\{0\}\right.$ : \\ $\left.\left.\sum_{i=1}^{n} p_{i}=1\right\}\right)$. \\ $\mathfrak{g} \quad$ A relation on $\mathscr{X}$ or $\mathscr{L}$ (meaning "at least as good as"). \\ $\mathfrak{p} \quad$ A relation on $\mathscr{X}$ or $\mathscr{L}$ (meaning "strictly preferred than"). \\ $\mathfrak{i} \quad$ A relation on $\mathscr{X}$ or $\mathscr{L}$ (meaning "indifferent to"). \\ $\mathfrak{g}^{T} \quad$ The transpose of $\mathfrak{g}$. \\ $\mathfrak{p}^{T} \quad$ The transpose of $\mathfrak{p}$. \\ $I_{j} \quad$ Given $L_{j} \in \mathscr{L}$, the set $\left\{L \in \mathscr{L}: L \mathfrak{i} L_{j}\right\}$. \\ $u \quad$ A utility function or index $u: \mathscr{X} \rightarrow \mathbb{R}$. \\ $U \quad$ An expected utility function $U: \mathscr{L} \rightarrow \mathbb{R}$. \\ ○ Function composition.
}





\section{CONTENTS}

Introduction $\ldots \ldots \ldots \ldots \ldots \ldots \ldots \ldots$

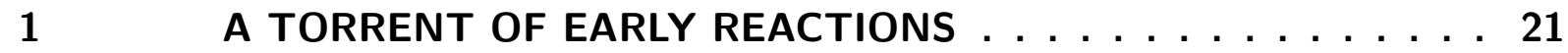

1.1 A Path Through Book Reviews . . . . . . . . . . . . . 23

1.2 The Theory of Games' Immediate Reception . . . . . . . . . . 27

1.2.1 Reviews in Statistics, Philosophy and Social Sciences . . . . . . . . . . . . 28

1.2.2 Reviews in Economics and Mathematics . . . . . . . . . . . . . . . 36

1.3 Reviewers Who Translated . . . . . . . . . . . . 47

1.4 The Delicate Subject of Non-Ordinal Utility . . . . . . . . . . 59

$1.5 \quad$ Concluding Remarks . . . . . . . . . . . . . . . . . 65

2 TWO WAYS OUT OF UNCERTAINTY . . . . . . . . . . . 67

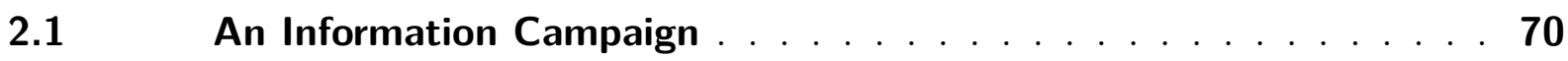

$2.2 \quad$ Crafting Two Paths to Existence and Uniqueness . . . . . . . . . 73

2.2.1 The Cowles Discussions Papers . . . . . . . . . . . . . . . . . . . 74

2.2.2 The Econometrica Papers . . . . . . . . . . . . . . . . 80

2.3 How Economists Reacted to Marschak and Herstein . . . . . . . . 86

2.3.1 Organizing Previous Results . . . . . . . . . . . . . . 87

2.3.2 New Research Possibilities . . . . . . . . . . . . . . . . . . 93

$2.4 \quad$ Concluding Remarks . . . . . . . . . . . . . . . . . 98

3 THE TWISTED HISTORY OF INDEPENDENCE . . . . . . . 101

$3.1 \quad$ Nash's Controversial Debut in Economics . . . . . . . . . 103

3.1.1 Expected Utility in Nash's Bargaining Model . . . . . . . . . . . . . . 104

3.1.2 How Economists Reacted to Nash . . . . . . . . . . . . . . . . . . . 106

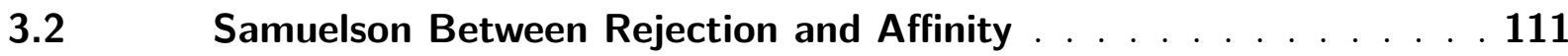

3.2.1 Samuelson's Puzzle: Where is Independence? . . . . . . . . . . . . . 112

3.2.2 How Economists Reacted to Samuelson . . . . . . . . . . . . . . . . 116

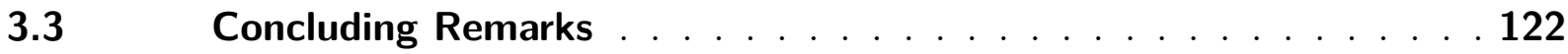

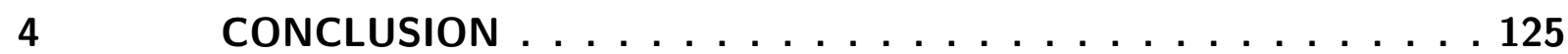

BIBLIOGRAPHY $\ldots \ldots \ldots \ldots \ldots \ldots \ldots \ldots \ldots$ 



\section{INTRODUCTION}

Expected utility theory is everywhere in micro and macroeconomics. Besides its role as a standard approach to choice under uncertainty, its usefulness reaches game theory, contract theory, dynamic stochastic general equilibrium models, and many other branches of economics. Present-day economists relate expected utility theory to Daniel Bernoulli's work (a Swiss mathematician from the eighteenth century; for instance, Mas-Colell, Whinston and Green (1995, p. 184) call utility index functions "the Bernoulli function" for such an association). However, considering how modern economists approach that framework by presenting a list of axioms governing preferences and establishing properties and facts by chaining successive statements and proofs, expected utility theory is far more connected to John von Neumann and Oskar Morgenstern's Theory of Games and Economic Behavior (hereafter Theory of Games), published in 1944, than to Bernoulli's legacy. Indeed, in a survey of the subfield of individual decision-making over risky alternatives, Arrow (1951a, p. 405) classified the Theory of Games' publication as one disruptive event of that subfield precisely because of its "axiomatic treatment [...] leading to a new understanding of the rule of maximizing the expected utility".

Though today expected utility theory's dominance is well-acknowledged (to illustrate, most economics Ph.D. students only learn it when it comes to individual choice under uncertainty), when the Theory of Games appeared most economists did not immediately accept its approach to preference representation, nor they embraced the axiomatic method as a standard reasoning tool. Reasons for the Theory of Games' unenthusiastic welcome were manifold, but two were fundamental. First, by the early 1940s economists had just finished an exhaustive debate that lasted over twenty years about how they should interpret utility and what properties representation of preferences should have. They concluded that values a utility function assumes should be unrelated to any concrete meaning (that is, they resolved utility functions could not measure individual pleasure or well-being). Moreover, they settled that such mappings should be unique up to increasing transformations (that is, applying an increasing transformation on a utility function would not imply a loss of its property of representing preferences). In opposition, expected utility functions are inherently unique up to positive affine transformations. Economists interpreted that type of uniqueness implied in the measurement of pleasure or well-being, so they read it as an unsatisfactory property. Consequently, von Neumann and Morgenstern's use of expected utility theory encountered an audience skeptical of such a form to represent preferences. Second, the Theory of Games proposed expected utility theory in an unusual way: by establishing a system of axioms and (in its second edition of 1947) formal proofs of existence and uniqueness. Until then, no employment of axiomatics was as widely influential as the 
Theory of Games became in economics. To illustrate how economists were unfamiliar with any higher mathematics, most of the United States economics departments did not require its Ph.D. students any preparation in calculus (as it is a practice in undergraduate training today) in the 1940s. ${ }^{1}$ Therefore, most economists would be locked out of the Theory of Games, unable to fully follow von Neumann and Morgenstern's arguments.

Many historians of economics worked over game theory's history after the Theory of Games appeared. For example, Leonard (2010) wrote a very detailed narrative of how von Neumann, a gifted mathematician, and Morgenstern, an Austrian economist, met and started working on a 600-page volume intended to start a full reshape of economics as a scientific field. Regarding its dissemination, Leonard's main conclusion was that the Theory of Games had first an instrumental use for military purposes - as its publication happened in the dawn of Cold War, it provided the Armed Forces with a framework to determine optimum courses of action in war-related situations. In academia, the Theory of Games had a limited impact, especially among economists. These found themselves far more interested in how von Neumann and Morgenstern resurrected a non-ordinal approach to preference representation than by their new foundation for economics. Besides Leonard's account, the History of Political Economy had in 1992 a supplement devoted to the history of game theory. It includes narratives written by professional historians and recollections of game theorists who witnessed the Theory of Games' appearance.

The history of expected utility theory and that of how economists used axiomatics after the Theory of Games have several gaps today. Fishburn and Wakker (1995) provided a general recollection of steps that choice under uncertainty went through after von Neumann and Morgenstern published their book, mentioning successive reformulations their axiomatic system would pass until it reached the form presented today in graduate textbooks. In turn, Moscati (2016) provided a narrative explaining how Paul A. Samuelson, initially skeptical towards expected utility, came to accept it in the early 1950s. Similarly, Herfeld (2017) investigated why some renowned mathematical economists (such as Jacob Marschak) approached choice under uncertainty via axiomatics between 1944 and the early 1950s. However, it remains unclear how the Theory of Games acted as to disseminate the axiomatic method among economists in a general sense (that is, including nonmathematical and less renowned economists) interested in individual-decision making over risky alternatives during the first years after its publication. ${ }^{2}$ This dissertation will

\footnotetext{
${ }^{1}$ Bowen (1953, pp. 134-135) surveyed graduate education in economics in the United States. He observed that several scholars felt that mathematics should become a formal requirement for Ph.D. students by interviewing faculty members of several economics departments. Still, the topic was controversial: many economists believed it was unnecessary for Ph.D. students to receive such training.

${ }^{2}$ Doehne and Herfeld (2018) employed co-citation analysis to understand how economists used and modified the Theory of Games' contributions during 1944-1970. Their focus was broader than choice under uncertainty (they also considered topics related to game theory, collective-decision making, and individual choice over riskless outcomes). In turn, this dissertation focuses on decision over uncertain outcomes. Since co-citation analysis deals with a high number of works simultaneously, it provides a wider
} 
tackle that problem. It will construct a broad picture of von Neumann and Morgenstern's reception on its first ten years of publication and will analyze how economists who had contact with it, directly or not, employed the axiomatic method in their research agendas (focusing on theoretical works on individual choice).

To analyze the Theory of Games' reception, this dissertation explores two sources of evidence. First, it uses book reviews written for von Neumann and Morgenstern's work to capture general impressions readers had (for example, to identify what key problems economists had when reading it, what controversies they raised, and how they interpreted expected utility theory). This study serves as a broad context for the Theory of Games' direct reaction (that is, how mathematically-skilled economists who read von Neumann and Morgenstern's text felt about it). Second, this dissertation explores axiomatic contributions inspired by the Theory of Games (for example, that refined its axioms or proofs) and citations they received until 1954 to understand the indirect reception of von Neumann and Morgenstern's book (since these served to open the Theory of Games' discussion to a wider audience who could not read it directly). The decision to stick to citations that appeared in articles published up to 1954 is due to Leonard J. Savage's publication of a book that generalized the Theory of Games' approach to choice under uncertainty by allowing agents to follow subjective probabilities in making decisions. Naturally, that choice of collecting citations up to 1954 imposes a limitation on this dissertation's accomplishments. This approach prevents it from answering more broadly how economists stabilized an axiomatic approach to expected utility (since by 1954 it was still under debate). Another limitation is not tracking citations to non-axiomatic articles from economists who directly had access to the Theory of Games (that would have shed some light on how von Neumann and Morgenstern's book impacted on verbal expositions and their receptions).

This dissertation has three chapters and a conclusion. Chapter 1 analyzes book reviews published in journals of economics, mathematics, statistics, philosophy, and social sciences. These provide a big picture of how economists reacted to the Theory of Games when its first two editions appeared. Furthermore, four different, unusual evaluations among these serve to show that to understand how von Neumann and Morgenstern's axiomatic approach spread itself among economists, it is crucial to consider secondary texts written by mathematically-skilled authors who would explain the Theory of Games to a more extensive audience of economists who were not mathematically trained to fully appreciate it. Chapters 2 and 3 analyze such works derived from von Neumann and Morgenstern's volume. In particular, Chapter 2 explores two articles that reshaped the Theory of Games' axiomatic system (by modifying its assumptions and demonstrations). These appeared in the Cowles Commission for Research in Economics, a leading institution in mathematical economics' history. That chapter also tracks citations to these articles to

view of the Theory of Games reception. This dissertation will focus on particular cases and detail them. 
understand what uses economists had for axiomatic expected utility theory. Chapter 3 follows an exercise similar to that of Chapter 2, but it considers two papers that are central in the history of a particular assumption of expected utility theory: the independence axiom. This hypothesis is crucial for the existence and uniqueness of expected utility functions, but economists found it confusing how von Neumann and Morgenstern applied it. 


\section{A TORRENT OF EARLY REACTIONS}

In his "Introduction" for Princeton's 60th-anniversary edition of the Theory of Games and Economic Behavior by John von Neumann and Oskar Morgenstern, Harold W. Kuhn (2007, p. vii) — a mathematician who researched game theory ${ }^{1}$ _declared: "The book reviews that greeted the publication of TGEB [the Theory of Games] were extraordinary, both in quantity and quality; any author would kill for such reviews." That particular volume reprinted some of such evaluations. Namely, those written by Herbert A. Simon, Arthur H. Copeland, Leonid Hurwicz, and Tibor Barna. Besides, Kuhn (2007, pp. vii-viii) presented a list of reviews (including some not reprinted in Princeton's commemorative edition) and begged his reader to pay "special attention to the length of these reviews, the quality of the journals, and the prominence of the reviewers". ${ }^{2}$ His point was that the Theory of Games had reviews in prestigious periodicals elaborated by prominent economists.

Journals of multiple fields hosted at least nineteen reviews of von Neumann and Morgenstern's book: evaluations stemmed from economics, mathematics, statistics, philosophy, and social sciences. Indeed, some of them were surprisingly lengthy. For instance, Hurwicz's, Marschak's, Carl Kaysen's, and Stone's assessments ranged from 15 to 19 pages. Table 1 lists all of the Theory of Games' reviews. ${ }^{3}$

Naturally, numerous reviews were of "regular size": they had 6.5 pages on average, and half of them possessed up to four pages (in contrast to evaluations from Hurwicz, Marschak, Kaysen, and Stone). The journal prestige of some evaluations is also noticeable. By current standards, the names The American Economic Review, The Review of Economic Studies, and The Economic Journal draw any economist's attention. Moreover, some reviewers have indisputable prominence in our discipline: Simon, Stone, and Hurwicz (alongside Eric S. Maskin and Roger B. Myerson) became Nobel laureates in 1978, 1984, and 2007, respectively. Although Kuhn (2007, p. viii) added that some quotes from these reviews were "a publisher's dream", he felt the Theory of Games was nonetheless "too

\footnotetext{
${ }^{1}$ Usually, economists know Kuhn from his set of first-order conditions for solutions of nonlinear programming problems named "Karush-Kuhn-Tucker Conditions".

${ }^{2}$ Princeton University Press' commemorative edition listed reviews from Herbert A. Simon, Arthur H. Copeland, Leonid Hurwicz, Jacob Marschak, Tibor Barna, Carl Kaysen, David Hawkins, John R. N. Stone, Erik Ruist, Georges-Théodule Guilbaud, E. Justman, and K. G. Chacko.

${ }^{3}$ This dissertation explores reviews written in English and published in research journals exclusively. Still, the Theory of Games received evaluations in different languages - as Guilbaud's, a forty-five-page review in French for Economie Appliquée - and non-academic periodicals - as Claude Chevalley's "Theory of Games" for View, an American magazine. Guilbaud's was particularly important in disseminating game theory in France. Kuhn (2007, p. x) stated: "Among the reviews and reviewers, the review of G. Th. Guilbaud is surely unique. [...] it contained not only an account of the main themes of the TGEB but also went further into consideration of the difficulties that the theory then faced." His assessment received a translation in 1951 (see Guilbaud ([1949] 1951)), what is unusual for a book review.
} 


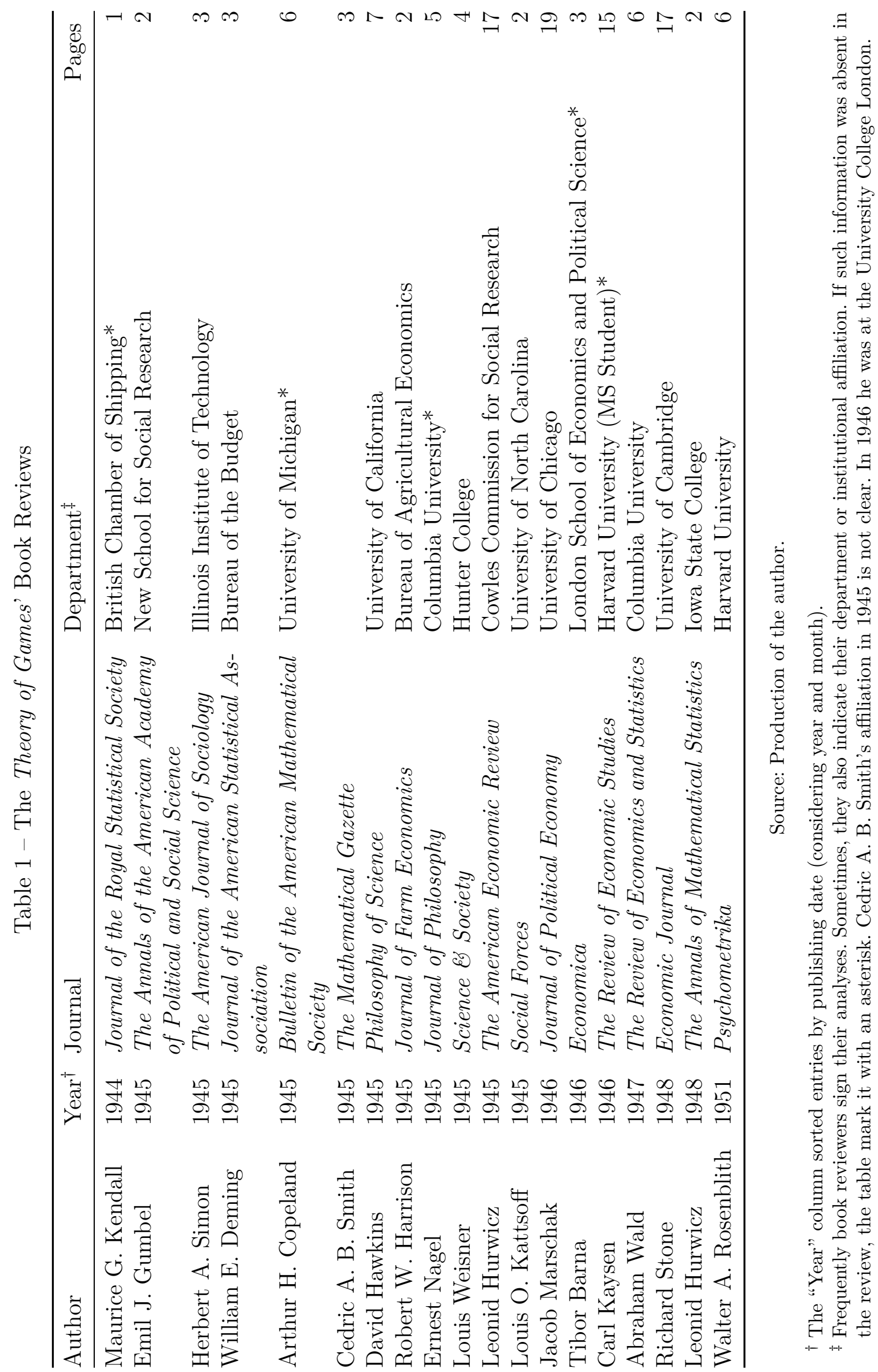


mathematical" for economists' taste (KUHN, 2007, p. xii). Admittedly, von Neumann and Morgenstern ([1944] 2007, p. vi) themselves advised that an "economically interested reader" would find an "easier approach" to their book in reviews authored by Hurwicz and Marschak in their preface for the Theory of Games' second edition, dated of 1947. As Leonard documented, only a few readers would have full access to it:

\begin{abstract}
Although the book found isolated, thorough readers such as Gérard Debreu, Herbert Simon, and John Harsanyi, and although von Neumann's treatment of expected utility caught the interest of economistsstatisticians such as Friedman and Savage, the work as a whole was not widely embraced by the community of economists. As predicted by von Neumann and heralded in some of the reviews, the book's mathematical apparatus, difficulty of access, and sheer strangeness of subject combined to make it appear rebarbative in the eyes of many economist readers. (LEONARD, 2010, p. 264)
\end{abstract}

This chapter analyses how the Theory of Games' book reviews portrayed it. The main conclusion is that secondary sources - research which ensued from von Neumann and Morgenstern's volume - are essential in understanding how economists received the Theory of Games. Section 1.1 introduces a historiographical framework to support further considerations and highlights particular features of book reviews as study objects for the history of economics. It also takes a historiographical approach focused on practices (due to Stapleford (2017)) to study the Theory of Games' history. Section 1.2 analyzes several such evaluations (again, see Table 1), identifying how reviewers felt about von Neumann and Morgenstern's text and what information and opinions they conveyed for their readers. Section 1.3 shows how reviews from Hurwicz, Marschak, Kaysen, and Stone acted as translators of the Theory of Games' points, summarizing its concepts and results in an informal setting capable of reaching a larger audience than von Neumann and Morgenstern's original volume. Section 1.4 inspects how commentators characterized utility and axiomatics in their writings since these are of fundamental concern to the following chapters.

\title{
1.1 A PATH THROUGH BOOK REVIEWS
}

Historians of economics can build narratives using different historiographical methods. A historian of mathematics, Corry advanced a framework designed to address unique features of his field of interest. ${ }^{4}$ In particular, Corry (1989, p. 413) employed it to discuss

\footnotetext{
${ }^{4}$ Leonard (2010) provided important background information about how von Neumann and Morgenstern met and started working on a new foundation for economics and what economists first did when they read the Theory of Games. More interestingly, Leonard (2010, pp. 233-240) commented how von Neumann had a particular way of working on axiomatics. Weintraub and Mirowski (1994) had a similar point about Gérard Debreu and his relationship with mathematics. These works show personal values and views have an important role in mathematical economics. Here, choosing Corry's framework is a reaction to these earlier findings in the literature.
} 
mathematics' "reflexive character", a label he used to designate simultaneously two characteristics of that discipline. ${ }^{5}$ First, "what is mathematics?" remains an open question for mathematicians. Second, mathematics can study itself mathematically (that is, it can use its tools to study itself as a branch of knowledge; an example is proof theory: it interprets demonstrations as mathematical objects in themselves, subject to analysis by logic and other instruments). Regardless of Corry's specific research agenda, his framework applies to other scientific disciplines, such as economics. For instance, Weintraub (2002) adopted it to argue how it became a mathematical science. Corry's platform has two essential categories to analyze statements in a discipline. In his words,

\begin{abstract}
We may distinguish, broadly speaking, two sorts of questions concerning every scientific discipline. The first sort are questions about the subject matter of the discipline. The second sort are questions about the discipline qua discipline, or second-order questions. It is the aim of a discipline to answer the questions of the first sort, but usually not to answer questions of the second sort. These second-order questions concern the methodology, philosophy, history, or sociology of the discipline and are usually addressed by ancillary disciplines. (CORRY, 1989, p. 411)
\end{abstract}

Corry (1989, p. 411) labeled these first- and second-order questions "body" and "image" of knowledge. Respectively, they encompass "theories, 'facts,' methods, and open problems" and "guiding principles, or selectors". To illustrate, statements answering how agents choose under uncertainty (for instance, maximizing an expected utility function) and guidelines governing how economists model or theorize individual decision-making over risky alternatives (for example, striving for rigor and mathematical tractability) belong to body and image, accordingly. ${ }^{6}$ However, statements are not readily discernible between body and image for many reasons. First, body and image are not always separable, especially because values related to images play roles in electing what body problems are most important and how those could be adequately tackled, slipping into them inherently. Second, Corry ([1996] 2004, p. 3) argued second-order problems are usually "implicitly or tacitly" answered: only a few practitioners deal with them explicitly and intentionally. Then nearly every attempt to characterize some scientist's image of his discipline would have to follow from body statements in his published works. Third, these categories are contingent on time and space: historians can at most affirm that some statement refers to one or another only given historical circumstances. That is, characterizations of body and image are not timeless: they vary in time as history evolves.

There are numerous historiographies at hand for historians of economics to choose from. Concerning how von Neumann and Morgenstern's book helped to disseminate the

\footnotetext{
${ }^{5}$ Corry ([1996] 2004) used his framework to question how "mathematical structure", a regularly employed terminology in mathematics, could be historically characterized.

${ }^{6}$ Economists usually assign different meanings for "risk" and "uncertainty". A discussion about how economists interpreted them during the 1940s and early 1950s is beyond scope here. Henceforward, consider "risk" and "uncertainty" to be synonyms (meaning simply the absence of certainty in general terms).
} 
axiomatic method among economists, Corry's images of knowledge are especially helpful since they distinguish two dimensions in economists' texts. In particular, axiomatics seems to be in-between body and image as it plays an active role in raising questions and answering them. ${ }^{7}$ Also, it carries aesthetic values: among any two systems of axioms, economists commonly perceive one of greater generality, simplicity, and rigor as superior. However, to carelessly characterize images relying on published material, taking written declarations for granted, could be potentially misleading in developing a narrative. ${ }^{8}$ Stapleford (2017) proposed a solution. His approach of analyzing practices (see definition in his words below) is appropriate to understand the Theory of Games' reception because it puts a magnifier on how economists sustain and evaluate their knowledge production. Corry's and Stapleford's approaches mesh well since they support the coexistence of different systems of assessment (for instance, some economists believe it is better to address choice under uncertainty axiomatically, whether others do not share that view) and recognize some past contributions that can possibly be perceived as irrelevant nowadays could had a meaningful role in the stabilization of these practices (for example, the articles Chapters 2 and 3 focus on might not be interpreted today as important for choice under uncertainty but they were essential in the formation of what economists today understand for expected utility). Combining them is important here because while Stapleford guides historians on how to approach shreds of evidence, Corry stresses what features are important and how they can relate to each other:

Practices, as I'm using the term here, are comprised of three components: (1) collections of actions that are (2) linked by teleology (they can be understood as elements in a goal-oriented process) and (3) are subject to normative evaluation (they, or the overall process of which they are a part, can be done poorly or well). These three components have different roles. Practices are constituted by relationships of accountability that provide the normative assessments. That normativity implies teleological claims, views of what constitutes relative success in the practice. Finally, practices are enacted through embodied actions, typically involving other people or artifacts. (STAPLEFORD, 2017, p. 116)

To understand the Theory of Games' reception, it is crucial to know what openproblems it approached and what controversies it raised among economists. Dimand and Dimand (1995) and Leonard (2010, pp. 260-264) explored the Theory of Game's book reviews to build a context for it. This first chapter will give book reviews a fuller analysis, as Dimand and Dimand (1995) focused on strategic optimization-related topics and Leonard (2010, pp. 260-264) used them to sketch a big picture of von Neumann and Morgenstern's reception. An immediate difficulty of analyzing such material is historians of science's

\footnotetext{
${ }^{7}$ See Boumans and Dupont-Kieffer (2011, p. 23) for a similar point regarding econometrics.

${ }^{8}$ Besides the danger of considering true every statement someone wrote, characterizing an image of knowledge is not an easy task and different interpretations might arise from evidence.
} 
incomprehension about how economists write and read book reviews. ${ }^{9}$ Nevertheless, these "second class citizens of scientific literature" (as Riley and Spreitzer (1970, p. 361) called them in a survey of reviewing practices) constitute a valuable source to analyze dissemination. ${ }^{10}$ First, they have an evaluative nature. Reviewers often highlight particular features of their examined object as they will, generally outlining a book's objective, method, and significant results. Second, appraisals frequently have critiques. Reviewers react to books grounded on perceptions of their fields yet untouched by any impact the evaluated material would eventually unfold. Third, this perceptive information is not as prevalent as in published articles or other scholarly documents. Hence historians interested in how economists evaluate one another can find in book reviews written evidence in which they pass judgment on their fellows.

As an illustration, consider quotes Kuhn (2007, p. viii) reproduced in his introduction to exemplify why comments von Neumann and Morgenstern's volume received were "a publisher's dream" (emphases are not from originals): "every social scientist who is convinced of the necessity for mathematizing social theory - as well as those unconverted souls who are still open to persuasion on this point - to undertake the task of mastering the Theory of Games" (SIMON, 1945, p. 560); "Posterity may regard this book as one of the major scientific achievements of the first half of the twentieth century" (COPELAND, 1945, p. 498); "The techniques applied by the authors in tackling economic problems are of sufficient generality to be valid in political science, sociology, or even military strategy" (HURWICZ, 1945, p. 909); and "Ten more such books and the progress of economics is assured" (MARSCHAK, 1946, p. 115). These quotes relate to personal views of economics as a science (for instance, of what progress is and how some contribution can achieve it). The next section analyzes reviews of von Neumann and Morgenstern's book considering practices they embodied and giving special attention to second-order problems they elected relevant when reading the Theory of Games.

To conclude, there is no standard way to study the history of economics, even less a methodology to examine book reviews. No approach has supremacy; each type of narrative has its value for that field. However, via Stapleford's historiographical approach (focusing on practices reviewers engaged in instead of blindly believing their words) and Corry's categories (keeping in mind values economists have today were not always or close to consensual) book reviews become a fruitful source of evidence to analyze the dissemination of books; here in particular, the Theory of Games.

\footnotetext{
${ }^{9}$ Hartley (2006, p. 1194) claimed "not a lot is known about how people read and write book reviews" and "few studies have been carried out to assess the impact of book reviews on scholarly fields". There are studies dedicated to some fields (as sociology and linguistics, for instance), but to naively borrow them disregarding economics' particularities would be inaccurate.

${ }^{10}$ Riley and Spreitzer (1970, p. 361) called book reviews "second class citizens" because in interviews with journal editors they perceived practices of book reviewing as emergent, informal. There was no clear and preferred protocol to choose which books to review, how to assign each book a reviewer, or what constituted an adequate, publishable evaluation.
} 


\subsection{THE THEORY OF GAMES' IMMEDIATE RECEPTION}

Book reviews constitute a valuable source to discuss the Theory of Games' immediate reception since they captured impressions readers had when they first met to von Neumann and Morgenstern's new way of studying economic behavior. ${ }^{11}$ Naturally, some reviewers would see some of its first unfoldings, but in 1944 there was a long way for game theory and expected utility theory until they stabilized their roles in economics. Besides, reviewers can express opinions freely, unlike other scholarly published materials, such as research articles. Regardless of their helpfulness in identifying second-order questions, this section will not try to characterize any particular reviewer's image of knowledge since such a task would demand a deeper knowledge of him (of his research and career). Instead, it will focus on what burning issues evaluators highlighted when they studied von Neumann and Morgenstern's text as a mean to identify essential points for its reception among economists. $^{12}$

This section analyzes the Theory of Games' book reviews grouping them in accordance to their journals' fields. This arrangement is interesting because in the 1940s (when all but one review appeared) it was more likely that an economics journal would reach an economist than a mathematics or statistics periodical. Provided this narrative focus on how von Neumann and Morgenstern contributed to spread axiomatics as a reasoning tool among in the field of choice under uncertainty, evaluations that targeted economists and mathematicians have greater importance than those aiming researchers in other fields. Therefore, Subsection 1.2.1 discuss book reviews in journals related to statistics, philosophy, and social sciences, whereas Subsection 1.2.2 cover those of economics and mathematics. This section's objective is twofold. First, it will discuss general characteristics of book reviewing practices, as the history of economics lacks a study of such source of historical evidence. ${ }^{13}$ Second, it will use the Theory of Games book reviews to assemble a context for its immediate dissemination, electing vital topics to understand such a dispersion process. This dissertation will pursue further these points in subsequent chapters.

\footnotetext{
${ }^{11}$ Dimand and Dimand (1995) and Leonard (2010) already explored the Theory of Games' book reviews. They suggested von Neumann and Morgenstern's book would require some aid from intermediaries to disseminate its content. This chapter follows a lead left by Dimand and Dimand (1995): book reviews could have acted as such mediators between economists and the Theory of Games. It provides the history of economics a more detailed view of the Theory of Games' book reviews (using even those considered of lesser importance) and explains how some evaluations acted as intermediaries between economists and von Neumann and Morgenstern's book.

${ }^{12}$ Understanding each book reviewer's image of knowledge would result in an outright analysis of how they evaluated the Theory of Games. However, selecting a more modest objective will allow this dissertation to explore points beyond book reviews in further chapters. In this sense, book reviews serve to build a context and identify essential aspects from von Neumann and Morgenstern's welcoming for study in further Chapters 2 and 3.

${ }^{13}$ Comments on book reviewing practices should be taken lightly, as only evaluations for a single book are under analysis here. However, making such remarks is important due to the material's unusualness in the history of economics.
} 


\subsubsection{REVIEWS IN STATISTICS, PHILOSOPHY AND SOCIAL SCIENCES}

The Theory of Games received book reviews from journals in several fields aside from economics and mathematics. ${ }^{14}$ Statistics journals published two evaluations for von Neumann and Morgenstern's text. ${ }^{15}$ Statisticians Sir Maurice George Kendall ${ }^{16}$ and William Edwards Deming evaluated von Neumann and Morgenstern's volume, respectively, for the Journal of the Royal Statistical Society and the Journal of the American Statistical Association. Additionally, Ernest Nage ${ }^{17}$ and David Hawkins (at University of California, Berkeley) prepared reviews for philosophy journals; in order, The Journal of Philosophy and Philosophy of Science. Nagel's career records an interest in foundational queries (for instance, in measure theory, geometry, and probability) and methodology of social sciences. A wide diversity of disciplines attracted Hawkins, economics and mathematics included. For example, he participated in developing the "Hawkins-Simon Condition", related to input-output analysis. Finally, social sciences (and sociology, more specifically) journals invited Emil J. Gumbel, a mathematician at the New School for Social Research, Herbert A. Simon, an economist and political scientist at the Illinois Institute of Technology, and Louis O. Kattsoff, a philosophy professor at the University of North Carolina to evaluate the Theory of Games. Their assessments circulated via, respectively, The Annals of the American Academy of Political and Social Science, American Journal of Sociology, and Social Forces. All these reviews were diverse not only concerning the journals they appeared in but also on how they analyzed the von Neumann and Morgenstern's book. The next paragraphs illustrate such heterogeneity.

Most reviewers outlined the Theory of Games' content to have their readers minimally familiarized about its subject before advancing any evaluative remark. They emphasized features of it that they thought were more valuable to convey. In their preface, von Neumann and Morgenstern ([1944] 2007, p. v) asserted their book contained "an exposition and various applications of a mathematical theory of games", having two central applications: "games in the proper sense", such as poker and chess, and

\footnotetext{
${ }^{14}$ Apart from statistics, philosophy, and social sciences, which had two or three reviews each, two assessments appeared isolated. First, Louis Weisner (a mathematician) published an evaluation of von Neumann and Morgenstern's book for Science $\&$ Society. It was a periodical specialized in Marxist studies covering history, economics, philosophy, literature, and the arts. Second, Walter A. Rosenblith (a biophysicist) had one distributed by Psychometrika, which embraces any research that treated psychology quantitatively. Because Weisner's and Rosemblith's analyses alone are insufficient to make robust points on the Theory of Games' direct reception for these particular fields, this dissertation will neglect them.

${ }^{15}$ Leonid Hurwicz reviewed the Theory of Games' second edition for The Annals of Mathematical Statistics, a statistics journal. Subsection 1.2.2 analyzes it alongside his first (and more important) evaluation for The American Economic Review.

16 "M. G. K." signed the Journal of the Royal Statistical Society's book review. It is possible to infer Kendall's identity since he was a council and executive committee member from that periodical then. Richard Stone, who would also publish a book review for von Neumann and Morgenstern's text four years later in 1948, was a was a council member of the Royal Statistical Society alongside with Kendall in 1944.

${ }^{17}$ In 1945, Nagel's edited The Journal of Philosophy. This information identified "E. N.", the reviewer. Interestingly, that journal counted with von Neumann among editorial associates and advisors in 1945.
} 
"economic and sociological problems", as duopoly models. Having such a great volume as the Theory of Games and a restricted space to describe it in full detail, summaries could go in multiple directions. ${ }^{18}$ For example, in a one-page review issued in a statistics journal a few months after the Theory of Games' first publication, Kendall (1944, p. 293) succinctly judged this "unusual book's" ultimate mission was to study a problem that opposed economists' ordinary approach of constrained maximization of a utility function. For him, interdependence of player's behavior typified von Neumann and Morgenstern's rationale. Although Deming (1945, p. 264) considered they attacked the nonexistence of any "satisfactory treatment of the question of rational behavior", he also opted to endorse von Neumann and Morgenstern ([1944] 2007, pp. 3-4) on the inexistence of any "fundamental reasons why mathematics should not be used in economics", accentuating critiques on how economists misused mathematics.

Neither Kendall nor Deming misread the Theory of Games, or had faulty outlines; the text they examined backed their views of whichever subjects had primacy. For instance, von Neumann and Morgenstern ([1944] 2007, pp. 9-12) explained how their theory diverged from the "Robinson Crusoe model" (a single-agent problem of constrained utility maximization). In a game-theoretical approach, each agents' behavior is contingent on what other players do, so their query was "certainly no maximum problem, but a peculiar and disconcerting mixture of several conflicting maximum problems". Hence Kendall (1944) had a legitimate point. Additionally, von Neumann and Morgenstern ([1944] 2007, pp. 2-6) analyzed why mathematics had not been as fruitful in economics as they had been in the natural sciences (especially physics). They explicitly argued for two reasons for that backwardness. First, economic puzzles were ill-defined. Where descriptive methods had attained any degree of precision, economists misapplied mathematics' instruments. For example, von Neumann and Morgenstern condemned counting equations and unknown variables in a general equilibrium system as a criterion for assessing solution existence. Second, they considered that economics suffered from a scarcity of adequate empirical knowledge of "relevant facts of economics". Thus Deming (1945) had a proper sketch as well, even if distinct from that of Kendall (1944).

Summarizing a book's contents involves second-order questions and thus carries information about the reviewers' images of knowledge. Hence Corry's framework demonstrates how different outlines of the Theory of Games emerged. A sharp manifestation of such influence that images exercised comes from analyzing reviews for philosophy journals, as they concentrated on methodological points closely related to burning issues in their field. Similarly to Kendall (1944) and Deming (1945), Nagel (1945, p. 550) characterized von Neumann and Morgenstern's volume as a technical contribution steered towards

\footnotetext{
${ }^{18}$ Book reviewing practices are nearly everywhere emergent - there is no rule-book for editors and reviewers to follow. However, reviewers face a space constraint in general. Table 1 displays that most of the Theory of Games' reviews were not excessively long.
} 
mathematicians and mathematical economists. Instead of detailing how games deviated from conventional approaches in economics, he switched focus to the Theory of Games' methodology because it could appeal to philosophers considering "it initiates a radically new direction in constructing a mathematical analysis of human behavior, and it also has important implications for the theory of inductive inference" (NAGEL, 1945, p. 550). Likewise, Hawkins (1945, p. 221) was hooked by its methodological innovativeness: although social scientists found physics' tools alluring, he accentuated that "methods are only relatively separable from practice", thus positively rating von Neumann and Morgenstern's avoidance of physics' already established instruments. His reflection proceeded to a consideration about sources of methodological principles for economics, social sciences, and physics, distancing himself from what statisticians found most relevant.

Besides using individual guidelines to pick subjects to cover, reviews also showed an influence of another practice of book reviewing: tailoring texts to specialized audiences. As explained previously, evaluations published by periodicals of social sciences would most likely reach social scientists (than statisticians and philosophers). Consequently, any such study would target social scientists. Writing for specific publics affected how commentators criticized the Theory of Games. Naturally, assessments shared some criticism: for example, Nagel (1945, p. 553) claimed that von Neumann and Morgenstern were "deceived into supposing that they have achieved an adequate universal science of economic behavior". He sustained his opinion arguing that their theory was static and depended on several simplifying assumptions. ${ }^{19}$ Having a static theory at hand was also problematic for evaluators from other areas (for instance, Nagel (1945, p. 553) and Simon (1945, p. 560) also discussed it, even if for different purposes). However, reviews had unique points correlated to what public they targeted. For example, Hawkins (1945, p. 226) (who wrote for philosophers) had a critique to von Neumann and Morgenstern's view of science, inferring they deemed their contribution a foundational work upon which economists should erect a scientific discipline. Hawkins thoroughly disapproved conceiving science via a construction metaphor. For him, it was a flaw worth debating on his book review. His point was to show the Theory of Games' importance as means of analysis of economic phenomena was open:

[... The growth-process of theory is not one of simple extension. Even the three-body problem in mechanics is not solved; yet the basic principles of mechanics provide analytical tools of great power throughout the domain of physical science. So in the theory of games it would be most surprising if the theory of the $n$-person game would automatically solve basic economic problems. The essential point in both cases is that "fundamental" theory is fruitful only as its application is guided by profound study, in their

\footnotetext{
${ }^{19}$ The Theory of Games also discussed its static nature: von Neumann and Morgenstern ([1944] 2007, pp. 44-45) acknowledged that the static character of their theory would seem to be a shortcoming. However, leaned on other sciences' history, they claimed it would be fruitless to pursue a dynamic theory if a static - and consequently more straightforward - version was not yet ripe.
} 
own right, of the phenomena which occur at levels of higher complexity. To avoid this study would be a mark of dilettantism. On the other hand to neglect such a study as is here reviewed is to miss the chance of fruitful analogies and clarifying points of view. It is in the region of interaction that progress occurs, and it is here also that a general audience is most likely to find reward from the study of the present work. (HAWKINS, 1945, pp. 226-227)

Such criticism of how science grows or how economists should make theory was not present in examinations outside of philosophy. This shows that book reviewers from different areas held many divergences on selecting what was essential to incorporate in their analyses. Further, it shows how many and diverse problems someone could raise when reading von Neumann and Morgenstern's text. Images of knowledge and particularities of each field account for such heterogeneity. However, studies for journals in statistics, philosophy, and social sciences shared a mutual worry about the Theory of Games' readability. For instance, Kendall (1944, p. 293) related that von Neumann and Morgenstern ([1944] 2007) handed out few economic interpretations to its mathematical developments of nearly 500 pages, distinguishing an imbalance between advancing theory and illustrating applications that would ease their readers' comprehension. ${ }^{20}$ Nevertheless, he also portrayed von Neumann and Morgenstern's mathematics as a closed system: they developed every mathematical device upon necessity. Consequently, reading the Theory of Games required no training in higher mathematics at first sight. Therefore Kendall suggested some positive and negative aspects of von Neumann and Morgenstern's volume regarding how it would be received.

Additionally, Kendall (1944, p. 293) particularized which branches of mathematics appeared in constructing game theory, such as set theory. This type of information is fundamental for book review readers: they could use it to estimate their intimacy with von Neumann and Morgenstern's tools. For example, if a reader browsed Kendall's remarks and had previous instruction in set theory, he would expect a smoother study if he chose to give the Theory of Games a try. Conversely, if he was utterly unaware of what set theory is, he could waver in deciding if he would study it. Regardless of an apparent absence of technical requirements, understanding von Neumann and Morgenstern's contribution demanded some intimacy with mathematical reasoning. In particular, Kendall (1944, p. 293) offered an odd warning considering that he wrote for a statistics journal (and would likely reach more statisticians): economists could meet obstacles in their studies, having not full access to the Theory of Games. In his words, just a "fairly competent mathematician" could follow von Neumann and Morgenstern's reasoning:

Although the mathematics are self-contained, in the sense that the theory is developed from primitive ideas, an extensive use is made of set-theory, functionals and, of course, mathematical notation. From the point of view of familiarity with the notation alone it is doubtful whether anyone

\footnotetext{
${ }^{20}$ The edition under inspection by Kendall had 625 pages.
} 
but a fairly competent mathematician would follow the argument and appreciate what the authors are driving at. This was unavoidable, but seems a pity, as the book will remain closed to those economists who are unfamiliar with mathematical ideas and methods. (KENDALL, 1944, p. 293)

While Kendall (1944) was the first to review von Neumann and Morgenstern's volume, his apprehension on how its mathematics could harm its reception would find an echo in nearly all succeeding reviews, in every area of knowledge. Still in statistics periodicals, Deming (1945, p. 264) made no remarks on the Theory of Games's mathematics (mentioning it relied on set theory, for example, or discussing if it required previous exposure to higher mathematics). However, he explicitly suggested secondary sources would be vital in propagating its contents among "usual" economics students who had, if any, only limited mathematical training. In particular, he inferred subsequent research would act as a translator, illuminating von Neumann and Morgenstern's points to an audience who could not follow their reasoning by direct reading:

\begin{abstract}
It has been said that the best mathematicians are also the most practical people in the world when they set their minds to application. When a mathematician like von Neumann turns his attention to practical problems, something is going to happen. Mathematicians now, as during the past few years, are leaving their imprints on techniques in psychology, medicine, marketing research, techniques of surveying in social and economic fields, and economics. The results may be expected to remake economic theory. However, the reader should be warned that the book under review is really different. The usual student of economics, without appreciation for mathematical processes and logic, will have difficulty until translations and interpretations have been made. (DEMING, 1945, p. 264)
\end{abstract}

Curiously, it is unlikely that many economists would read Kendall (1944) or Deming (1945) and learn from their warnings. This external preoccupation on how economists would receive the Theory of Games is a particularity of statistics journals. Nevertheless, evaluations from philosophy and social sciences also mentioned reading difficulties, even if their comments did not target a particular public. Among reviews in philosophy, Nagel (1945, p. 551) echoed arguments made in statistics journals - for him, the Theory of Games did not presume higher-mathematics education from its readers (since it comprised explanations of every required tool) and he specified von Neumann and Morgenstern employed set theory, linear algebra and, group theory in composing a new foundations for economics. Strangely, Hawkins (1945) was silent about readability considering that a philosopher's training is no more mathematical than a statistician's, such observations would be particularly beneficial for his readers. Nevertheless, Nagel's assessment comprised a reading strategy aimed at grasping the Theory of Games' construction: 
[...] Accordingly, central logic issues in the construction of a systematic theory of social behavior arise in a new and arresting form; and philosophers who are prepared to struggle through a complicated mathematical discussion will find much in the book to reward their effort. No specific knowledge of advanced mathematics is presupposed; indeed, practically no use is made of the ideas of the differential calculus, and unfamiliar though advanced techniques (such as set theory, linear algebra, and the theory of groups) are fully explained as the need for them arises. Moreover, a careful study of the first four chapters (approximately 200 pages) will supply the reader with enough of the fundamental ideas to permit him to form a decent conception of the manner in which the theory of games is constructed. (NAGEL, 1945, p. 551)

That advice was not available in other evaluations. He recommended his audience to study its first four chapters exclusively. ${ }^{21}$ They covered a qualitative outline of von Neumann and Morgenstern's contribution and detailed zero-sum two-person games. His advice insinuates what would interest philosophers lied not in mathematical developments and results per se, but their making. Consequently, it was not necessary for philosophyoriented readers to struggle with more than 600 pages of a rather complicated text. Social sciences reviews also exhibited similar descriptions of tools von Neumann used-for instance, Gumbel (1945, p. 209) asserted readers would learn "the tool is no longer calculus but mainly the theory of sets and groups", or according to Simon (1945, p. 559), "point-set theory and topology". However, authors on social sciences also had unique comments among evaluations. Acknowledging the Theory of Games' hardship, Gumbel (1945, p. 210) advocated that a nontechnical outline of its content would lessen study struggles without harming von Neumann and Morgenstern's mathematical rigor. It is noteworthy that he associated form of exposition and a probable lousy reception by arguing: "Page after page full of formulae discourage the reader" (GUMBEL, 1945, p. 210). However, it is conceivable to maintain von Neumann and Morgenstern fed their public such a summary on their opening chapter, "Formulation of the Economic Problem". It encompassed basic concepts, as of solution and dominance, stated verbally. On later chapters, they picked up these notions again but in a formal setting. In opposition, Simon (1945, p. 559) subscribed to von Neumann and Morgenstern's stance on their "Technical Note": the Theory of Games demanded no prior mathematical training, but familiarity with mathematical reasoning.

We have attempted to present the subject in such a form that a reader who is moderately versed in mathematics can acquire the necessary practice in the course of this study. We hope that we have not entirely failed in this endeavor.

In accordance with this, the presentation is not what it would be in a strict mathematical treatise. All definitions and deductions are considerably broader than they would be there. Besides, purely verbal discussions and analyses take up a considerable amount of space. We have in particular

\footnotetext{
${ }^{21}$ The first four chapter of the Theory of Games were "Formulation of the Economic Problem", General Formal Descriptions of Games of Strategy", "Zero-Sum Two-Person Games: Theory", and "Zero-Sum Two-Person Games: Examples".
} 
tried to give, whenever possible, a parallel verbal exposition for every major mathematical deduction. It is hoped that this procedure will elucidate in unmathematical language what the mathematical technique signifies - and will also show where it achieves more than can be done without it. (VON NEUMANN; MORGENSTERN, [1944] 2007, p. xxxi)

Simon (1945, p. 559) enforced his point by examining his own study experience, stating: "the reviewer found the Theory of Games at all times a model of clear and careful exposition". Curiously, Kattsoff (1945, pp. 245-246) portrayed the Theory of Games as a "difficult" and "technical" book, but underscored no possible challenges readers would eventually face. Additionally, he charged von Neumann and Morgenstern's volume had an imbalance between mathematical theory and economic application since it assigned roughly 100 (out of 625) pages to economics itself. The rest of it was pure mathematics. Therefore any student pursuing detailed economic analysis "would be largely disappointed" since for von Neumann and Morgenstern "economic theory is an interpretation of the symbols descriptive of certain games of strategy" (KATTSOFF, 1945, p. 246). Despite his critique against overuse of mathematics, Kattsoff (1945, p. 245) also affirmed the Theory of Games remained "basically an analysis of games in more or less mathematical terms", showing some inconsistency in his comments. Generally, reviewers would agree it was a "rigorous mathematical development", as Simon (1945, p. 558) considered it.

Neighboring readability problems, the Theory of Games' complexity snowballed for an increasing number of players. That characteristic served some reviewers as a foundation for critique. For example, it contained no detailed treatment of five-person games, and the two-person games theory was far more complete than that of three- and four-person. Kattsoff (1945, p. 246) abstained himself from assessing the Theory of Games' significance due to its lack of in-depth development (for three or more players games, in particular) and its technical character, asserting it "may be an extremely valuable new direction or it may be an interesting but useless development". Further, Gumbel (1945, p. 210) used its static nature to argue "there is a long way to travel to the point where this line of [static] thought may furnish tangible results for the rational solution of economic problem". ${ }^{22}$ As pointed out before, von Neumann and Morgenstern developed a static theory because of how difficult it would be to allow dynamisms. Also because of difficulty, the detail they gave games decreased as they considered more players. Interestingly, their volume suffered typographical critiques as well. Kattsoff's words are so incisive they deserve a full-quote. It is essential to emphasize that indicating how many typos a text has is welcome in book reviewing - since it might supply scholars and librarians guidance on buying or not a copy - , but Kattsoff embedded his comment in irony, showing his distaste for the Theory of Games:

\footnotetext{
${ }^{22}$ Gumbel (1945, p. 210) also criticized von Neumann and Morgenstern's theory for being inappropriate to describe non-capitalist economies aside from its static nature.
} 
The book is a formidable one both intellectually and stylistically. The involved sentences, the numerous (and often unnecessary) footnotes, and the many misprints and typographical errors add to the cumbersome quality of the book. (The copy in the possession of this reviewer contained an enclosure with some 100 corrigenda). (KATTSOFF, 1945, p. 246)

Reviewers also had good reactions reading the Theory of Games regardless of its complicatedness. For instance, Hawkins (1945, p. 221) thought it had "considerable methodological value, quite apart from its scientific content" since it explored conceptual problems and attempted to lay a deductive foundation for economics. Simon (1945, pp. 558-560) tried to sound not too overoptimistic about von Neumann and Morgenstern's book immediate usefulness, but could not help himself concerning their contribution of moving economics out of a literary state to a stage of greater formalism and rigor (see quote below). Indeed, he recognized that social scientists often discussed mathematical approaches' applicability to their fields. In this sense, Simon (1945, p. 559) saw "marginal analysis" as a flourishing case within economics, and he commended its accomplishments "even if they [marginalists] sometimes translated their thought into the more acceptable literary form for presentation". In turn, he placed Theory of Games above similar efforts in social sciences in terms of modesty and impressiveness. As a methodological contribution, it still needed to survive a long-run test: any evaluation of its meaning should emanate from the results it managed to produce.

The reviewer can only hope that the foregoing remarks will serve to indicate the potential importance of this volume and to encourage every social scientist who is convinced of the necessity for mathematizing social theory - as well as those unconverted souls who are still open to persuasion on this point - to undertake the task of mastering the Theory of Games. The student of the Theory of Games will learn from it the directions his own mathematical education must take if he is to make contributions to formal social theory. He will come away from the volume with a wealth of ideas for application and for development of the theory into a fundamental tool of analysis for the social sciences. (SIMON, 1945, p. 560)

In conclusion, book reviews in statistics, philosophy, and social sciences journals diverged in some aspects. In statistics, they were disquieted by how economists would welcome the Theory of Games and discussed if it could assist them elevating their discipline's formality level. In turn, philosophy and social sciences' evaluations focused on methodological points, insisting that von Neumann and Morgenstern's contribution should pass a long-run test common to all foundational works. The Theory of Games had an unusual approach to economics and its importance was yet not clear. Naturally, general reactions were mixed, pointing out positive and negative features of it. Nevertheless, analyses converged on one position: von Neumann and Morgenstern's text was a highly technical and challenging reading. Although it invited any reader regardless of his background due to 
how it presented its mathematical tools, this characteristic could hinder its direct diffusion. Most economists, especially if not backed by some mathematical training, would find their

path after Chapter 1 excessively arduous. Book reviews suggest readability is the main topic to understand the Theory of Games reception, as a general audience of economics would depend on secondary sources - translations and interpretations - to grasp what von Neumann and Morgenstern proposed. The next subsection cover evaluations published in economics and mathematical journals, registering particularities of assessments in these fields and examining how they discussed readability.

\subsubsection{REVIEWS IN ECONOMICS AND MATHEMATICS}

Journals of economics published most of the Theory of Games' book reviews. Their authors were Robert W. Harrison (American Journal of Agricultural Economics), Leonid Hurwicz (The American Economic Review), Jacob Marschak (Journal of Political Economy), Tibor Barna (Economica), Carl Kaysen (The Review of Economic Studies), Abraham Wald (The Review of Economics and Statistics), and Richard Stone (Economic Journal). Still, von Neumann and Morgenstern's volume also fascinated mathematicians, as two reviews appeared in periodicals in such field: one from Arthur H. Copeland (Bulletin of the American Mathematical Society) and another from Cedric A. B. Smith (The Mathematical Gazette). Table 1 shows reviews from Hurwicz, Marschak, Kaysen, and Stone were peculiarly lengthy, filling between 15 and 19 pages. While book reviews are commonly titleless - their headings display information about the volume under examination, such as title, author, publisher, year, number of pages, and price-, their analyses had titles. Those deviations from a standard assessment hint they played different roles than other (smaller and titleless) examinations. Section 1.3 discuss them in detail, particularizing how they strayed from traditional reviews. Instead, this subsection will analyze the whole bulk of reviews in economics and mathematics paralleling what Subsection 1.2.1 did.

Having a more in-depth knowledge of particular problems Theory of Games targeted, economists could contextualize it by establishing connections. For example, a reviewer could contrast it to previous works on a particular subject, or link it to open problems in a subfield. Before addressing evaluations directly, it is worth to point out how the book presented itself to its readers. Already in Chapter 1, von Neumann and Morgenstern ([1944] 2007, p. 5) justified their decision of undertaking issues of individual behavior and simple forms of exchange exclusively. They had a twofold motivation for that choice. First, they avoided empirical problems because these compounded a "task of vast proportions", exceeding "the limits of any individually planned program". Besides, they hoped progress in other fields (in statistics, for instance) would eventually alleviate the situation of empirical economics. Second, since mathematization was a "not at all obvious" process, their effort encompassed only "commonplace experience concerning human behavior which 
lends itself to mathematical treatment". To precipitately engage burning questions could harm economics' evolution as a scientific discipline. It should grow step-by-step, starting from a foundation for human behavior. This subject had a role when von Neumann and Morgenstern discredited mathematical economics for mirroring physics. Economics needed tools explicitly devised to address the complexities involved in describing behavior:

The importance of the social phenomena, the wealth and multiplicity of their manifestations, and the complexity of their structure, are at least equal to those in physics. It is therefore to be expected - or feared - that mathematical discoveries of a stature comparable to that of calculus will be needed in order to produce decisive success in this field. (Incidentally, it is in this spirit that our efforts must be discounted.) A fortiori, it is unlikely that a mere repetition of the tricks which served us so well in physics will do for the social phenomena too. The probability is very slim indeed, since it will be shown that we encounter in our discussions some mathematical problems which are quite different from those which occur in physical science.

These observations should be remembered in connection with the current overemphasis on the use of calculus, differential equations, etc., as the main tools of mathematical economics. (VON NEUMANN; MORGENSTERN, [1944] 2007, p. 6)

Considering that most mathematical economics relied on differential and integral calculus as its fundamental technique until the Theory of Games arrived, von Neumann and Morgenstern's stand against it would provoke arguments on how should economists apply mathematics and about its choice of scope. Book reviews captured such controversies. For example, Barna (1946, p. 136) deemed the Theory of Games as an "outright condemnation of the particular mathematical methods used in economics" fated to "become a fundamental textbook of economic theory". He summarized von Neumann and Morgenstern's case on why economics had not been thriving in its mathematical endeavors. As previously discussed, economists' problems were ill-defined and lacked a proper empirical background. ${ }^{23}$ Barna stressed for his readers the book did not confront both problems: its purpose was to supply economics a solid foundation for "common human behaviour", setting experimental issues aside. Similarly, Harrison (1945, p. 725) ranked the Theory of Games "a work of utmost importance for all who earnestly seek to remove from the social sciences the atmosphere of vague description and generalization which has grown up about them", primarily because von Neumann and Morgenstern "made it unmistakably clear that progress towards a rigorous social science, as in the physical sciences, is apt to come only through a careful accumulation of exact knowledge first about familiar events and situations and later about the more complex and less obvious". Concurrently to a technical critique, von Neumann and Morgenstern suggested what was essential in their approach to human behavior was interdependence:

\footnotetext{
${ }^{23}$ See Subsection 1.2.1, especially comments related to Deming (1945).
} 
The fact that every participant is influenced by the anticipated reactions of the others to his own measures, and that this is true for each of the participants, it is most strikingly the crux of the matter (as far as sellers are concerned) in the classical problems of duopoly, oligopoly, etc. When the number of participants becomes really great, some hope emerges that the influence of every particular participant will become negligible, and that the above difficulties may recede and a more conventional theory become possible. These are, of course, the classical conditions of "free competition". Indeed, this was the starting point of much of what is best in economic theory. (VON NEUMANN; MORGENSTERN, [1944] 2007, p. 13)

Interdependence between agents epitomized the Theory of Games. Consequently, it would serve as a bridge to contrast it against past results in economic theory. To illustrate, consider Stone (1948, pp. 185-186), who distinguished rational behavior within a social economy as von Neumann and Morgenstern's fundamental concern in economics, resembling Barna. While Marie-Esprit-Léon Walras and Alfred Marshall were traditional readings in exchange around the mid-1940s, their assumptions eradicated any roles interdependence (so dear to the Theory of Games) could play. For example, interdependence between firms was ruled out by perfect competition models. ${ }^{24}$ Before game theory, economists commonly resorted to extraneous hypotheses to obtain resolute outcomes for imperfect competition problems. Considering a duopoly case, one of such premises consisted of admitting one firm fixed its price first, and only then its competitor solved its problem of maximizing profits, taking that price as a given constant. Marschak (1946, pp. 97-98) endorsed that using external reasons to reach a solution was undesirable for economics as a science. He accused economists of escalating their difficulties to sociologists, political scientists, and psychologists by using alien arguments of "'bargaining powers,' 'institutional framework,' and 'oligopolistic uncertainty." In his view, economics should refine itself as a discipline and internalize mechanisms capable of solving any indeterminacy found on imperfect competition models. The Theory of Games offered a structure for that:

[...] Put in another way, the specification of rational behaviour for one participant under general conditions of imperfect competition calls for some assumptions about the responses of competitors, e.g., that a duopolist fixes his price on the assumption that his competitor will leave his unchanged. This kind of assumption not only leads to a concentration on one out of a large number of behaviour patterns in the general situation envisaged, but also leads in many cases to recurrent oscillations in prices or some such phenomena which in all probability do not take place in the real world. This means that the partial theories put forward are in many cases misleading and suggests that a more general approach is required. (STONE, 1948, p. 186)

\footnotetext{
${ }^{24}$ The Theory of Games did not venture into perfect competition models. While von Neumann and Morgenstern ([1944] 2007, p. 14) hoped perfect competition would emerge from their theory as a limiting case, even for "moderate numbers" their developments were still unfinished: "only after the theory of moderate numbers of participants has been satisfactorily developed will it be possible to decide whether extremely great numbers of participants simplify the situation. Let us say again: We share the hope - chiefly because of the above-mentioned analogy in other fields! - that such simplification will indeed occur".
} 
The Theory of Games offered a conceptual reshaping of imperfect competition models. For example, three-person games allowed any two agents to ally (forming a coalition) to secure themselves higher gains, as Stone (1948, p. 185) discussed in his evaluation. Suggesting a new approach to an old problem would elicit claims related to the images of knowledge among reviewers in economics. Whenever the Theory of Games mentioned earlier models on imperfect competition, it cited Eugen Böhm Ritter von Bawerk (an Austrian economist). Particularly, von Neumann and Morgenstern ([1944] 2007, p. 562) cited von Bawerk's Positive Theorie des Kapitals (its fourth edition, of 1921). To contrast his and von Neumann and Morgenstern's approaches, consider an exchange problem of one seller and two buyers. A traditional (as von Bawerk's) approach would chase a single-price solution. Reinterpreted by games, coalitions enabled different prices to coexist as solutions because many compensation schemes were feasible. Consequently, game theory broadened previous predictions for equilibrium prices. These circumstances could support establishing the Theory of Games had a greater generality over previous economic theory. Hurwicz (1945, p. 923) relativized this point claiming recent developments on consumer surplus had an analogous extension of relaxing "Böhm-Bawerk's assumption of a unique price". However, he didn't cite such contribution explicitly. At any rate, this case is specific to a model. Hurwicz stood beside von Neumann and Morgenstern's higher generality viewpoint:

It will stand repeating, however, that the Theory of Games does offer a greater generality of approach than could be attained otherwise. The existence of "discriminatory" solutions, discovered by purely analytical methods, is an instance of this. Also, the possibility of accounting for various types of deals and collusions mentioned earlier in connection with the three-person and four-person cases go far beyond results usually obtained by customarily used methods and techniques of economic theory.

The potentialities of von Neumann's and Morgenstern's new approach seem tremendous and may, one hopes, lead to revamping, and enriching in realism, a good deal of economic theory. But to a large extent they are only potentialities: results are still largely a matter of future developments. (HURWICZ, 1945, p. 923)

As any second-order statement, classifying the Theory of Games as of greater generality over past contributions in imperfect competition is subject to dispute. For example, Kaysen labeled his reviews' final section "Criticism and Evaluation". It comprised critiques towards von Neumann and Morgenstern's concepts of utility and solution. Section 1.4 analyzes Kaysen's (as well as other reviewer's) arguments concerning utility functions. To present his objections related to solutions and generality, it suffices to take verbal descriptions of von Neumann and Morgenstern's definitions of imputation, dominance, and solution, presented on their opening chapter. ${ }^{25}$ First, in current game theory jargon,

\footnotetext{
${ }^{25}$ In Chapter 1, "Formulation Of The Economic Problem", von Neumann and Morgenstern discussed verbal variants of these ideas. More than 200 pages later in Chapter 4, "Formulation of The General Theory: Zero-Sum n-Person Games", they rigorously defined them.
} 
imputation is a payoff vector (given $n \in \mathbb{N}$ agents, it is an element on $\mathbb{R}^{n}$ representing gains and losses of every player). They used $x$ and $y$ to denote two arbitrary imputations. Second, imputation $x$ dominates $y$ when some players have larger payoffs in $x$ than in $y$ and can enforce its realization. Third,

A set $S$ of elements (imputations) is a solution when it possesses these two properties:

(4:A:a) No $y$ contained in $S$ is dominated by an $x$ contained in $S$.

(4:A:b) Every $y$ not contained in $S$ is dominated by some $x$ contained in $S$.

(4:A:a) and (4:A:b) can be stated as a single condition:

(4:A:c) The elements of $S$ are precisely those elements which are undominated by elements of $S$.

$[\ldots]$

Since our definitions (4:A:a) and (4:A:b), or (4:A:c), are circular-i.e. implicit-for $S$, it is not at all clear that there really exists an $S$ which fulfills them, nor whether - if there exists one - the $S$ is unique. (VON NEUMANN; MORGENSTERN, [1944] 2007, p. 40)

Instead of interpreting the Theory of Games' wider solution as an improvement in generality, Kaysen considered it did not constitute a solution at all. His opposing viewpoint of von Neumann and Morgenstern's concept of solution and results had two components. First, supporting coalitions implied producing more outcomes in more complex games, so its underlying indeterminacy could only grow. Consequently, games would be of limited usefulness for predicting an equilibrium price - for him, it was desirable to achieve determinate answers for imperfect competition problems. Second, Kaysen complaint that von Neumann and Morgenstern introduced a solution uniqueness proof for two-person zero-sum games (a setting where players had no incentives to join coalitions). Because the association of agents was precisely a feature that the Theory of Games proposed itself to explore, it did not help their case against traditional approaches in economics. For Kaysen, they should had found a way through uniqueness for any games:

Thus, only a little light is shed by the "solution" of the problem of the three-person market given by the theory of games. A true solution of this problem requires an analysis of what determines the particular coalitions formed, the "principles" of compensation which the arbitrary function describes, and the particular amount of compensation which is paid. Such a solution requires a study of actual market situations analogous to the theoretical three-person market, for no amount of speculation can lead to a just estimation of which forces are, and which are not, important in shaping actual market decisions. [...] Both the nature of the analysis, and the solutions of the problems actually worked in the book, lead to the expectation that each addition to the complexity of the problem will lead to a multiplication of the amount of arbitrariness or indeterminacy in the solutions. This being so, it is extremely doubtful whether the degree of restriction of possible solutions offered by the "solution" of 
game-theory will be great enough to be of much practical value in really complex cases.

It may be argued that the theory-of-games analysis has at least the merit of uncovering problems, if it does not provide solutions! (KAYSEN, 1946-1947, p. 14)

In contrast to Kaysen, Wald (1947, p. 49) found von Neumann and Morgenstern's "fundamental theorem" on the existence of solutions for two-person games of finite, pure strategies a "remarkable result of great importance with far reaching consequences". While no exhaustive result existed yet (for games of any number of players, or for allowing infinite strategies), Wald (1947, p. 50) appeared convinced that a proof would emerge: "there seems to be hardly any doubt that every game has a solution, but no general existence theorem has yet been established". This point of existence was crucial for von Neumann and Morgenstern ([1944] 2007, p. 42): if their approach implied not solution existence, "this would certainly necessitate a fundamental change in the theory". Besides, von Neumann and Morgenstern ([1944] 2007, p. 40) noted: "The single imputation is an often used and well understood concept of economic theory, while the sets of imputations to which we have been led are rather unfamiliar ones". They understood that solution multiplicity was not inevitably an adverse quality. Society has a diversity of stable configurations - or "standards of behavior", as they called it-, even if only one occurs in reality. It would be possible to argue multiplicity grasped that property. Either way, the Theory of Games' aims lied not in establishing what social principles and forces determine what standard of behavior would occur, but rather to examine any feasible equilibria.

Debating if some contribution - as the Theory of Games' concept of solution - is meaningful or not to economics follows no strict rules or reasonably consensual criteria, as they have roots on images of knowledge. Comparing von Neumann and Morgenstern's title with economic theory was a way for reviewers to evaluate it. For Kaysen (1946-1947, pp. 14-15), if coalitions were to survive as part of economics, it was imperative to "uncover the mechanism of compensations and coalitions", solving his indeterminacy difficulty. For him, solutions on three-person market models should be unique, while Wald was not strictly committed to uniqueness. This discussion around a solution concept's adequacy naturally extends itself to general claims about the Theory of Games as a whole. Kaysen (1946-1947) entitle his book reviews "A Revolution in Economic Theory?" and proposed himself to assess von Neumann and Morgenstern's enterprise in comparison to already established economics mostly due to their hostile posture towards it. The answer to his heading was negative: traditional economics and game theory related to each other as algebraic analysis and geometry did. They were "isomorphisms", as he called until von Neumann and Morgenstern could not solve any games for a unique solution, they would be reliant to external influences - as forcing one firm to chose prices first - as traditionally economists supposed. Having two equivalent approaches at hand, Kaysen then minimized 
the Theory of Games' relevance for its innovativeness:

[...] we would then have an isomorphism between this theory and more familiar analytical techniques, analagous to the isomorphism between analysis and geometry. It would make little sense to argue the virtues of analysis over geometry for the solution of the problems of economic theory. If a solution can be found in one way, its isomorph can be found in the other. But, of course, for any particular problem, it may be better, that is speedier and more convenient, to use geometry rather than analysis, or vice versa. Similarly, then, some problems of monopolistic markets which do not readily yield to the ordinary tools of economic analysis, may fruitfully be dealt with by the theory of games. This is, of course, a speculation; the author hopes to be able to treat the problem further at another time. (KAYSEN, 1946-1947, p. 15)

While journals in economics outlined and evaluated the Theory of Games holding close its applications (and even discussing its significance in terms of those), mathematicians took another route. A first striking difference is Copeland's technical description of von Neumann and Morgenstern's main concepts and results. His review had six pages, of which he dedicated roughly five to his summary. He used italic type in sentences concerning any of the Theory of Games' definitions or theorems. Besides emphasizing formal structures, often he chose symbols over words to display his points. To illustrate, see his quote below, where he explained the payoff vector concept. However, Copeland's form of exposition opposed that of Smith's, who also wrote for mathematicians. His exposition was much closer to those targeting economists. For his readers, Smith $(1945$, p. 132) simply described imputation as a "distribution of money" among players.

The concept of a game is formalized by a set of postulates. Even the status of information of each player on each move is accounted for and is characterized by a partition of a certain set. The amount which player $k$ receives at the conclusion of the play is a function $\mathfrak{F}_{k}\left(\sigma_{1}, \sigma_{2}, \cdots, \sigma_{v}\right)$ of the moves $\sigma_{1}, \sigma_{2}, \cdots, \sigma_{v}$ where some of the $\sigma$ 's may be the moves of chance (dealing cards, throwing dice, and so on). (COPELAND, 1945, p. 498)

If Copeland and Smith were distant in terms of how they structured their texts, they were alike in how much space they left for economics - and it was not much. Given that they wrote for mathematicians and consequently had greater concerns for mathematical problems, they focused on von Neumann's mathematics and games as a general category. For instance, Copeland placed no link among payoffs and intuitive concepts, such as money or utility (see quote above). Furthermore, Copeland (1945, p. 503) gave imperfect competition (so emphasized among economics' journals) only three lines of comments, asserting: "The authors apply this theory of games to the analysis of a market consisting of one buyer and one seller and also of a market consisting of two buyers and one seller". In turn, Smith (1945, p. 131) ranked if that book "full of new and important ideas" had a highest achievement, it was to provide games a general and formal definition, which 
encompassed different mixtures of strategies and allowed the inclusion of information variables, and a solution concept, even if only developed for simpler games (of two- or three-person games). ${ }^{26}$

Book reviews in statistics, philosophy, and social sciences insinuated the Theory of Games' mathematics could award it a lukewarm (or frigid) reception. In journals of economics, evaluations also discussed such topic. For instance, Harrison (1945, p. 725) asserted von Neumann and Morgenstern exercised "point-set theory and topology" techniques while traditional mathematical economics approaches rested on "calculus of differential equations". Furthermore, Barna (1946, p. 137) considered their main accomplishment was replacing mathematics as a symbolic language for mathematics as a reasoning tool, making it "possible to arrive at new truths". He even warned economists should not await new results from game theory: instead, they could anticipate rigorous treatment capable of scrutinizing past assumptions and results. These observations hint economists responded positively to von Neumann and Morgenstern's application of unfamiliar tools. Indeed, Marschak (1946, p. 114) felt their most significant achievement was to introduce modern logic to economics.

It is necessary to recall not only the Theory of Games presented and applied new mathematical tools, but it contained entire sections criticizing how economists had employed mathematics so far. Reviewers also assessed its critiques aside from its body-related contribution. Falling again under images of knowledge, competing views on its criticism emerged. For example, Marschak (1946, p. 115) fully admitted von Neumann and Morgenstern's charge against uncarefully hiring calculus from physics. Notwithstanding Hurwicz (1945, p. 924) conceded that borrowing instruments had drawbacks, he regarded some of the Theory of Games' critiques untenable, especially because its negative commentaries on reusing methods from other fields downplayed recent progress in economics. Further, he concluded objections against literary economics usually failed to perceive they were more often than not grounded on mathematical reasoning. Hurwicz assumed a role of clarifying von Neumann and Morgenstern's words, arguing they were not attacking mathematical methods in particular - such as infinitesimal calculus - , but practices in economic theory common to verbal and mathematical approaches. At any rate, Hurwicz (1945, p. 924) and Kaysen (1946-1947, p. 14) observed that von Neumann and Morgenstern rejected nearly all past contributions in economics since they chose to keep citations at a minimum, making references only to von Bawerk, Carl Menger, and Pareto.

There is little doubt in the reviewer's mind that nothing could have

\footnotetext{
${ }^{26}$ Games were already a topic in mathematics before the Theory of Games appeared. For example, Félix Édouard Justin Émile Borel, a French mathematician, had worked on games in the 1920s. However, he understood them as non-mathematical objects. Since they are complex and strongly related to psychology, he thought mathematics would have limited power in its study. Naturally, von Neumann's way to explore games contrasts with that of Borel (LEONARD, 2010, pp. 57-62).
} 
been further from the authors' intentions than to give aid and comfort to the opponents of rigorous thinking in economics or to increase their complacency. Yet such may be the effect of some of the vague criticisms contained in the first chapter; they hardly seem worthy of the constructive achievements of the rest of the book. (HURWICZ, 1945, p. 924)

Resources as calculus lie between body and image - using them have a specific impact on what body statements a field can produce while its employment also touches on methodological issues of picking a methodology to tackle a problem. Stone (1948, pp. 197-198) had a viewpoint matching that of Hurwicz's. He acknowledged the Theory of Games had attained a greater generality in some results. However, that accomplishment did not afford a free pass to disregard every past contribution in imperfect competition, maintaining that: "it is to be regretted that the authors are in places less than generous to their colleagues who have tackled, not without success, these difficult problems with far less powerful tools". Counterarguing von Neumann and Morgenstern, Barna (1946, p. 138) questioned if: "Is it not the case that the backwardness of the science of economics is due not only to the lack of success of mathematical economics but also to the essential difference between the social and natural sciences?"- unlike economists, physicists had controlled experiments and universal constants. For him, economics had fundamental differences from physics. Using the later as a rule to judge what economics had achieved would result in an unfair assessment: "the perfection of the natural sciences must needs [sic] be unattainable".

Readability (as an issue disconnected from von Neumann and Morgenstern's critiques) also reverberated in book reviews targeted at economists. Unlike assessment in other fields, evaluators in economics were less concerned towards von Neumann and Morgenstern's reception. ${ }^{27}$ For example, Kaysen (1946-1947, p. 2) remarked their demonstrations always paralleled verbal, intuitive explications. Therefore convoluted reasonings filled by symbols accompanied accessible, textual materials strengthening its understandability. Besides, he considered the Theory of Games organized a careful cross-referencing system producing a "remarkable clarity of exposition". Similarly, Wald (1947, p. 52) felt von Neumann and Morgenstern's book was "understandable" even for those unfamiliar with any advanced mathematics. Non-mathematical arguments everywhere in the Theory of Games supported his argument. However, if Wald (1947, p. 52) suggested anyone could study it, it did not mean lessons would be easy: for him, cramming non-mathematical arguments side-by-side formal deductions was "not really elementary, because of the intricate nature of many of the mathematical deductions".

Estimating how an audience would welcome a book depends on several conditioning factors, as how one perceives his fellows and his study experience. Naturally, some reviewers

\footnotetext{
${ }^{27}$ The Theory of Games also suffered critiques of being too mathematical. For instance, Barna (1946, p. 138) lamented von Neumann and Morgenstern approached economic problems "from the point of view of the mathematician only".
} 
in economics felt more apprehended than Kaysen or Wald. For instance, Harrison (1945, p. 726) believed that he should reflect on the Theory of Games' difficulty, but considered it "quite difficult to say just what level of mathematical knowledge is required to appreciate this work". His guess was that an elementary training would serve, but it alone would "hardly suffice". Even if several evaluators echoed that "the mastering of the new technique [game theory] does not require previous knowledge of higher mathematics" as Barna (1946, pp. 136-137), the Theory of Games readability problem lied more on a difficulty of following von Neumann's reasoning than of having knowledge about a subject (such as set theory) beforehand:

The mathematics employed do not, so far as the applications are concerned, involve a large technical knowledge and as far as is necessary they are explained in the text. Through out, the severely symbolic treatment is re-expressed as far as possible in words. Yet, partly on account of the length and partly on account of the closeness of the reasoning, it is a most exacting book to read and may for this reason fail to reach as wide a public as it should. I believe there would be great scope for a short introductory volume, somewhat on the lines of P. A. MacMahon's introduction to his great work on Combinatory Analysis, if the authors could find the time to prepare one. (STONE, 1948, pp. 200-201)

Reviewers weighted the Theory of Games' difficulty and its (still probably only) significance for economics when they recommended reading it or not. While Hurwicz (1945, pp. 924-925) felt von Neumann and Morgenstern's exposition was "remarkably lucid and fascinating, no matter how involved the argument happens to be", it could still show some obstacles to economists. He concluded: "The great majority of economists should be able to go through the book even if the going is slow at times; it is well worth the effort. The appearance of a book of the caliber of the Theory of Games is indeed a rare event". The general impression was the prize of understanding Neumann and Morgenstern's arguments would largely exceed any investment (in terms of effort) needed for it. Marschak (1946, p. 115) was even more incisive in his incentives since for him "Ten more such books and the progress of economics is assured":

Every reader of the Journal must know, however, that that spirit is within his reach: the book presupposes no special knowledge of the tools used. Elements of the theories of sets and of groups, the logic of relations, and some propositions of functional analysis are introduced with utmost simplicity, clarity, and patience. Any reader willing to exercise the same patience (and, for example, use fully the numerous cross-references provided, to exercise his understanding and refresh his memory) will be richly rewarded. He will appreciate some particular results pertinent to our discipline. He will enjoy the spectacle of vigorous thinking. He may also much improve his own habits and tools of thought as a worker in economics. (MARSCHAK, 1946, p. 115)

Reviews in journals of mathematics also discussed the Theory of Games' reading prerequisites and meaningfulness. Smith (1945, p. 133) felt its mathematics was "modern 
in spirit" and required no previous specific knowledge (see quote below, where Smith also pinpointed some printing issues; however, he was not as ironical as Kattsoff (1945)). Copeland (1945, p. 498) praised von Neumann and Morgenstern's endeavor as "one of the major scientific achievements of the first half of the twentieth century" for making economics an "exact science". He also endorsed no higher knowledge was demanded but warned that "the non-mathematically trained reader will be called upon to exercise a high degree of patience if he is to comprehend the theory", while "the mathematically trained reader will find the reasoning stimulating and challenging". Curiously, Copeland informed his readers about needed knowledge in economics: for him "a limited background" would do (COPELAND, 1945, p. 498).

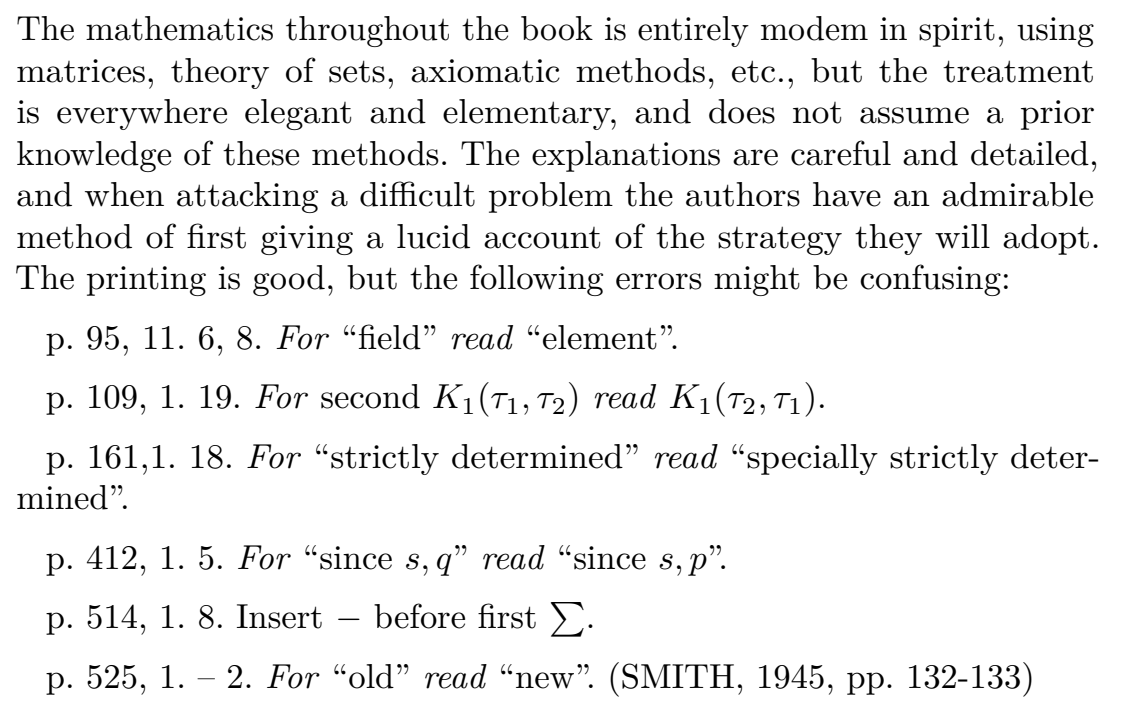

To conclude, reviews directed at economists appraised the Theory of Games immersed in a context of problems economists explored, in opposition to mathematicians who treated game theory almost as a subfield of mathematics. Hence for evaluations in economics, it was subjected to praise and criticism grounded on the results it produced in such problems (as in imperfect competition, for example). While von Neumann and Morgenstern's contribution rested on economics' body of knowledge, it raised second-order questions related to how economists envision their field. For instance, there was not a clear line between characterizing von Neumann and Morgenstern's solution as more general - because it widened possibilities of previous models - or unwarranted - since it overlooked prediction by allowing multiple solutions to emerge. Naturally, the Theory of Games was particularly difficult to assess due to all its open problems. Economists then did not have a distinction of non-cooperative and cooperative frameworks, nor did they know how far the existence of solutions could go for more sophisticated games of more players and infinite strategies.

Besides how the Theory of Games inserted itself on economics' body and provoked several image issues, it also presented a hostile face towards past economics, especially 
previous mathematical economics. By the mid-1940s, it was not clear which ways our field would take; if it should abandon calculus for more sophisticated tools. Nor it was obvious as a whole what other effects that critique could create. Regarding von Neumann and Morgenstern's influence on reshaping economists' relation with mathematics, book reviews left it manifest economists could - and for some they should - read the Theory of Games, even if it was a challenging reading. However, people often can fail to stand up to such challenges. If they did, they would depend on secondary sources, as translations and interpretations, to grasp its ideas. Indeed, book reviews written by Hurwicz, Marschak, Kaysen, and Stone show, regardless of how they explicitly defended economists should study the Theory of Games (except by Kaysen, who was more skeptical), it depended on secondary sources to have wider dissemination. Those reviewers engaged in practices of simplifying and exposing game theory for their readers besides usual roles of outlining and evaluating that reviewers usually engage. This is the subject of the next section.

\subsection{REVIEWERS WHO TRANSLATED}

Hurwicz, Marschak, Kaysen, and Stone composed peculiar reviews in numerous dimensions. First, they earned titles - respectively, "The Theory of Economic Behavior", "Neumann's and Morgenstern's New Approach to Static Economics", "A Revolution in Economic Theory?", and "The Theory of Games". Second, they filled a surprising amount of pages (between 15 and 19 each). Third, journal editors indexed them alongside regular research articles, separated from other book reviews. Remarkably, Kaysen occupied The Review of Economic Studies' first 15 pages, receiving an unpaired eminence in that journal's number. However, they still preserved a conventional structure of book reviewing. All evaluations (except for Kaysen's) possessed footnotes listing editorial information on the volume they assessed. This section examines how some book reviewers acted as translators for the Theory of Games, showing what and how they conveyed its concepts and results for a broader audience of economists. ${ }^{28}$

Those reviewers made it explicit why their evaluations had extraordinary length. It emerged from a task not engaged by other evaluators: to explain the Theory of Games' basics in an uncomplicated manner. To illustrate, Hurwicz, Marschak, Kaysen, and Stone spent roughly 13,14,11, and 11 pages of their assessments in didactical expositions,

\footnotetext{
${ }^{28}$ The translation metaphor follows from Doehne and Herfeld (2018) who discussed that sometimes contributions carry innovations (say, from von Neumann and Morgenstern) to specialized fields of inquiry (for instance, individual choice over risky alternatives). In particular, translators explain how innovations can contribute to specialized topics and connect them to past research. Taking Hurwicz, Marschak, Kaysen, and Stone as translators seems a fitting metaphor. Their reviews contained expositions of some of the Theory of Games' concepts and results, but they focused on rendering them as simple as possible. These evaluators acted as if they had read von Neumann and Morgenstern's text, acknowledged not every economist would be able to understand their points due to its mathematical reasoning, and stated those less technically, providing simple numerical examples. Their effort was to change the form of exposition of von Neumann and Morgenstern's volume.
} 
respectively. They aimed at opening von Neumann and Morgenstern's book to economists untrained in mathematics. In a footnote, Hurwicz (1945, p. 909) reported his exposition was "mostly carried out utilizing comparatively simple numerical examples. This involves loss of generality and rigor, but it may be hoped that it will make the presentation more accessible". In opposition, Kaysen justified his explanation of von Neumann and Morgenstern's text because he needed his reader to understand the nature of their solution concept minimally to show his argument against it (see quote below). At any rate, composing an exposition focused on explanations requires particular structures ruled by a purpose of making the text clear and accessible. The reviewers under analysis in this section consistently showed such care. For example, Marschak (1946, p. 98) stated: "italics will be used when a technical term defined by the authors is introduced here for the first time", also in a footnote, showing he would use a stylized typeface to highlight concepts originating in the Theory of Games, keeping it separate from his presentation of them.

\begin{abstract}
Of course, no attempt can be made within the compass of a survey, to reproduce any part of the rigorous mathematical development of the theory of games. However, it is worth-while to give even a sketchy idea of the problems which can be solved by the theory, and the methods by which it deals with them. Moreover, a clear understanding of the nature of the "solutions" is essential for an economist who wishes to evaluate the implications of this contribution to his science. (KAYSEN, 1946-1947, p. 2)
\end{abstract}

Tables representing specific games were central in translating the Theory of Game's concepts. After intuitively briefing what game, play, move, choice, and strategy meant, Stone (1948, pp. 187-188) employed an example of a zero-sum game in matrix form to illustrate each player's gain, called value of the play (see Figure 1). His reader could use that particular case to follow how an individual, if behaving according to von Neumann and Morgenstern's theory, would make choices (see quote below). In particular, Stone (1948, p. 189) used his example to advance a general claim that row minima and column maxima are vital in foretelling any players' optimal behavior. Besides, he registered that if "the highest minimum value for $A$ is equal to the lowest maximum value for $B[\ldots]$ the game is called strictly determined". In Stone's example, this equality implied neither $A$ or $B$ would possess incentives to shift their strategy even if one knew beforehand what his rival would choose. Still, he remarked not every game is strictly determined. What Stone's exposition shows is an educational approach of introducing a subject by an example to later comment of general rules governing it (that apply to other cases as well). However, it is important to stress that von Neumann and Morgenstern ([1944] 2007, pp. 98-106) also used devices as tables to introduce strictly determined games. However, if a reader used the Theory of Games to grasp such idea directly, he would face a table where players had an arbitrary (although finite) number of strategies at hand, whose gains were not 
Figure 1 - Column Maxima and Row Minima

\begin{tabular}{|c|c|c|c|}
\hline \multirow{2}{*}{$\begin{array}{c}\text { A's } \\
\text { strategy. }\end{array}$} & \multicolumn{3}{|c|}{ B's strategy. } \\
\cline { 2 - 4 } & 1. & 2. & 3. \\
\hline 1 & 9 & 2 & 4 \\
\hline 2 & 1 & 8 & 3 \\
\hline 3 & 7 & 6 & 5 \\
\hline $\begin{array}{c}\text { Column } \\
\text { maxima. }\end{array}$ & 9 & 8 & 5 \\
\hline
\end{tabular}

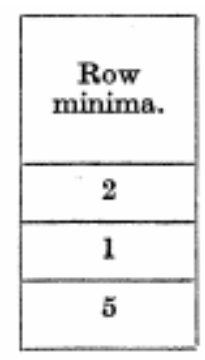

Source: Reproduction of Stone (1948, p. 188).

particular numbers but functions, and pages full of mathematical analysis. Stone's version would be easier and more appealing for an average economist. ${ }^{29}$

A sensible course for $A$ to follow will be to adopt the strategy which ensures him the maximum return whatever $B$ does. $A$ 's three strategies are compared from this point of view in the final column headed "row minima". Thus, if $A$ follows his first strategy he can count on getting only 2 , since although he would get 9 if $B$ followed his first strategy he would get only 2 if $B$ followed his second strategy, so that it would be in $B$ 's power to restrict $A$ 's gain to 2 . Clearly therefore it would be sensible for $A$ to adopt his third strategy, since in this way he could be sure of getting 5 independently of $B$ 's action. In general $A$ will choose that strategy which gives the highest minimum value for different strategies adopted by B. (STONE, 1948, p. 188)

For Hurwicz (1945, p. 913) "a major achievement of the Theory of Games is the analysis of the conditions and nature of coalition formation". Before introducing coalitions, he decided to tackle two-person zero-sum games - or, as he designated, games of "constant sum profits". In zero-sum games, any earnings of a player occasions another some loss. He felt "it is intuitively obvious (although the authors take great pains to show it rigorously) that no coalition will be formed" in two-person scenarios. If Hurwicz opted to speak of zero-sum as referring to something as tangible as firms' profits, Marschak (1946, p. 105) resorted to a creative analogy to illustrate what specifically summed to zero. Fist, he mentioned: "In a two-person zero-sum game, the positive gain of one player equals the loss (negative gain) of the other." Subsequently, he presented a structure to reason with

\footnotetext{
${ }^{29}$ While Stone (1948, p. 188) merely described payoffs as a generic "gain" in his examples, Hurwicz measured these speaking specifically of firm's profits. The difference is subtle, but a reader could think it was confusing what Stone meant by "gain". In opposition to Hurwicz, Kaysen (1946-1947, pp. 3-4) used a more technical language (though not as formal as von Neumann and Morgenstern's). For example, he specified payoffs in terms of functions, offering his reader no practical example to improve his exposition's accessibility (but he did not specify its domain and image, as a formal definition of a function requires). Those differences show reviews had a varying degree of simplification. Nonetheless, they remained simpler than the Theory of Games.
} 
zero-sum two-person games. In his exemplification, a player $A$ picked a latitude and $B$ a longitude (denoted by $x$ and $y$, respectively). Any resulting point on the United States of America's map would imply a gain for $A$ measured by its hypsometry (in his notation, $f(x, y))$. This way to depict zero-sum two-person games not only gave gains a tangible dimension (understood as a distance) but showed how one player's choices seeking his benefit affected his rival's welfare negatively.

\begin{abstract}
[...] Geometrically, $f(x, y)$ can be represented as the altitude of a point on a map of the United States, the point having latitude $x$ and longitude $y$. Player $A$ wants to make altitude $f$ as large as possible. But he knows that for any $x$ he chooses, his opponent $B$-if $B$ is a good player-will choose a $y$ such as to make altitude $f$ as small as is compatible with the chosen $x$. Player $A$ knows that for the case in which he chooses $40^{\circ}$ latitude, $B$ has prepared himself to choose the longitude of the dip formed by the Mississippi River; and that if $A$ names $45^{\circ}, B$ will choose the longitude of the Great Lakes dip. $A$ 's best policy is therefore to name a latitude such that even the lowest point on it is higher than the lowest point on any other latitude. (MARSCHAK, 1946, p. 105)
\end{abstract}

Visual representations of games served reviewers as devices of exposition, but also acted as tools of reasoning for their readers. They supported a method to find out solutions for any two-person games. Using a two-person zero-sum specific example, Hurwicz (1945, p. 914) explained not always games are strictly determinate. He clarified that a game was solvable if it exhibited a saddle-point, defined by him by two properties: "it is the highest of all the row minima, and at the same time it is lowest of the column maxima". Although Stone (1948, pp. 188-189) did not explicitly mention saddle-points, he and Hurwicz (1945, pp. 913-914) lectured their readers how to discover one from any given two-person game represented by a table. Using a matrix-form, it was necessary to calculate row minima (labeled maximum minimorum) and column maxima (minimum maximorum), as done in Figure 1. If both values matched, then strategies leading to that outcome would compose a saddle-point. More mathematically, Marschak (1946, pp. 105-106) and Kaysen (1946-1947, pp. 3-4) presented that concept as a pair $(x, y)$ such that (in Marschak's notation as presented above) minimizing $f(x, y)$ by $y$ and then maximizing it by $x$ would be equivalent to maximizing it by $x$ and then minimizing it by $y$. Neither of them afforded a numerical illustration or step-by-step illustration of how to detect such values. Their readers would have to rely on a previous understanding of optimization techniques. Still, Marschak stretched his geographical analogy to saddle-points: aware of B's behavior (of minimizing altitude) player $A$ would pick his plan securing himself the higher altitude he could get after $B$ had tried to minimize it. This analysis relates to minimizing and then maximizing. A symmetrical consideration follows for $B$ 's strategy.

[...] Now it may happen that the values $x$ and $y$, which make $A$ 's gain assume the value $g_{A}(A)$, coincide with those that make $A$ 's gain assume the value $g_{B}(A)$, i.e., that it does not matter whether $f$ is first minimized 
with respect to $y$ and then maximized with respect to $x$, or whether the two operations are reversed in order. In this case the surface $f(x, y)$ is said to have a saddle-point (think of a mountain pass, i.e., the lowest point of a ridge!). But, in general, such a point need not exist. Hence, in general, $A$ and $B$ will not agree upon an imputation that will express each man1s best policy. There will be no unique equilibrium position. (MARSCHAK, 1946, p. 106)

Unfortunately, reasoning supported by tables and graphics had limited use for discussing the Theory of Games' solutions, as readers could use them to find saddle-points for games of pure strategies only. All four reviewers noticed that not every two-person zerosum games warranted saddle-points. However, von Neumann and Morgenstern provided a fix for such a problem via mixed strategies. ${ }^{30}$ Hurwicz (1945, pp. 915-916) described them with remarkable lucidness. He defined chance coefficient as A's and B's odds of playing a specific pure strategy in some given game (in his example, each had only two strategies to choose between). Supported by Figure 2, Hurwicz investigated several chance coefficients and concluded if $A$ 's was $2 / 3$ and $B$ 's was $1 / 3$, then row minima and column maxima would share a common value. Therefore, these probabilities framed a solution under mixed strategies as they satisfy equality between maximum minimorum and minimum maximorum. However, if some of Hurwicz's readers were to use chance coefficients as a tool to locate a solution, he would depend on his luck to guess them correctly; otherwise, he would find himself calculating a never-ending quantity of payoff tables.

The Theory of Games assured mixed strategies guaranteed every zero-sum twoperson games would possess some solution. Naturally, von Neumann and Morgenstern did not reason by calculating several tables, blindly chasing a chance coefficient by trial and error. Hurwicz (1945, p. 917) explained: "It is shown (the theorem was originally proved by von Neumann in 1928) that in the table of mathematical expectations (like Table 6) [here Figure 2] a saddle point must exist; the problem is always determinate." Although he presented his reader with an illustration of how mixed strategies warranted solution existence, Hurwicz did it so in a context of duopolies, as earlier mentioned. Thus his reader was left clueless about if that theorem held (and if yes, under what conditions) to games of greater complexity (as of $n$ players, or more than two strategies). Stone (1948, pp. 190-191) also discussed the Theory of Games' "remarkable theorem" of solution existence, specifying it was valid only if players choose among a finite number o strategies. Besides, he also taught that result to his readers by a table similar to Figure 2. However, he went one step down in his approach. Stone's review had instructions to calculate a mathematical expectation - he showed readers should multiply probabilities (associated with each player's strategy) and payoffs, and then sum all such values to obtain a measure to calculate row

\footnotetext{
${ }^{30}$ Marschak (1946, p. 107) mentioned that another escape for solution non-existence would be to add premises differentiating each player's information. Instead, he thought von Neumann and Morgenstern opted to conceive players as driven by "the long-run value of the game".
} 
Figure 2 - Mixed Strategies and Saddle-Points

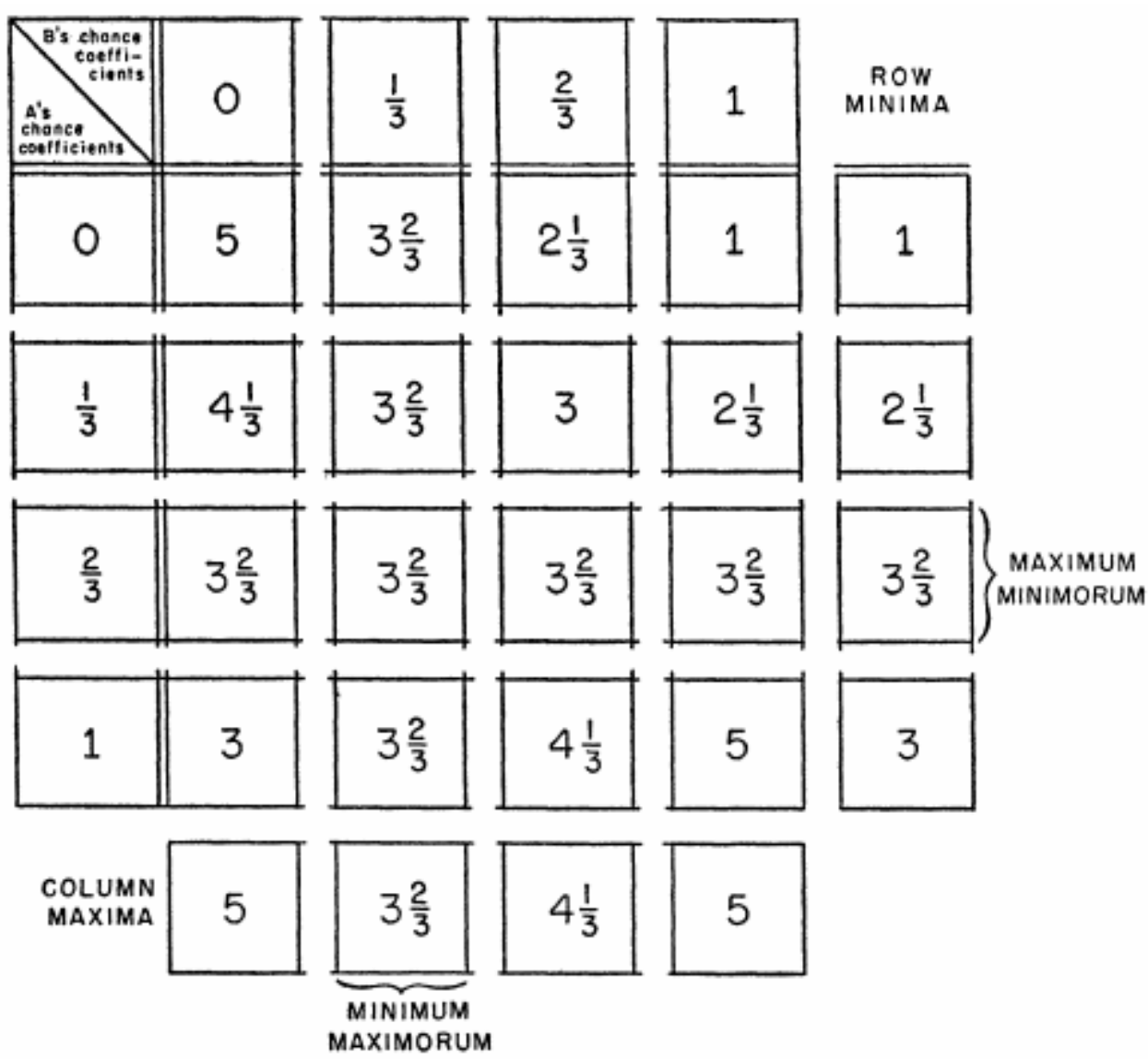

Source: Reproduction of Hurwicz (1945, p. 916).

minima and column maxima. ${ }^{31}$ He was not alone in discussing mathematical expectations: in a footnote, Marschak (1946, p. 107) explained that they are "doubly weighted sums", also commenting they are "bilinear functions", using a more technical label likely unknown to readers unfamiliar with linear algebra.

The mathematical expectation of $A$ 's gain is a sum of all expressions $f(x, y)$ for all possible pairs of values of $x$ and $y$; each such expression being weighted by the probability of the corresponding pair, i.e., by the product of the probability of the given value of $x$ and the probability of the given value of $y$. The existence of the saddle-point follows from certain properties of such doubly weighted sums or bilinear functions. Like all other mathematical proofs of the book, the proof of these properties is given in full detail, with great patience, and without presupposing any previous knowledge of the matter on the part of the reader. (MARSCHAK, 1946, p. 107)

Mixed strategies received different interpretations from reviewers. For instance, Kaysen (1946-1947, pp. 4-5) introduced them when discussing games in which one player

\footnotetext{
${ }^{31}$ Stone (1948) went as far as calculating one of the relevant cases for his example, showing his readers explicitly what they should multiply and sum.
} 
might outguess another, predicting his behavior and hence inflicting a loss on him, such as matching pennies. Consequently, he read mixed strategies as a mechanism to shield oneself against having his strategy foretold. ${ }^{32}$ This interpretation is entirely different from suggesting mixed strategies are a way out of indeterminateness. For Hurwicz (1945, p. 918), von Neumann and Morgenstern's usage of mixed strategies implied dropping valuable information in decision making - commenting it carried "a price to be paid". If players behaved using mixed strategies, then they made choices by comparing expected values (of profits, in his exposition). Consequently, allowing for mixed strategies left important variables aside, such as variance. As a second-order question, he left open a discussion of whether the Theory of Games needed solution determinacy and suggested an alternative approach to solutions:

[...] Contrary to the initial impression, it is possible to render the problem determinate. But there is a price to be paid: acceptance of mixed strategies, assumption that only the mathematical expectation of profit (not its variance, for instance) matters, seem to be necessary. Many an economist will consider the price too high. Moreover, one might question the need for introducing determinateness into a problem of this nature. Perhaps we should consider as the "solution" the interval of indeterminacy given by the two critical points: the Minimum Maximorum and Maximum Minimorum. (HURWICZ, 1945, p. 918)

Moving from two- to three-person games would add a thick layer of complexity in non-zero-sum games. Nonetheless, Hurwicz (1945, p. 918) maintained his zero-sum hypothesis supported by von Neumann and Morgenstern's fictitious player: an instrumental participant whose strategies do not affect outcomes and who always receives the negative of all others players' earnings. Such an apparatus can reshape any $n$-person game into an equivalent $(n+1)$-player zero-sum game. Similarly, Marschak (1946, p. 105) used it to justify how only zero-sum games needed investigation in game theory. He felt "this is one of many devices used in the book to strip every problem to its essentials. It is with the help of such devices that the authors free themselves from the accident of empirical occurrence and are able to give general analysis". However, Kaysen (1946-1947, p. 8) noticed relying on a fictitious player demanded adjustments in some concepts, such as imputation and domination (yet it did not affect solutions).

While the economic problems' nature entirely changed when advancing from a one(the Robinson Crusoe approach) to a two-person game, stepping into three-person games brought some complications as coalitions could then emerge. As Kaysen (1946-1947, p. 5) and Stone (1948, p. 191) maintained, a third participant erases any natural rivalry from two-person problems. Any two players could cooperate against a third. Four-person

\footnotetext{
${ }^{32}$ Kaysen (1946-1947, pp. 4-5) also mentioned mathematical expectations are bilinear forms and that mixed strategies secured two-person zero-sum games always produced at least one solution, emphasizing "what is determined is not the value of the game to each of the players, but rather the mathematical expectation of this value".
} 
games enabled even more arrangements to take place beside pairs. When Hurwicz (1945, p. 918) started discussing three-person games, he explained economic theory until then ruled out coalitions by hypothesis, adding "we discuss the economics of a cartel without rigorously investigating the necessary and sufficient conditions for its formation". Hence economists disregarded coalitions aware they existed in reality. For him, this showed how the Theory of Games, "though seemingly more abstract than economic theory known to us, approaches reality much more closely on points of this nature". However, being more real costed in simplicity. Stone (1948, p. 194) observed von Neumann and Morgenstern put a lot of effort in three- and four-person settings, yet their results were far scarcer if compared to two-person games.

Stone (1948, p. 196) established a combinatorial formula to determine how many distinct coalitions could appear in a generic game of $n$ participants and $p$ "persons" (each lone player and coalition count as one person in Stone's review). For example, three-person games yield 5 configurations: 1 of no coalitions, 3 of coalitions of two players, and 1 of the three-person coalition. Four- and five-person games would elevate this quantity to 15 and 52, respectively. Stone went over 10-person games, estimating 115975 viable configurations. More involved problems demanded a new artifice: characteristic functions. Stone (1948, pp. 191-192) explained verbally what the characteristic function of a game was. Roughly, it is simply a generalization of the value of a play in zero-sum two person-games. Consequently, its importance lied on its potential to compare what members of a coalition can secure gaining against what they would achieve alone or by joining other arrangements:

\footnotetext{
The leap from the two-person to the $n$-person (three or more) zero-sum game is made with the aid of the following device. In any $n$-person game, denote the set of all the players, $1,2,3, \ldots, n$, by $I$. Then, consider any hard and fast coalition of players which acts as a unit; denote this coalition by $S$. The remaining players are considered as another coalition, $I-S$ (or simply $-S)$. Since the original game was zero-sum, the transformed game, played by the two "players" $S$ and $-S$ is also zero-sum. The solution of this transformed game is known for mixed strategies: it is $\max \vec{p} \min \vec{q} K$, as we saw above. By a similar transformation, we can determine the value of the game for every coalition, from $S$ containing one player to $S$ containing $n-1$ players. We can call this value the value of the coalition. Since we know the game is zero-sum, the value of the coalition $I$ (all the players) must be zero; and the value of a coalition $S$ with $n-1$ players must be minus the value of the coalition $-S$ consisting of the excluded player. The function $K$, which tells the value of each coalition $S$ in a certain game, the authors denote by $V(S)$, and call the "characteristic function" of that game. (KAYSEN, 1946-1947, p. 5)
}

To illustrate how coalitions would emerge, Stone (1948, p. 192) used another numerical example. Consider a three-person game where a player acting alone always earn -1 ; coalitions of two players win 1 ; and if all players join a single coalition, it receives 0 . He argued a two-person coalition would undoubtedly arise under such circumstances: individuals can only lose by playing by themselves. Moreover, he remarked von Neumann 
and Morgenstern showed a coalition would always appear if summing total gains from each two-person coalition resulted in a positive number (but naturally, which coalition would rise depending on the game's payoff structure, or its characteristic function). For Kaysen (1946-1947, p. 5), coalitions changed the landscape of game theory completely. The Theory of Games established a one-to-one correspondence between games and their characteristic functions. Hence he claimed "the study of $n$-person games thus becomes a study of coalitions", like every two games sharing a characteristic function are virtually the same even if each one is "clothed in different garments".

Before addressing how von Neumann and Morgenstern's two-person game solution would undergo a revision because of coalitions, reviewers lent definitions and examples for imputation and domination within three-person games. For example, consider three players called $A, B$, and $C$. Hurwicz (1945, p. 920) examined if opponents $B$ and $C$ could enforce imputations $(6.5,8.3,10.2)$ and $(5,9.5,10.5)$ (triplets indicate gains for $A, B$, and $C$, respectively) via coalition formation, they would never chose strategies as to support $(6.5,8.3,10.2)$. Intuitively, they are better off in $(5,9.5,10.5)$. Thus in the Theory of Games' language, $(5,9.5,10.5)$ dominates $(6.5,8.3,10.2)$. While Hurwicz used a numerical case to depict domination, Marschak (1946, pp. 99-100) also supplied his readers a "precise definition of domination" in general terms besides a concrete illustration: "Imputation $X$ is said to dominate imputation $Y$ if some of the participants have separately greater gains in $X$ than in $Y$ and can, by acting together, enforce $X$. The words 'enforce $X$ ' are equivalent to "secure for themselves a combined gain at least equal to that provided in $X$."

Some reviewers took an additional step in describing domination. Kaysen (19461947, p. 6) and Stone (1948, p. 193) delivered descriptions similar to Marschak's, but they remarked the Theory of Games' concept constituted an intransitive relation on an imputation space. Their explanations are fairly straightforward, putting in words intransitiveness' formal definition. To illustrate, Kaysen (1946-1947, p. 6) maintained: "It is worth noting that dominance is not a transitive relation; $\vec{a}$ may dominate $\vec{b}$, and $\vec{b}$ may dominate $\vec{c}$, and yet $\vec{a}$ need not dominate $\vec{c}$. This can happen because the effective sets for the dominance of $\vec{a}$ over $\vec{b}$, and for that of $\vec{b}$ over $\vec{c}$ may be different". Instead, Hurwicz opted to approach that quality assisted by a visual model (see quote below, besides Figure 3 ). His representation of intransitiveness was not amenable to reuse, differently from his expositions of saddle-points and mixed strategies. Readers could not use it as a reasoning tool applicable to a three-person games that interested them.

To get a geometric picture of this somewhat unusual situation one may turn to Figure 1 [here, Figure 3], where points on the circle represent different possible imputations. (The reader must be cautioned that this is merely a geometrical analogy, though a helpful one.) Let us now say that point \#1 dominates point \#2 if \#2 is less than $90^{\circ}$ (clockwise) from \#1. It is easy to see in Figure 1 that \#1 dominates \#2 and \#2 dominates \#3, but in spite of that, \#1 does not dominate \#3. (HURWICZ, 1945, 
Figure 3 - Visual Approach to Intransitivity

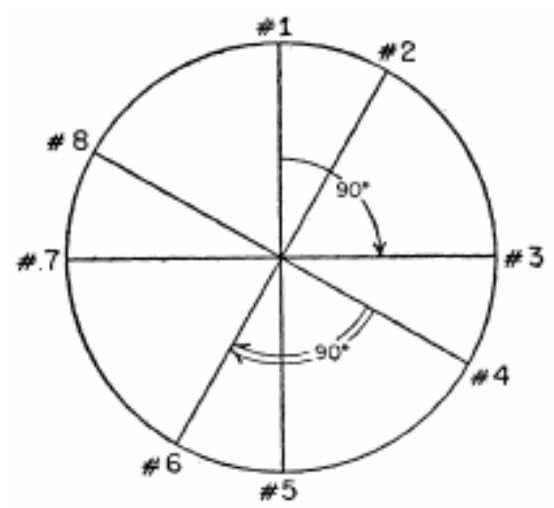

Source: Reproduction of Hurwicz (1945, p. 921).

p. 921)

Such an approach was not expected to be a functional tool for discovering cases of intransitivity, but to demonstrate how domination and intransitivity are not contradictory concepts, as an unfamiliar reader could mistakenly assume. Besides, Figure 3 also acted as to illustrate what a solution was. He defined it verbally as a set of imputations armed of two properties. First, no imputation within a solution can dominate another. Second, any imputation outside a given solution must suffer domination from at least one of its imputations. Albeit counterintuitive, imputations outside a solution could still dominate some imputations inside it. For instance, in Figure 3, \#1, \#3, \#5, and \#7 constitute a solution. Still, while \#7 dominates \#8 it is also true \#8 dominates \#1. Hurwicz (1945, p. 921) explained that phenomena did not imply \#1 should be out of that solution set: if it were, then no remaining imputation would dominate \#2. Consequently, the suggested set would no longer fulfill the solution definition. Observing \#2, \#4, \#6, and \#8 also are a solution, he demonstrated solutions were not necessarily unique. Hurwicz (1945, p. 922) also built another case similar to Figure 3 to point solutions not always existed (he just changed the distributions of imputations in the circle).

Marschak (1946, p. 99) exhibited an inventive way of depicting a three-person game's imputations and solutions. In particular, his example described a market of one seller, "Adam", and two buyers, "Clark", and "Black". Henceforward, call them $A, B$, and $C$, respectively. They had reservation prices equal to 9,17 , and 22 . He argued only coalitions of $A$ and $C$ or of all players needed attention: in short, $B$ and $C$ could achieve nothing by playing together because $A$ would "refuse to sell;" $A$ and $B$ 's union would only produce imputations dominated by some other from a coalition of $A$ and $C$. Furthermore, only imputations summing 13 in aggregate gains would emerge (again, by a domination argument). To transfer his case to a graphical environment, Marschak (1946, p. 101) 
Figure 4 - Graphical Model of One Seller and Two Buyers

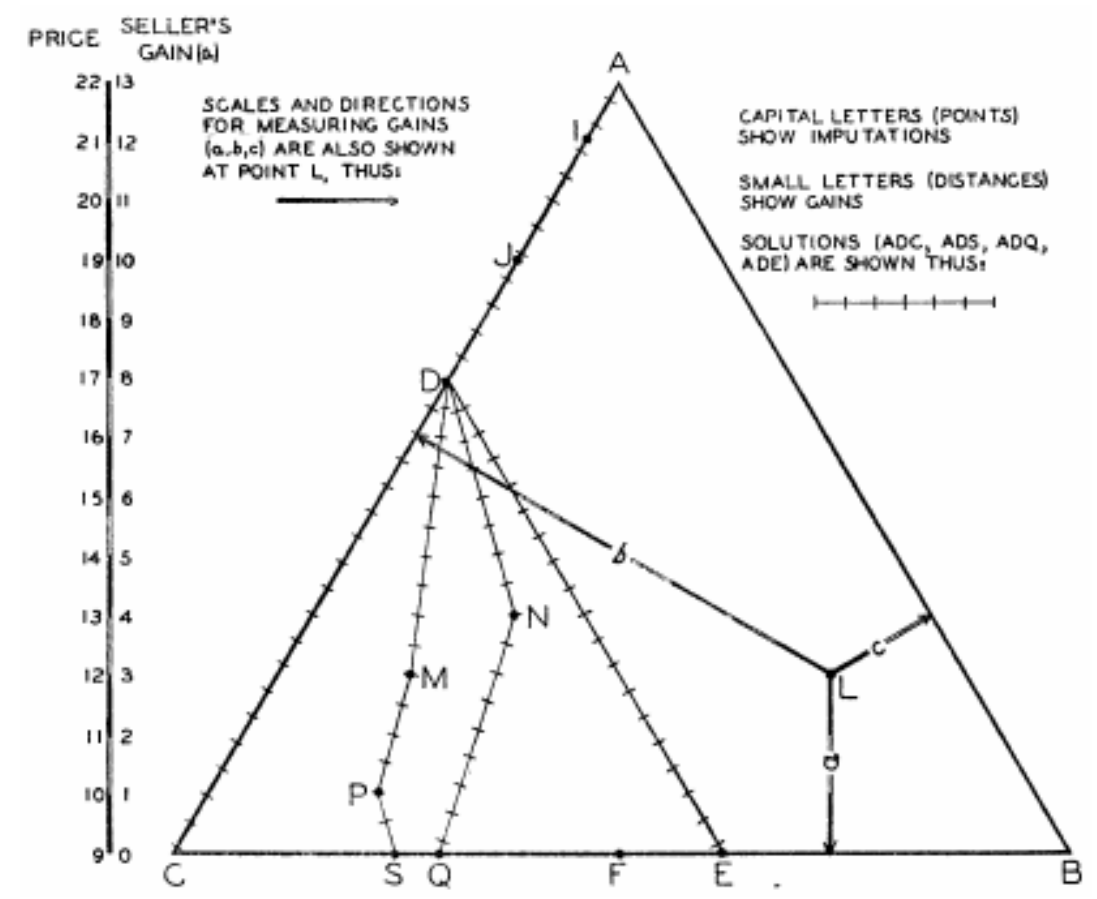

Source: Reproduction of Marschak (1946, p. 102).

resorted to a result known as Viviani's Theorem: for any equilateral triangle, summing distances from some of its interior points to each of its sides always equals the polygon's altitude. Therefore, that problem of one seller and two buyers could be "conveniently treated graphically" by an equilateral triangle of altitude 13. In particular, each vertex corresponded to a player and points were imputations. The distance from any point to a side opposite to a vertex displays that player's (attached to that vertex) gains. Figure 4 replicates Marschak's drawing. It contains imputations $I=(10,0,3), J=(12,0,1)$, $L=(3,8,2)$, and $M=(3,2,8)$. The quote below shows how Marschak tried to make clear his drawing, as well as identifies some information available in Figure $4 .^{33}$

Mark on the left side of the triangle the point $D$ having altitude $a_{D}=8$ and draw $D E$ parallel to (and obviously having distance 5 from) $A B$. All points in or on the triangle can then be grouped into three regions " $\mathrm{M}$ ", "I", "L", so named in correspondence to the example-points $M, I, L$.

Region "M": in or on the small triangle $C D E$; that is, $c \geq 5$; hence $a \leq 8$, $b \leq 8, a+b \leq 8$.

Region "I": on line $A D$; that is, $c<5, b=0$; hence $a>8, a+b>8$, $a+c=13$.

\footnotetext{
${ }^{33}$ Kaysen (1946-1947, pp. 10-12) used a model of an equilateral triangle to discuss a three-person market. In a footnote, he cited Marschak's review: "these numbers have been taken from the exposition of the same problem in the review of the 'Theory of Games,' by Prof. J. Marschack [sic] in Journal of Political Economy, April, I946, pp. 97 to 115".
} 
Region "L": all other points in or on large triangle $A B C$; that is, $c<5$, $b>0$; hence $a \leq 8, a+b>8, a+c<13$. (MARSCHAK, 1946, pp. 101-102)

Figure 4 was a tool to understand how domination restricted solutions. Marschak (1946, p. 102) felt an unwarned reader could imagine regions $I$ and $M$ constituted a solution. However, Marschak (1946, p. 102) explained: "Points of Region ' $M$ ' are related to each other in a way different from how the points of Region ' $I$ ' are related to each other and those of Region ' $M$ '". For example, $N=(4,3,6)$ dominates $M=(3,2,8)$ because $A$ and $B$ can both earn more under $N$. Hence $M$ and $N$ could never belong simultaneously to a solution (see quote below). Furthermore, Marschak (1946, p. 103) explained his particular problem admitted solutions "in two parts". First, $\overline{A D}$ pictures imputations concerning the coalition formed by $A$ and $C$. That answer represents something economic analysis previous to von Neumann and Morgenstern had already established (Marschak (1946, p. 103) judged such part "self-evident"). Second, a curve descending from $D$ to a point anywhere in $\overline{C E}$, but never straying from the vertical over $30^{\circ}$. In a footnote (of half-page long) Marschak demonstrated his remarks algebraically, sustaining his proof would serve as an exercise to his readers to train concepts of imputation and domination. Intuitively, these concern cases where $C$ pays $B$ some compensation to leave the market so he can pay $A$ a lower price.

\begin{abstract}
The "solution" concept is perhaps best understood if we first define those imputations which are not elements of a given solution: An imputation is not an element of a given solution if and only if it is dominated by some element of the solution. (Thus point $N$ does not belong in the solution which includes points $I, J, M$; and point $M$ does not belong in the solution which includes points $I, J$, and $N$.) Or, in positive phrasing: The elements of a given solution are those and only those imputations which are undominated by any element of it. (MARSCHAK, 1946, p. 103)
\end{abstract}

To conclude, book reviews written by Hurwicz, Marschak, Kaysen, and Stone show that the Theory of Games would not find a wide audience among economists. These authors attempted to teach concepts and results in a language as uncomplicated as they could. It is remarkable how they explained both simple and complex ideas, ranging from lecturing what mathematical expectations are and how to solve three-person zero-sum games. A regular assessment does not need such careful explanations: usually, evaluators only give a brief outline of a book's objective, methods, and conclusions. These unusual four appraisals stand in opposition to others in these considerations. Their efforts hint that the Theory of Games relied on secondary sources (such as these same reviews) to extend its influence among economists, regardless of its self-contained mathematics and verbal discussions. It is essential to look at what skilled readers did from reading von Neumann and Morgenstern's volume to understand its dissemination, especially in simplified contexts 
of smaller problems (not laying the foundations for a new science of economics; for example, discussing duopolies only). These less intricate articles would have a broader public at hand (even if still limited) than the Theory of Games. However, before proceeding to an analysis of what mathematics proficient economists did after reading von Neumann and Morgenstern's volume, Section 1.4 will analyze what book reviews mentioned utility functions and axiomatics, as these topics are of particular interest for this dissertation.

\subsection{THE DELICATE SUBJECT OF NON-ORDINAL UTILITY}

Utility functions may have many interesting qualities. For instance, one such mapping can be differentiable or not. Applying transformations over utility functions can imply those characteristics' conservation or loss. Nowadays, textbooks call ordinal every property preserved under strictly increasing transformations. ${ }^{34}$ If not, they name it cardinal or non-ordinal. ${ }^{35}$ Therefore any preference representation by a utility function establishes an ordinal property whereas every utility measure is a cardinal one (since only positive affine transformations uphold units) (MAS-COLELL; WHINSTON; GREEN, 1995, p. 9). ${ }^{36}$ An economist acquainted with set theory would likely be surprised with these lexicons' foundation on ordinal and cardinal numbers. Notably, these terms follow from an earlier definition already outcast in modern mathematics (SCHMIDT; WEBER, 2008). Around 1944, to approach preference representation as an ordinal property was a predominant practice among economists. However, von Neumann and Morgenstern's expected utility approach embodied a non-ordinal preference representation. Consequently, Moscati (2016) argued that the Theory of Games faced a skeptical community towards non-ordinal property's usefulness and legitimacy. This disbelief appeared in book reviews, as this section will demonstrate.

This section will explore how the Theory of Games' book reviewers portrayed its utility concept. ${ }^{37}$ In most cases, they alluded to it only casually: evaluators did not

\footnotetext{
${ }^{34}$ Given $S \subset \mathbb{R}$, a map $f: S \rightarrow \mathbb{R}$ is a strictly increasing transformation if $\forall x_{1}, x_{2} \in S x_{1}<x_{2} \Leftrightarrow$ $f\left(x_{1}\right)<f\left(x_{2}\right)$.

${ }^{35}$ Naturally, there are other definitions for cardinal. Moscati (2013) uses cardinal to label properties preserved under positive affine transformations. Given $S \subset \mathbb{R}$, a map $g: S \rightarrow \mathbb{R}$ is a positive affine transformation if $\exists a \in \mathbb{R}_{+}$and $\exists b \in \mathbb{R}$ such that $\forall x \in S g(x)=a x+b$. In this dissertation, cardinal stands for non-ordinal (unless specified otherwise).

${ }^{36}$ Oftentimes economists say "a utility function is ordinal" describing its preference representation property. Ordinal and cardinal may regard other utility functions' features as well. Given any $n \in \mathbb{N}$, let $\mathscr{X} \subset \mathbb{R}^{n}$ be a commodity space. Consider a continuous utility function representing some preference relation $u: \mathscr{X} \rightarrow \mathbb{R}$. If $h: u(\mathscr{X}) \rightarrow \mathbb{R}$ is a strictly increasing and discontinuous transformation, then $h \circ u$ represents the same preferences as $u$. Hence representation is a ordinal property. However, $h \circ u$ is discontinuous. Thus continuity is a cardinal attribute (MAS-COLELL; WHINSTON; GREEN, 1995, p. 49).

${ }^{37}$ The history of expected utility have several dimensions. For example, Moscati (2013) showed its problem of terminology (a narrative about how economists used expressions as "ordinal utility" and "cardinal utility" describing how they acquired their modern meaning). In another work, Moscati (2016) analyzed how Paul A. Samuelson accepted expected utility as a legitimate economic theory. An exhaustive
} 
seek further support for their claims or detailed their comments, as if von Neumann and Morgenstern's approach to preference representation had no peculiarities worth describing. For example, Kendall (1944, p. 293) affirmed von Neumann and Morgenstern ([1944] 2007) proposed "a simplified conceptual model of economic behaviour, and a study of that theory can do much to throw light on certain basic concepts of economics, notably that of utility". Besides, Gumbel (1945, p. 210) indicated they began "with the fundamental notion of utility to which a number can be assigned". Neither shared how the Theory of Games could enlighten economists on utility-related subjects or what to ascribe real numbers to utilities signified. Nevertheless, some commentators conferred more careful considerations: Nagel (1945, p. 551) declared von Neumann and Morgenstern exercised "the simplifying assumption that utility can be expressed in monetary units", and Copeland (1945, p. 498) asserted they substituted "the questionable marginal utility theory by a new theory which is more suitable to their analysis". These remarks place expected utility functions in opposition to the dominant interpretation and have a second-order dimension: what constitutes a "simplification" and to label marginal utility "questionable" subsume personal reflections and standpoints on economics qua economics.

Reviews of expository nature - namely, those written by Hurwicz, Marschak, Kaysen, and Stone - held more involved arguments on utility. Besides, they testify that economists had no universal way to evaluate an axiomatic system. To show one side of it, consider Kaysen's assessment first. While in section II, "The Theory of Games", Kaysen (1946-1947, p. 8) explained game theory's key concepts, such as value of the game, inside section III, "Economic Applications", he treated what such amount meant. To bridge applications of von Neumann and Morgenstern's text to economics, he estimated it unavoidable to "translate this value into some dimension with economic meaning". In particular, he charged their utility was measurable: "The authors have chosen for this measure a modification of the notion of 'utility.' This is essentially a return to an older concept, the idea of measureable [sic] utility, in contrast to the currently fashionable conception of utilities as quantities which can be ordered but not measured". ${ }^{38}$ In a footnote, he let it clear how absurd von Neumann and Morgenstern's expected utility function was for him (see quote below). Not only Kaysen (1946-1947, p. 8) believed in a standard view of how to interpret utility functions conflicting with von Neumann and Morgenstern's approach, but he searched for an explanation on why such dissimilarity occurred, as it was not fully clear

history, covering every aspect of expected utility theory, is out of scope here: this chapter only complements former research on such history by showing how economists first reacted to von Neumann and Morgenstern's cardinal interpretation of preference representation in book reviews.

${ }^{38} \mathrm{An}$ utility function is measurable if its ratios have a definite meaning, that is, given $x_{1}, x_{2} \in \mathscr{X}$ and $u\left(x_{2}\right) \neq 0$, if $u\left(x_{1}\right)\left[u\left(x_{2}\right)\right]^{-1}$ has an economic interpretation. For example, consider a rectangular room and a map assigning to each side its length in meters. An economist would say that function is measurable. If dividing what it results to any given side and its adjacent equals 2 , then one side is twice as long as the other. Utility usually does not hold that property: saying one bundle gives 2 times more utility than another only informs it is preferable, but not how many times more desirable it is. 
for him how the Theory of Games produced its utility function from its axioms. For him, it inadvertently supposed utility functions were additively separable by an "interesting" argument: ${ }^{39}$ this property followed from von Neumann and Morgenstern's operation of mixing lotteries. ${ }^{40}$

\begin{abstract}
Mathematical economists will not be surprised at the authors' seeming to come up with the impossible - the cardinal measurement of utility. By assuming that in stochastical situations consumers maximise a linear sum (namely a "mathematical expectation"), the authors have already slipped into their axioms the usual assumption of additive, independent utilities, which naturally leads them to a unique cardinal index of utility. (KAYSEN, 1946-1947, p. 9)
\end{abstract}

For Kaysen (1946-1947, pp. 12-13), the Theory of Games' utility function had two flawed properties: measurability and transferability. Regarding measurability, he discussed von Neumann and Morgenstern rendered a set of premises that formally implied such characteristic. However, it comprised "an assumption about economic behaviour which is contrary to experience": agents weighed only mathematical expectations when choosing under uncertain outcomes. In particular, it neglected any additional information (such as variance) by hypothesis. Kaysen disapproved measurability since it disaccorded with "hundreds of examples" in economics. For instance, people purchase lottery tickets regardless of their negative expected earnings, so they consider something beyond mathematical expectation to make decisions. In a subsection labeled "General Remarks Concerning the Axioms", von Neumann and Morgenstern ([1944] 2007, p. 28) declared they could not combine a "specific utility of gambling" (referring to "a (positive or negative) utility of the mere act of "taking a chance"") in their axiomatic system without incurring in inconsistencies, adding in a footnote: "This may be a paradoxical assertion. But anybody who has seriously tried to axiomatize that elusive concept, will probably concur with it." Kaysen (1946-1947, p. 13) responded directly: "And if, as the authors say in a footnote, it is impossible to formulate the concept of the utility of gambling in a consistent way, so much the worse for their postulate systems."

Economists did not consensually see measurability as a problem. Instead of a shortcoming, Marschak (1946, p. 110) interpreted it as a simplifying move: games and economics would be more straightforward if economists were willing to adopt "the simplifying algebraic properties of mathematical expectation" and their resulting non-ordinal utility.

\footnotetext{
${ }^{39}$ Let $u: \mathscr{X} \rightarrow \mathbb{R}$ be a utility function. Then $u$ is said to be an additively separable utility function if there exist functions $u_{1}, \ldots, u_{n}: \mathbb{R}_{+} \cup\{0\} \rightarrow \mathbb{R}$ such that $\forall\left(x_{1}, \ldots, x_{n}\right) \in \mathscr{X} u\left(x_{1}, \ldots, x_{n}\right)=\sum_{i=1}^{n} u_{i}\left(x_{i}\right)$. Further, if $u$ is an additively separable utility function, then its inherent preference representation is cardinal.

${ }^{40}$ Let $A, B$, and $C$ be gambles. Define $\alpha \in(0,1)$ such that an hypothetical individual is indifferent between $A$ and a mix giving $B$ and $C$ with odds $(1-\alpha)$ and $\alpha$, respectively. von Neumann and Morgenstern ([1944] 2007, p. 18) suggested $\alpha$ as a "numerical estimate for the ratio of the preference of $A$ over $B$ to that of $C$ over $B$ ".
} 
In-between Kaysen's negative and Marschak's positive positions, Hurwicz (1945, p. 910) left a footnote about that minor issue. For him, the Theory of Games' reader should not judge its worth grounded on its utility; it as a negligible characteristic of von Neumann and Morgenstern's enterprise (see quote below). ${ }^{41}$ Since his review dates from 1945, he had not seemed their proofs concerning utility subjects - in their first edition, von Neumann and Morgenstern ([1944] 2007, p. 8) promised proofs would appear in a future article, as "the conceptual and practical difficulties of the notion of utility, and particularly of the attempts to describe it as a number, are well known and their treatment is not among the primary objectives of this work". For Hurwicz (1945, p. 910), any evaluation on the Theory of Games's utility function should wait for that promise's fulfillment. Here it becomes clear how judging von Neumann and Morgenstern's utility goes through several second-order questions in economics. First, measurability could receive different interpretations, being either a drawback or an advantage. Second, how important it was for assessing the Theory of Games was a debatable point. Third, what evaluators required for analyzing its merits varied: while Hurwicz felt proofs would have a meaningful role in appraising measurability, Kaysen and Marschak act as results alone were sufficient.

But it should be emphasized that the validity of the core of the Theory of Games is by no means dependent on measurability or transferability of the utilities and those who feel strongly on the subject would perhaps do best to substitute "profits" for "utility" in most of the book in order to avoid judging the achievements of the Theory of Games from the point of view of an unessential assumption. (HURWICZ, 1945, p. 910)

Utility transferability was also a questionable characteristic of von Neumann and Morgenstern's approach to utility, but it was a less important subject. Kaysen (19461947, p. 13) raised no objections to it in models applied to firms since profits are readily measurable, divisible, and transferable. To queries in which agents try to maximize their "non-measurable, personal utility", he regarded von Neumann and Morgenstern's approach unfit. Nevertheless, this was not the Theory of Games' primordial deficiency, as he stated: "This [utility transferability] is a serious limitation since the study of interesting and important markets is left outside its scope. However, it is not a fatal one, and there is always the hope of a greater generalization of the theory, which will dispense with the limitations." ${ }^{2}$ Conversely, Marschak (1946, p. 112) presented no judgmental remarks to this hypothesis and described it plainly: "these numbers - the individual gains which constitute an imputation - can be transferred from person to person and can be added to obtain the 'value of the gain' to a coalition, as if they were coins". ${ }^{3}$

\footnotetext{
${ }^{41}$ That quote also contains Hurwicz's only mention to utility transferability.

${ }^{42}$ For Kaysen (1946-1947), the Theory of Games' most serious weakness was its solution definition and any indeterminacies it warranted. Concerning utility only, it was its measurability property.

${ }^{43}$ The Theory of Games suggested an "coin" approximation: von Neumann and Morgenstern ([1944] 2007, p. 8) clarified considering their intention was not to debate utility measurability, they
} 
The appraisals mentioned above - Hurwicz's, Marschak's, and Kaysen's — assessed the Theory of Games' first edition. Its second edition adjoined an appendix entitled "The Axiomatic Treating of Utility" comprising von Neumann and Morgenstern's proofs showing that their axiomatic system implied the existence of a non-ordinal utility function. Stone (1948) and Hurwicz (1948) (published by The Annals of Mathematical Statistics) had access to these. Hurwicz (1948, pp. 436-437) evaluated using mathematical expectations as a decision-making criterion had a "restrictive nature since it implies that the game is played for numerical ('measurable') stakes and that the second and higher moments of the probability distribution of the losses are immaterial". However, he highlighted it allowed von Neumann and Morgenstern to deepen their analysis in other dimensions. Consequently, he concluded: "Given the great complexity of the problem, even in its restricted version, the authors' decision can hardly be criticized." In turn, Stone also informed his reader the Theory of Games worked over a utility function subject to severe limitations, as being unique up to positive affine transformations only. Still, he felt such constraint could enhance economics' scientific status by comparing utility and thermodynamics:

[...] The authors prove in their new appendix that their axioms of utility make utility a number up to a linear transformation, i.e., without fixing a zero or a unit of utility. In seeing the significance of this statement, it may be helpful to consider an example in physics. As long as only the concept of "warmer" was known, temperature was a number only up to a monotonic transformation. With the study of the concordant behaviour of ideal gases, there emerged a rigid numerical scale which restricted the transformations to linear ones. Subsequent developments of thermodynamics even fixed the absolute zero so that the transformation system of thermodynamics consists only of the multiplication by constants. Only the absolute unit is missing. The authors' treatment of utility, if accepted, puts utility on the same level as the physical concept of energy which is also a number up to any linear transformation. (STONE, 1948, p. 197)

The Theory of Games had its axiomatics as a central component in developing individual decision-making theory over risky choices, as von Neumann and Morgenstern ([1944] 2007, p. 19) maintained "an exact and exhaustive elaboration of these ideas [utility] requires the use of the axiomatic method" (emphasis added). If commentators often addressed the Theory of Games' approach to utility, its properties and its place in economics, such commonness do not apply to axiomatics. In general, evaluators disregarded how von Neumann and Morgenstern delivered utility by a set of complete and consistent hypothesis (later followed by proofs), or only mentioned that subject lightly. For instance only Kattsoff (1945, p. 246) offered a remark among social sciences journals: "an axiomatic formulation of the general notion of a game is given and explained". However, nowhere in his text "axiomatic formulation" is further explained. In economics reviews, Barna (1946,

would try to simplify their analysis assuming "the aim of all participants in the economic system, consumers as well as entrepreneurs, is money, or equivalently, a single monetary commodity". 
p. 138) stated von Neumann and Morgenstern "of course accept some of the axioms of economic theory, notably that of the profit motive". This silence on axiomatics elongates itself even for more extended assessments: while Kaysen and Stone mentioned their axioms when addressing what hypotheses implied non-ordinal utility, they did not develop for his readers what roles axiomatics played. There was only one exception among all reviewers. Marschak (1946, pp. 114-115) not only provided his readers with a summary explaining what it meant to treat a subject axiomatically but also defended it as a tool of investigation in economics.

\begin{abstract}
[...] Every empirical situation - be it poker or bilateral monopoly - is divested of inessential features and expressed in unambiguous symbols. Formalized concepts and axioms are constructed. Just as the concept of the length of a segment and that of a real number, just as the axioms and theorems on length and those on real numbers, can be expressed by formal symbols that apply to both fields (geometry and arithmetic) and to some other fields as well; thus concepts such as "domination" or "value of a game," the axioms which these concepts satisfy, and the theorems derived from those axioms need not be attached to the empirical images of the market or the card table. "Intuitive" or "heuristic" considerations generated in the authors' minds by experience are formalized into concepts and propositions which, once stated, are detached from experience until the final conclusions are reached. Such detached reasoning safeguards against any subconscious smuggling-in of undefined terms and operations or of assertions that have not been proved, yet had not been stated explicitly as axioms. The formal conclusions thus obtained are then materialized: they are translated into the language of the concrete fieldgames or economics in our case - and are thus prepared for empirical test. Not only are conclusions obtained in this way more reliable, not only do they more audibly respond to any deliberate modification of the premises, but they are also richer and better ordered and their mutual relations are revealed with greater clarity than if one had studied one empirical case after another, encumbered with every accidental detail and exposed to the risk of misunderstandings and fallacies. (MARSCHAK, 1946, pp. 114-115)
\end{abstract}

To conclude, book reviews are central to understanding the Theory of Games' reception. Particularly to how von Neumann and Morgenstern decided to treat preference representation, book reviews bridged expected utility's non-ordinal character to an earlier understanding of utility functions (applied to riskless choices). These views clashed: before, economists agreed utility functions should be unique up to any strictly increasing transformation. In contrast, in an expected utility framework, (expected) utility functions can only undergo positive affine transformations. Book reviews emphasized that point and established a connection between von Neumann and Morgenstern's way and an old debate over what can economists do with utility functions. It would be natural for reviewers to also discuss axiomatics as a reasoning tool given its central place in the Theory of Games' attainment of utility. Still, evaluators overlooked axiomatics and values related to picking it over other means (as developing a theory verbally). Consequently, to understand the Theory of Games' role in dissemination axiomatics as a standard approach to individual-decision 
making it is important to look for how economists used von Neumann and Morgenstern's lead in research papers, as book reviews were reticent on that point.

\subsection{CONCLUDING REMARKS}

This chapter explored book reviews as a material to analyze the Theory of Games' direct reception and how it raised many controversies among economists. There was no consensus on what a proper definition of equilibrium was, nor a universal rule to compare different theories in terms of generality. More importantly here, von Neumann and Morgenstern's volume resurrected an outcast conception of utility functions. Economists had expelled non-ordinal properties in the 1930s, as assumptions of additive separability. As expected utility functions are unique only up to positive affine transformations, the Theory of Games would bring back a hot issue: how should economists define and interpret preference-representing functions. Reviewers could not provide an answer, but they offered their readers second-order statements to ponder over. Values of generality, applicability, and proximity to reality could guide economists in picking a side. That issue would not settle quickly, as expected utility would demand years to stabilize. Chapters 2 and 3 show some examples of how still in the 1950s some economists refused expected utility theory altogether.

However, if book reviews helped to identify issues von Neumann and Morgenstern's presentation of expected utility theory, they masked a readability issue their book would face among economists. Commentators from statistics, philosophy, and social sciences suggested the average economist would have a hard time reading the Theory of Games (if he could understand it at all). However, reviews published in economics journals suggested that readability was not such a severe obstacle, and only some effort would do to overcome it. Still, reviews written by Hurwicz, Marschak, Kaysen, and Stone translated von Neumann and Morgenstern's concepts and results in a less involved way given evidence supporting readability was a crucial issue for the Theory of Games' reception. They frequently resorted to verbal descriptions, simplified and numerical examples, and visual illustrations to explain von Neumann and Morgenstern's book. Consequently, to understand how economists received the Theory of Games it is necessary to analyze how mathematically skilled researchers used it to produce articles in simplified contexts - for example, only covering individual decision-making instead of a 600-page book offering a new foundation for economics - and how other economists applied these in turn. Chapter 2 follows that lead and studies how two Econometrica articles (one written by Marschak, a leading reviewer for the Theory of Games) tackled expected utility theory alone and what uses economists found for them. 



\section{TWO WAYS OUT OF UNCERTAINTY}

The preceding chapter analyzed how the Theory of Games' book reviews were important disseminators of von Neumann and Morgenstern's contribution among mathematically unskilled economists. Section 1.3 discussed how Marschak (1946) and Hurwicz (1945) composed unusually lengthy evaluations as they attempted to translate the Theory of Games for a wider public. Coincidentally, they read von Neumann and Morgenstern's book while they were at the Cowles Commission for Research in Economics, an research institute centered on econometrics and mathematical economics. ${ }^{1,2}$ To illustrate, see its logo and motto in Figure 5 (where measurement signifies specifying economic variables mathematically and obtaining estimations of such values).

Besides housing two major reviewers of the Theory of Games, Cowles also shows in its record a substantial flow of axiomatic research. For instance, Kenneth J. Arrow and Gérard Debreu are outstanding names in the history of general equilibrium models. They (axiomatically) studied equilibrium existence at Cowles. This chapter will show that Cowles also produced axiomatic research on choice under uncertainty inspired by von Neumann and Morgenstern's volume and will analyze its diffusion among economists. ${ }^{3}$

As in Chapter 1, this dissertation will not characterize images of knowledge of particular authors. ${ }^{4}$ That would demand a deeper knowledge of each such economists'

Figure 5 - Cowles' Logo: "Science is Measurement"

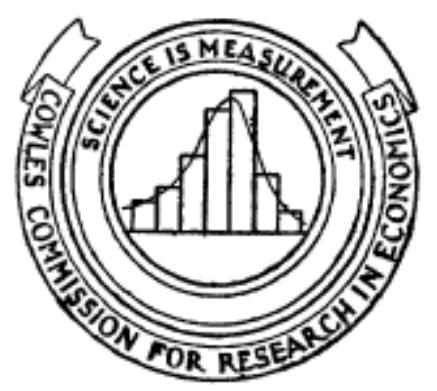

Source: Reproduction of Cowles Commission for Research in Economics (1946, cover).

\footnotetext{
${ }^{1}$ Nowadays Cowles Foundation for Research in Economics, as it became following its move to Yale University in 1955.

${ }^{2}$ Marschak was at Cowles during 1943-55 (first as director of research, later as a research associate). In turn, Hurwicz acted as a research associate (1942-45) and later returned as a visiting professor (1950-51) (HILDRETH, [1986] 2012, pp. 133-134).

${ }^{3}$ Arrow and Debreu were at Cowles during 1947-50 and 1950-55, respectively (HILDRETH, [1986] 2012, pp. 132-133). While at the Commission, their most relevant working papers in general equilibrium theory were Debreu (1952) and Arrow and Debreu (1953).

${ }^{4}$ Historiographically, this chapter will follow Stapleford (2017). See Subsection 1.1.
} 
work and would escape the goal of understanding the Theory of Games' reception via secondary sources. For example, Cherrier (2010) analyzed Marschak's intellectual history and showed how his perception of economics (as his interpretation of what mathematics meant for economics, for instance) have roots in his private life. Such a background would be extremely valuable in characterizing Marschak's image of economics. However, a history that interprets some articles (as Marschak's) as an intermediate between von Neumann and Morgenstern ([1944] 2007) and a wider public of economists should focus on what economists who read those had at hand - they would have to understand Marschak's points that touched on second-order problems without access to a history of his personal experiences. Instead of characterizing particular images of knowledge, Chapters 2 and 3 will explore a broader dissemination web by considering that some mathematically skilled authors dispersed von Neumann and Morgenstern's influence through their articles. ${ }^{5}$

Before proceeding, it is worth presenting some facts of Cowles' history around 1940-55. When the Theory of Games appeared in 1944, Cowles was under transformation. In September 1939, the Commission relocated its facilities from Colorado Springs to The University of Chicago, initially filling only four rooms at the Social Science Building's fourth-floor (CHRIST, 1952, p. 20). Besides moving to a more flourishing academic environment, World War II induced a critical leave for Cowles' staff: Theodore O. Yntema, then the Commission's research director, was dragged to the war efforts and resigned in November 1942. He took a position at the Committee on Economic Development to "organize a study of conditions favorable and unfavorable to full employment after the war" (CHRIST, 1952, p. 24). Succeeding Yntema, Marschak ${ }^{6}$ and Tjalling C. Koopmans ${ }^{7}$

\footnotetext{
${ }^{5}$ There are several narratives establishing a connection between the Cowles Commission and formal, axiomatic choice theories. For example, Giocoli (2003) interpreted such phenomena as an "escape from psychology", where economists favored formalism in order to build a consistent discipline, free of any mental variables. Herfeld (2017) complemented Giocoli's analysis (studying Marschak and Koopmans at Cowles), arguing that that axiomatization was also related to efforts of making economics "more scientific" by reshaping its theoretical foundations (besides, she also depicted the tension between the formal and behavioral approaches). Besides, starting on the 1950s several empirical tests of expected utility would appear - and eventually, challenge its descriptive power (see Moscati (2017)). These contributions show the many facets of expected utility theory's history. Chapters 2 and 3 here will focus on theoretical issues related to axiomatics only. An exhaustive understanding the dissemination of axiomatics and expected utility demands attention to different topics already brought up on the literature.

${ }^{6}$ Jacob Marschak (1898-1977) was born on Kiev, Ukraine. He fled his country to Germany due to the Russian Revolution, studying statistics and economics at the University of Berlin. In 1922, he obtained his Ph.D. in economics at the University of Heidelberg. Until 1930 he lived as a journalist and applied economist. Because of new political events, he went to Oxford and became a lecturer. In 1939, Marschak moved to the United States of America, where he remained until his passing. He lectured across multiple departments: New School for Social Research (1940-1942), University of Chicago (1943-1955), Yale University (1955-1960), and the University of California at Los Angeles (1960-1977). An active player in the "econometric revolution that is commonly associated with the Cowles Commission for Research in Economics", his interests ranged through the theory of stochastic decision, "theory of the economic value of information", and economic theory of teams and organizations (RADNER, 2018).

${ }^{7}$ Tjalling Charles Koopmans (1910-1985) was born on Graveland, the Netherlands. In 1933 and 1936 respectively, he received his Master degree in mathematics and theoretical physics from Utrecht University and his Ph.D. in mathematical statistics with applications to economics from Leiden University. His career was "rather peripatetic for eight years", till he entered the Cowles Commission for Research in Economics
} 
served as Cowles research directors during the terms 1943-48 and 1948-55, respectively. ${ }^{8,9}$ These new directors would reshape that institutions' research interests and institutional organization. ${ }^{10}$ For example, just before Cowles moved to Yale University in 1955, its motto became "Theory and Measurement", showing higher importance its members granted theoretical research.

Hildreth ([1986] 2012, p. 6) stated that Marschak, once ahead of the Commission, "quickly provided an eminently effective organizational framework, performed astounding recruiting magic, and cultivated a spirit of free and imaginative yet dogged inquiry". For instance, Christ (1952, pp. 29-30) asserted that in order to showcase the staff's high-quality research, he launched a regular seminar series focalized on econometrics in 1943, held every three or four weeks at the University. Hildreth ([1986] 2012, p. 6) added that while these seminars featured the "more nearly finished" pieces in a formal environment, Marschak also arranged weekly or bi-weekly staff meetings to discuss on-going projects, sometimes "barely started" within a casual atmosphere. Additionally, in late 1943 Marschak set up "Cowles Commission Papers, New Series", a collection of published paper reprints authored by staff members "bound in paper either singly or in groups of two or three related articles". Selected people at the Commission received these costlessly. Seminars and the New Series will be relevant in explaining how the Theory of Games circulated among Cowles' members (see Section 2.1).

This chapter has three sections besides a conclusion. Section 2.1 builds a context for the Theory of Games at Cowles Commission, showing how staff members became acquainted with it. Besides, it shows Cowles' members also became interested in choice under uncertainty and utility around 1950. Section 2.2 presents two works on individual decision-making over risky outcomes that emerged under these circumstances by Marschak (1950) and Herstein and Milnor (1953). The working papers related to these contributions show different approaches that appeared at Cowles regarding how to structure and deliver a mathematically rigorous article. Section 2.3 tracks and analyzes all the citations Marschak (1950) and Herstein and Milnor (1953) received until 1954, when Savage ([1954] 1972) published his book. It investigates how economists reacted to them, emphasizing what uses

at the University of Chicago. "A theorist by nature, but a theorist interested in real problems",", his main contributions were in econometrics, activity analysis, and optimization. He became a Nobel laureate alongside Leonid V. Kantorovich in 1975 due to their "contributions to the theory of optimum allocation of resources" (CHRIST; HURWICZ, 2018).

${ }^{8}$ Christ (1952, pp. 17-18) reported that in 1937, Ragnar A. K. Frisch, Marschak, and Yntema were surveyed to become research directors, but none of them felt inclined to accept due to Colorado Springs isolation from "large academic centers". The office was vacant until 1939.

${ }^{9}$ Christ (1952, p. 25) stated that Chicago's economics department lacked a mathematical economist due to Oscar R. Lange's leave to Columbia University during 1942-44. Marschak simultaneously substituted Lange and assumed Cowles' directorship in early 1943.

${ }^{10}$ Herfeld (2018) showed different approaches Cowles had on rational choice under Marschak's and Koopmans' directorships. Her narrative suggests to explore Cowles' history is of central importance to this dissertation's goal. 
economists found for Marschak (1950) and Herstein and Milnor (1953) in their research agendas.

\subsection{AN INFORMATION CAMPAIGN}

Cowles members had several opportunities to acquaint themselves with the Theory of Games. ${ }^{11}$ On May 25-26, 1945, von Neumann presented his (and Morgenstern's) book at the Commission (Cowles Commission for Research in Economics, 1946, p. 17). Two-day seminars were extraordinary events: research reports covering 1943-52 show no recurrence of such a case. Besides directly discussing it alongside von Neumann, Cowles' members also arranged seminars where they presented and analyzed the Theory of Games' content. Later in 1949, from January to April, seven consecutive seminars exposed topics on game theory, figuring Savage, Arrow, Marschak, Girshick, and Simon as speakers. Although these debates focused on game theory, utility and uncertainty also became subjects of interest at Cowles after von Neumann's visit. The report for 1950-1951 entitled "Rational Decision-Making and Economic Behavior" recorded seminars on those years fitted two broad categories: "Utility and Probability" and "Economics of Welfare" (Cowles Commission for Research in Economics, 1951, pp. 24-26). Tables 2 and 3 list these. In particular, that research report characterized seminars headed by Savage, Marschak, Arrow, Chernoff, van Dantzig, and Thurstone as belonging to the first category (Cowles Commission for Research in Economics, 1951, pp. 24-25).

Besides exposure in seminars, von Neumann and Morgenstern's book circulated at Cowles via Hurwicz's and Marschak's book reviews. They underwent reprint via "Cowles Commission Papers, New Series". Until then, no book review had made its way into the New Series before (reprints always brought staff members' original research articles, often published in Econometrica). Cowles research reports maintained that those reviews had a role of supporting econometric research (Cowles Commission for Research in Economics, 1946, p. 12). It is necessary to appreciate how Cowles comprehended what econometrics was and what problems it faced in order to understand the Commission's assertion. The five-year report for 1942-1946 claimed that: "the statistical testing of economic theories, the measurement of economic relations, and the explanation of business fluctuations observed in

\footnotetext{
${ }^{11}$ There are several histories of Cowles Commission available for historians of economics. Most of them organize its history in terms of research programs, as if its members directed their research sticking to institutional goals (for example, see Christ (1952), Hildreth ([1986] 2012), Debreu (1983), Malinvaud (1983), and Arrow (1983)). This approach has its strengths as Cowles' directors could handpick who would join the Commission. However, its members rarely stayed for too long (see Hildreth ([1986] 2012, pp. 132-135) for a list of Cowles' staff and their time of residence during 1939-1955; most of them visited the Commission for two years). Consequently, it would be hard for any director to coordinate such a volatile team. Alternatively, it is reasonable to analyze the Commission's history as emerging from a small group of highly connected members. They shared research papers frequently and hence were always in contact with their peers' ongoing works. Consequently, it was not uncommon for their research to overlap. This chapter attempts one such narrative.
} 
Table 2 - Cowles Commission Seminars, January 1, 1949-June 30, 1949

\begin{tabular}{|c|c|c|}
\hline Date & Speaker & Title \\
\hline Jan 06 & $\begin{array}{l}\text { L. J. Savage (University of } \\
\text { Chicago, Mathematics) }\end{array}$ & "The Theory of Games: Zero-Sum Games" \\
\hline Jan 20 & K. J. Arrow & "The Theory of Games: Multi-Person Games" \\
\hline Feb 17 & K. J. Arrow & $\begin{array}{l}\text { "The Theory of Games: Applications to Eco- } \\
\text { nomics" }\end{array}$ \\
\hline Mar 03 & J. Marschak & "The Theory of Games: Measurable Utility" \\
\hline Mar 10 & $\begin{array}{l}\text { M. A. Girshick (Stanford } \\
\text { University, Statistics) }\end{array}$ & "The Theory of Games: Continuous Games" \\
\hline Mar 31 & L. J. Savage & $\begin{array}{l}\text { "The Theory of Games: Application to Sta- } \\
\text { tistical Inference" }\end{array}$ \\
\hline Apr 14 & H. A. Simon & $\begin{array}{l}\text { "The Theory of Games: Application to Poli- } \\
\text { tics and Administration" }\end{array}$ \\
\hline Apr 12 & H. Rubin & $\begin{array}{l}\text { "Statistical Treatment of Nonlinear Econo- } \\
\text { metric Models" }\end{array}$ \\
\hline May 26 & T. C. Koopmans & $\begin{array}{l}\text { "Utility Analysis of Decisions Involving Fu- } \\
\text { ture Periods" }\end{array}$ \\
\hline
\end{tabular}

Source: Cowles Commission for Research in Economics (1949, p. 27)

the past have an obvious scientific value in themselves" (Cowles Commission for Research in Economics, 1946, p. 2). Its first heading broke down in subsections entitled "Econometric Research", "Adapting Statistical Tools", "Constructing Economic Models", "Revising Economic Fundamentals", and "Problems for Further Study". These sections' headings illustrate Cowles' institutional goals in research - in a nutshell, the Commission understood "all useful knowledge implies prediction" and worked on subjects as to refine economists' prediction tools (where "to predict is, in general, to estimate, for given conditions and for a given probability level, a probable range of the results of a given policy") (Cowles Commission for Research in Economics, 1946, p. 3).

In "Revising Economic Fundamentals", the report claimed that rational behavior could serve as a first approximation to establish testable economic relations for individual behavior. However, if an econometrician resorted to rational choice theory, he would only find disappointment: "When trying to make use of theory for econometric purposes, one soon discovers, however, that much clarification is required to give the hypotheses a form amenable to statistical test" (Cowles Commission for Research in Economics, 1946, p. 12). Therefore "Revising Economic Fundamentals" was seen as a necessary step to enhance prediction tools by providing it propositions to test. The research report's explanation ended with a list of articles developed at Cowles that tackled individual behavior, including the Theory of Games' book reviews written by Marschak and Hurwicz. ${ }^{12}$ Consequently,

\footnotetext{
${ }^{12}$ The research report also mentioned as contributions to choice under uncertainty Hurwicz (1946) and Klein $(1946 \mathrm{a}, 1946 \mathrm{~b})$. The New Series reprinted these articles.
} 
Table 3 - Cowles Commission Seminars, July 1, 1950-February 15, 1951

\begin{tabular}{|c|c|c|}
\hline Date & Speaker & Title \\
\hline & & (1950) \\
\hline Oct 12 & $\begin{array}{l}\text { J. F. Nash (Princeton Uni- } \\
\text { versity) }\end{array}$ & "The Extended Bargaining Problem" \\
\hline Oct 26 & $\begin{array}{l}\text { R. Carnap (University of } \\
\text { Chicago, Philosophy) }\end{array}$ & $\begin{array}{l}\text { "A New Theory of Probability: Degree of } \\
\text { Confirmation and Inductive Inference" }\end{array}$ \\
\hline Nov 09 & $\begin{array}{l}\text { L. J. Savage (University of } \\
\text { Chicago, Statistics) }\end{array}$ & $\begin{array}{l}\text { "De Finetti's Theory of Subjective Probabil- } \\
\text { ity with Reference to the Statistical Decision } \\
\text { Problem" }\end{array}$ \\
\hline Nov 16 & $\begin{array}{l}\text { L. A. Metzler (University of } \\
\text { Chicago) }\end{array}$ & "The Pigou Effect and the Rate of Interest" \\
\hline Nov 30 & J. Marschak & $\begin{array}{l}\text { "Recent Discussions on Utility and Probabil- } \\
\text { ity, and the late Frank Ramsey" }\end{array}$ \\
\hline \multirow[t]{2}{*}{ Dec 21} & K. J. Arrow & $\begin{array}{l}\text { "Alternative Approaches to the Theory of } \\
\text { Choice in Risk-Taking Situations" }\end{array}$ \\
\hline & & $(1951)$ \\
\hline Jan 11 & H. T. Davis & $\begin{array}{l}\text { "Some Implications of the Curve of Income } \\
\text { Distribution" }\end{array}$ \\
\hline Jan 25 & $\begin{array}{l}\text { H. Chernoff (University of } \\
\text { Illinois) }\end{array}$ & "Rational Selection of Decision Functions" \\
\hline Feb 01 & $\begin{array}{l}\text { D. van Dantzig (University } \\
\text { of Amsterdan) }\end{array}$ & $\begin{array}{l}\text { "On the Linking up of Probability Theory to } \\
\text { Empirical Sciences" }\end{array}$ \\
\hline Feb 15 & $\begin{array}{l}\text { L. L. Thurstone (University } \\
\text { of Chicago, Psychology) }\end{array}$ & $\begin{array}{l}\text { "Consumer Preferences and the Prediction of } \\
\text { Choices" }\end{array}$ \\
\hline
\end{tabular}

Source: Cowles Commission for Research in Economics (1951, p. 25)

these had a double role at the Commission. First, they granted readers a comprehensive survey of von Neumann and Morgenstern's text. In recollection, Cowles' member during 1949-53, Hildreth ([1986] 2012, p. 98) recognized "many economists became aware of game theory through the early review articles by Hurwicz (1945) and Marschak (1946). They explained the abstract concepts and supplemented the examples". Second, they acted as advances in individual-decision making theory in themselves, even if they had no original contribution (besides their different ways to convey ideas, as using Viviani's Theorem; see Section 1.3).

Cowles' production on choice under uncertainty did not stop at Marschak's and Hurwicz' book reviews. Hildreth ([1986] 2012, pp. 101-102) documented the Theory of Games' approach to utility won "substantial attention" between 1944 and 1954 at the Commission, as shown by its research output. For instance, Hildreth ([1986] 2012, pp. 101-102) mentioned that Marschak (1950) worked in developing "axioms in terms more familiar to economists and which employed familiar indifference surfaces" and that Herstein 
and Milnor (1953) coauthored "a very elegant and concise derivation of expected utility representation" in 1953 (see quote below; in particular, observe it depicts Herstein and Milnor's research as an outgrowth of Marschak's). These articles participated in disseminating the Theory of Games. Arrow (1983, p. 11) argued that von Neumann and Morgenstern (alongside Savage ([1954] 1972)) "restored the confidence of economists in expected utility theory by showing that the theory could be reinterpreted in ordinalist terms, as reflecting only observed behavior satisfying certain additional rationality postulates appropriate to choice under uncertainty", but their work's dissemination passed through Marschak (1950) and Herstein and Milnor (1953), who "convinced doubters".

Cardinal utility - a procedure of expressing the preference for $B$ over $A$ as
a multiple of that for $C$ over $A$ - can be constructed by observing choice
in circumstances where the state of life achieved is the joint outcome of
an act of choice and a chance event, unknown at the time of choice. For
instance, an individual may be asked to choose between a glass of milk
and a fifty-fifty chance for a cup of tea as against a cup of coffee. Axioms
about individual choice that permit the construction of a cardinal utility
on this basis were first developed by John von Neumann and Oskar
Morgenstern. Stimulated by a reformulation of this axiom system by
Jacob Marschak, described in an earlier report (1949-1950), I. N. Herstein
and John Milnor (the latter of Princeton University) developed a further
simplified system of behavior axioms that leads to cardinal utility by a
more direct route of deductions. (Cowles Commission for Research in
Economics, 1952, p. 69)

To conclude, Cowles' members were highly interested in the Theory of Games. Their sympathy manifested itself in an invitation to von Neumann to present his book, a series of seminars discussing different aspects of game theory, and the reprinting and distribution of Marschak's and Hurwicz's book reviews. These facts explain how the Commission's members became acquainted with von Neumann and Morgenstern ([1944] 2007). As a consequence of having familiarity with the Theory of Games, it was only natural for some of them to research expected utility theory, one of its subjects. As mentioned above, two such instances were Marschak (1950) and Herstein and Milnor (1953). Section 2.2 will discuss Marschak's and Herstein and Milnor's articles on choice under uncertainty in detail. In turn, Section 2.3 will analyze their dissemination among a general audience of economists.

\subsection{CRAFTING TWO PATHS TO EXISTENCE AND UNIQUE- NESS}

Marschak (1950) and Herstein and Milnor (1953) produced articles for Econometrica based on von Neumann and Morgenstern's axiomatization of expected utility theory. Their focus was to reshape the Theory of Games' system, facilitating its proofs but preserving 
properties it had established on the grounds of existence and uniqueness. This section will present those adaptations and differentiate them from von Neumann and Morgenstern ([1944] 2007), paying special attention in how Marschak (1950) and Herstein and Milnor (1953) approached axiomatics (that is, on how they structured their texts and conveyed their arguments). This is a necessary step in order to assess their dissemination among economists (see Section 2.3 for that analysis), as to understand a reaction it is essential to know what is being reacted to. Subsection 2.2.1 employs Cowles Commission Discussion Papers to show how Marschak and Herstein interacted while pursuing their research agendas. Subsection 2.2.2 investigates the dissemination of their Econometrica articles.

\subsubsection{THE COWLES DISCUSSIONS PAPERS}

Marschak (1948b) circulated among his Cowles fellows a working paper entitled "Measurable Utility and the Theory of Assets" where he discussed how economists examined choice under uncertainty and utility functions until then. ${ }^{13}$ His "Acknowledgments" section praised the Theory of Games as his primary source of inspiration (especially, Marschak (1948b, p. 1) stated that part of his research was a mere paraphrase of von Neumann and Morgenstern's words). He intended to present economists with a "certain plausible axiom on rational human behavior" that would render utility functions unique up to positive affine transformations only. In particular, his "certain plausible axiom" would act as a bridge between a previous "theory of assets" (that settled preference representability should be an ordinal property) and his standpoint in favor of measurable utility functions. ${ }^{14}$ For him, measurability was not to be understood "in the same sense in which students' intelligence is measurable". Instead, his utility would mimic temperature measuring: it referred to an exact quantity admitting different but consistent measurements (due to an infinite number units of measurement). In opposition, measures of intelligence not necessarily agree between themselves. As Section 2.1 explained, theoretical work could support Cowles' ultimate goal inscribed in its motto "Science is Measurement". Marschak's aim was more modest than producing relevant, testable propositions for econometricians. Instead, his purpose was to argue in favor of expected utility theory because it simplified theoretical economics.

Two parallel, similar axiomatic systems structured Marschak's argument. This organization strengthened his view by showing how easily economists could jump from ordinal to nor-ordinal (measurable) utility functions. His first task was to rebuilt how economists usually modeled choice over risky assets. In a section entitled "Axiom A and the Old Theory of Assets", Marschak (1948b, pp. 5-6) proposed five axioms for "a set of

\footnotetext{
${ }^{13}$ Marschak also distributed an abbreviated and revised version of his work in progress. It had no qualitative differences from Marschak (1948b), except it included a copy of von Neumann and Morgenstern's axioms for reference (see Marschak (1948a)).

${ }^{14}$ Marschak understood utility measurability as tantamount to non-ordinal preference representability.
} 
sets" and a relation called "preferred to". ${ }^{15}$ That system was supposed to mimic "The Old Theory of Assets". Instead of working over a set of commodities or lotteries (as current economists usually do), Marschak's sets comprised indifferent choices among themselves. They held a direct analogy with indifference surfaces, familiar to economists. His axioms imposed that each element of any of his sets was a prospect, and any prospect should belong to only one subset. Further, he supposed "preferred to" to be a complete and transitive relation. His fifth axiom was a continuity assumption (although Marschak did not use "continuity" to label it). ${ }^{16,17}$

In presenting "The Old Theory of Assets", Marschak (1948b) resembled the Theory of Games for two reasons. First, he undressed his axiomatic system of any economic significance and worked over abstract categories (for instance, by speaking of a general "set of sets" instead of a space filled by indifference surface). At a second moment, he connected his definitions and economic concepts. While von Neumann and Morgenstern ([1944] 2007, pp. 26-27) also kept axioms and intuition apart, that trait was particular to how Marschak understood economists should practice axiomatics: in his book review, Marschak (1946, p. 115) had explained so. Second, after presenting their premises on choice under uncertainty, von Neumann and Morgenstern ([1944] 2007, p. 28-29) discussed how economists doubted non-ordinal preference representations and showed how little they had to suppose to achieve it: they only needed to add one hypothesis to economists' usual approach. Assuming individuals could extend preferences between any two options to a mix of these sufficed to change indifference curve analysis completely. ${ }^{18}$ Marschak (1948b, p. 8) reworded that point: after stating the traditional utility maximization problem, he argued he needed only to append an "Axiom B" to his "Axiom A" in order to achieve utility measurability. "Axiom B" ruled that mixing an element of some of his sets with any given prospect would always result in an element in a fixed set. ${ }^{19}$ However, unlike von Neumann and Morgenstern, he defended his last axiom in terms of how reasonable it would be to expect people to behave in accordance to it, arguing it would "hardly be

\footnotetext{
${ }^{15}$ It seems Marschak (1948b) started using "prospect" as a word for probability vectors. Henceforward, this dissertation will use that term as interchangeable with "lottery" in the modern sense.

${ }^{16}$ Let $\mathfrak{p}$ denote Marschak's relation meaning "strictly preferred than" over a set of indifference sets. Similarly, write $\mathfrak{i}$ for his relation meaning "indifferent to". Given any $j \in \mathbb{N}$, denote by $L_{j} \in \mathscr{L}$ a lottery and define $I_{j}=\left\{L \in \mathscr{L}: L i L_{j}\right\}$. Marschak's continuity axiom stated that $I_{1} \mathfrak{p} I_{2} \mathfrak{p} I_{3} \Rightarrow \exists \alpha, \beta \in(0,1), \alpha+\beta=$ $1, \exists L_{1} \in I_{1}, \exists L_{3} \in I_{3}$ such that $\left[\alpha L_{1}+\beta L_{3}\right] \in I_{2}$.

${ }^{17}$ In a footnote, Marschak (1948b, p. 5) thanked Herman Rubin for pointing out the necessity of his continuity axiom. Rubin was a mathematician who also distributed a working paper at Cowles inspired by the Theory of Games (see Rubin (1949)) on choice under uncertainty. However, his contribution never got published, so it did not serve the Theory of Games as a secondary source that would disseminate its content. Therefore, this dissertation will neglect Rubin's contribution.

${ }^{18}$ See von Neumann and Morgenstern ([1944] 2007, p. 26), especially axioms (3:B) and (3:C). They identified axiom (3:A) as a core component of the indifference curves technique. To proceed to a non-ordinal preference representation, they needed to add $(3: B)$ and $(3: C)$. These axioms governed the mixing of lotteries.

${ }^{19}$ Marschak's "Axiom B" stated given $L_{1}, L_{1}^{\prime} \in I_{1}, \forall L_{2} \exists \alpha \in(0,1), \exists I_{3}$ such that $\left[\alpha L_{1}+(1-\alpha) L_{2}\right] \in I_{3}$ and $\left[\alpha L_{1}^{\prime}+(1-\alpha) L_{2}\right] \in I_{3}$.
} 
refuted" in real choice situations. Considering two equally desirable lottery tickets offering a car and a house as a prize respectively, Marschak argued:

[...] imagine three more lotteries: one with a cow as the prize; one offering the odds $a:(1-a)$ for a ticket in the car lottery and against a ticket in the cow lottery; and one with the odds $a:(1-a)$ for a house-lottery ticket and against a cow-lottery ticket. Clearly there is no reason to prefer either one of these two "mixed" lotteries. (MARSCHAK, 1948b, p. 8)

If Marschak (1948b) closely resembled the Theory of Games on how he presented his axioms, he had a distinct way to convey proofs and defend his results logically. Two significant conclusions for Marschak's second system (including "Axiom B") were that indifference surfaces were parallel hyperplanes and that expected utility functions were linear mappings on probabilities. ${ }^{20}$ While von Neumann and Morgenstern ([1944] 2007, pp. 618-628) produced rigorous demonstrations for existence and uniqueness properties of expected utility functions, Marschak (1948b, pp. 9-12) provided his readers with a visual proof, showing graphically how his premises resulted in his central properties. Still, he also developed a formal, algebraic argument. To legitimate his statements, only one form of demonstration would suffice. In particular, his algebraic proof would satisfy any mathematically-inclined economist. Therefore, his visual argument was redundant in terms of validating his axiomatic system. Nevertheless, it was far more accessible for literary economists because it demanded no mathematical knowledge (except some simple geometrical concepts, such as recognizing what colinear points are). Interestingly, Marschak connected both of his ways to prove: his algebraic demonstration frequently referenced steps in his visual argument as if to help his reader to follow his formal reasoning.

Besides a particular way to prove statements, Marschak (1948b) had another significant difference from von Neumann and Morgenstern's title: the Theory of Games had a premise that Marschak opted to internalize as an implication of his axiomatic system. As mentioned above, von Neumann and Morgenstern ([1944] 2007, pp. 17-18) comprehended economists needed only a "very little extra effort" to move past traditional indifference curves analysis to non-ordinal preference representations. A crucial element in their argument was that while economists usually postulated that individuals could rank different events, they only needed to allow agents to compare probabilistic combinations of events. Consequently, von Neumann and Morgenstern observed that assuming so implied individuals could compare utility differences. It meant given outcomes $A, B$, and $C$ (presented here in order of decreasing preference), an individual would be able to say how many times his preference of $B$ over $C$ was stronger or weaker than his predilection of

\footnotetext{
${ }^{20}$ Naturally, Marschak (1948b, pp. 13-14) also proved that utility functions would be unique up to positive affine transformations only, what he characterized as measurable. Interestingly, he used that theorem to show utility differences were "strictly measurable" because they were unique up to a multiplication by constant only, just "like distance".
} 
$A$ over B. Furthermore, von Neumann and Morgenstern ([1944] 2007, pp. 18) suggested a device to measure such comparisons: if $\alpha \in(0,1)$ was such that $B \mathfrak{i}[\alpha A+(1-\alpha) C]$ (where $\mathfrak{i}$ denotes a relation meaning "indifferent to"), then $\alpha$ would be an estimate of a individual's preference ratio of $B$ over $C$ against that of $A$ over $B$. That was a despised property among economists who felt convinced that utility functions should be unique up to any increasing monotone transformation. Their disdain followed from a widespread interpretation that comparing preference ratios related to an intrinsic measure of utility (as if utility had a meaningful unit measure, like distance or temperature). ${ }^{21}$

In Marschak's working paper, the result numbered 27 was equivalent to the Theory of Games' estimation of ratios of utility differences. Marschak (1948b, p. 15) stressed von Neumann and Morgenstern presented that conclusion verbally as a "behavior postulate", whereas in his approach it was a consequence of "Axiom A" and "Axiom B". He opted to shape his system to obtain it as a conclusion "by the desire to avoid behavior postulates which while not immediately plausible, yet do not show themselves in easily observable action". In a self-evaluation, he argued that "Axiom A" only stated how agents choose among prospects and "Axiom B" suggested they did it in a non "absurd" way. In contrast, Marschak thought neither intuition nor direct observation backed result 27 as an acceptable hypothesis. For him, axiomatic systems should not only imply a set of desirable results, but its premises should as well have a substantial connection with reality. This point is an image issue: while his and von Neumann and Morgenstern's premises are equivalent (as they produce the same set of body statements in economics), Marschak considered it would be preferable for a set of assumptions to stick to commonplace facts of behavior.

Approximately one year later, Marschak (1951a, p. 1) issued another Cowles Discussion Paper. ${ }^{22}$ His primary motivation was a dissemination issue as he perceived von Neumann and Morgenstern's proof of "13 pages not counting interpretative sections" on expected utility functions' existence and uniqueness provoked "serious misunderstandings" among economists. In particular, his draft simplified a previous publication of his by reshaping its axiomatic structure, transforming "some lemmas or theorems of [2] [his Econometrica article analyzed in Subsection 2.2.1] into axioms, and conversely" (MARSCHAK, 1951a, p. 1). ${ }^{23}$ By comparing his current and preceding works on choice under uncertainty, Marschak (1951a, p. 1) claimed: "The new axioms (especially II.I) seem

\footnotetext{
${ }^{21}$ It is important to emphasize that von Neumann and Morgenstern ([1944] 2007) did not defend that a concrete unit of measurement of utility existed. That interpretation of non-ordinal preference representations dates back to debates before works as Hicks ([1939] 1975) stabilized how economists interpreted these concepts.

${ }^{22}$ In-between publications (Marschak (1948b) and 1951a), Marschak wrote an article for Econometrica. Subsection 2.2.1 will analyze it. The current subsection focuses on internal discussions that happened at the Commission.

${ }^{23}$ Marschak (1951a) provided no explicit citation distinguishing which of his previous works was his basis of comparison. However, his comments (for instance, when he recalls a past axiom by calling its alphanumeric code) suggest he was discussing Marschak (1950) (that is, it was necessary to deduce which article he was discussing).
} 
to appeal to intuition at least as strongly as those previously, yet the proof is considerably simpler." 24 After "intuition", he added a footnote explaining his wording choices (see quote below). As when Marschak (1948b, p. 15) compared his axiomatic system with that of the Theory of Games, he thought axioms should adhere to real-life behavior. In opposition, conclusions could be unappealing: mathematics served as a connector, granting non-intuitive statements (as saying individuals maximize an expected utility function) legitimacy borrowed from appealing premises.

\begin{abstract}
By saying that a proposed set of axioms defining rational choice appeals to the intuition of a given person (e.g., the reader), we mean the following conjecture: if that person were challenged with making a choice, and given sufficient opportunity for deliberation, he would reject decisions inconsistent with the proposed axioms. This is quite analogous to the intuitive appeal of axioms of arithmetic.

It is a remarkable fact that a proposition may be implied in a set of intuitively appealing propositions and yet be not itself intuitively appealing: there would be otherwise no need for mathematical textbooks. This answers the question "What is to be gained by not directly requiring rationality to imply maximization of mathematical expectations of utility?" (This question was asked by William J. Baumol in a stimulating correspondence in the course of which the need for simplified axiomatics and proofs became clear to me). (MARSCHAK, 1951a, p. 1-2)
\end{abstract}

That working paper established a connection between Marschak and Herstein at Cowles by its new premises. Two axioms (labeled II.I and III) were new in Marschak (1951a) compared to Marschak (1950). ${ }^{25}$ By "Axiom II.I", Marschak (1951a, p. 3) proposed "if $A$ is preferred to $B$, then the 'mixture' of $A$ with $C$ is preferred to the 'mixture' (with the same odds) of $B$ with $C$ ". ${ }^{26}$ In III, he had assumed there existed two prospects such that one was strictly more desirable than the other. This assumption represented a weakening of his Econometrica assumption set: before, Marschak (1950) assumed there existed different indifference surfaces. A second simplification came by disposing of one premise from his axiomatic system: "Postulate II (continuity): this becomes a theorem (Th 6)." ${ }^{27}$ Five months later, Herstein (1951b) would challenge Marschak's demonstration in a Cowles Discussion Paper. Not only had Marschak made a mistake in his proof, but it was impossible for his system to imply preference continuity. Herstein (1951b, pp. 1-2) showed

\footnotetext{
${ }^{24}$ The next paragraph explores Marschak's Axiom II.I.

${ }^{25}$ Marschak (1951a, p. 8) acknowledged von Neumann and Morgenstern's operation of mixing lotteries was possibly hiding an axiom, as suggested by discussions with Edmond Malinvaud. This issue is the subject matter of the next chapter.

${ }^{26}$ Marschak's Axiom II.I resembles what economists nowadays call the independence axiom. What is missing in his statement is the converse direction: that is, if a mix of $A$ and $C$ is preferable than another of $B$ and $C$, then $A$ is more desirable than $B$.

${ }^{27}$ Marschak (1951a) dropped his practice of proofing statements visually. Still, he maintained a concern of facilitating his reader's study. For instance, after he stated that his "Theorem of Moral Expectations" showing the existence of expected utility functions, Marschak (1951a, pp. 5-6) developed a simplified demonstration that used one hypothesis absent in his original system (he supposed there existed a "best" and a "worst" lottery).
} 
that by a counterexample: lexicographic preferences satisfied every axiom in Marschak (1951a), but not continuity. ${ }^{28}$ Still, Herstein's engagement in axiomatic approaches to choice of uncertainty would not stop at a 3-page correction.

Cowles would see two more working papers authored by Herstein on choice under uncertainty. Eighteen days after scrutinizing Marschak's proof, Herstein (1951a) distributed a Cowles Discussion Paper providing an alternative axiomatization for expected utility (see quote below). In his system, it is especially interesting for Section 2.3 how Herstein (1951a, p. 2) formulated continuity preference: for any lottery $\bar{L} \in \mathscr{L}$, he assumed $\{L \in \mathscr{L}: L \mathfrak{g} \bar{L}\}$ and $\{L \in \mathscr{L}: \bar{L} \mathfrak{g} L\}$ were closed sets. ${ }^{29}$ For comparison, Marschak (1950, p. 117) formulated continuity by affirming $L_{1} \mathfrak{p} L_{2} \mathfrak{p} L_{3}$ implied there existed an $\alpha \in(0,1)$ such that $L_{2} \mathfrak{i}\left[\alpha L_{1}+(1-\alpha) L_{3}\right] .{ }^{30}$ Eight months later, Herstein circulated another working paper coauthored with John W. Milnor, then a mathematics graduate student at Princeton University. Herstein and Milnor (1952, pp. 1-2) claimed that von Neumann and Morgenstern pioneered in providing a "completely rigorous treatment" to measurable utility functions. ${ }^{31}$ They also commended Marschak's effort "to give a more acceptable (to some economists) set of axioms, and to have a simpler derivation mathematically". Besides, they cited themselves, arguing their previous individual research "gave quite different axiom sets for this problem and succeeded in simplifying and shortening the mathematical details considerably". Compared to these, their joint Cowles paper removed topological considerations of their axioms because "in doing so the treatment actually becomes simpler and more transparent".

The economist is interested in finding a real valued, order-preserving, linear function on $\mathscr{S}$ [a mixture set, see paragraph below]. This function is the so-called measurable utility. If there are no restrictions on $\mathscr{S}$ other than it be a completely-ordered mixture set, such a measurable utility need not exist. The problem, then, is to impose 'natural' restrictions on the interrelation of the ordering and the mixing which give rise to a measurable utility.

Our aim has been many-fold; to use a system of axioms which was simple and seemingly not too restrictive, which seemed to approximate economic reality, which was transparent, and which led to the existence of a measurable utility with a minimum of mathematical difficulty or sophistication. Each of the axioms we use is true for $\mathscr{S}$ whenever a measurable utility exists on $\mathscr{S}$; so the axioms are at least necessary conditions. In this

\footnotetext{
${ }^{28}$ Herstein (1951b, p. 1) admitted he was not the one who discovered Marschak's proof was faulty-it was Hildreth, although he did not mention in what occasion did Hildreth criticize Marschak's demonstration. Herstein wanted to push Hildreth's critique further, showing no proof (of a different method) could justify Marschak's theorem of continuity.

${ }^{29}$ Herstein (1951a, p. 2) did not use the term "continuity" to refer to his axiom when he presented it.

${ }^{30} \mathrm{As}$ before, $\mathscr{L}$ is a lottery space (of which $L$ is an arbitrary element), and $\mathfrak{g}$ and $\mathfrak{p}$ stand for binary relations meaning "at least as good as" and "strictly preferred than", respectively.

${ }^{31}$ Herstein and Milnor (1952, pp. 3-4) spoke of a "measurable utility" as related to linear utility function preserved, having its preference representation property represented by positive affine transformations. While it is not a definition of "measurable", their labeling probably follows of how closely economists saw measurability and non-ordinal preference representations.
} 
paper we prove that they are also sufficient to lead to the existence of the desired order-preserving, linear function. (HERSTEIN; MILNOR, 1952, pp. 3-4)

Differently from Marschak (1948b), Herstein and Milnor (1952) (and Herstein (1951a) as well) were highly technical contributions that provided no didactic concessions for its readers. This characteristic appears in why and how they picked hypothesis. To illustrate, for a generality motive they reshaped topological properties from past works, what would demand adjusting axioms. Before Herstein (1951a, p. 1) had worked over a set of "feasible prospects", a subset of $\mathbb{R}^{n}$, closed, bounded, and convex by assumption. Later, Herstein and Milnor (1952, p. 2) studied a more general space, called "mixture set". It was not necessarily a subset of $\mathbb{R}^{n}$; they only required it to be a convex set endowed with the usual operations of sum and multiplication by a scalar of vector spaces over $\mathbb{R}$. To illustrate, any convex subset of $\mathbb{R}^{n}$ is a mixture set. That reorientation demanded an adaptation on Herstein's previous axiom of continuity. Once alongside Milnor, they postulated for all $L_{1}, L_{2}, L_{3} \in \mathscr{L}$ the sets $\left\{\alpha \in[0,1]: \alpha L_{1}+(1-\alpha) L_{2} \mathfrak{g} L_{3}\right\}$ and $\left\{\alpha \in[0,1]: \alpha L_{1}+(1-\alpha) L_{2} \mathfrak{g}^{T} L_{3}\right\}$ were closed. ${ }^{32}$ These details are almost a foreign, unknown language for not so mathematically-skilled economists. In general, Herstein and Milnor (1952) presented an uninterrupted sequence of statements and proofs, requiring readers to have previous training in higher mathematics.

To conclude, Cowles Discussion Papers display how Marschak's and Herstein's research on choice under uncertainty overlapped. While Herstein (1951b) directly confronted Marschak (1951a), all the texts mentioned in this section had a common goal: to reshape the Theory of Games' axiomatization. Purposes on that task could be twofold: to make it either clearer or more general. Additionally, those working papers show Marschak and Herstein had particular ways to axiomatize: Marschak introduced several opportunities for non-mathematical readers to follow his reasoning (as providing visual illustrations of demonstrations), whereas Herstein (and Milnor) made no concessions. While subtle, that dissimilarity is important to understand how two axiomatic systems could have different receptions among economists. Since Marschak's was more open to literary economists, it would likely reach a broader audience. The next subsection discuss published versions of the working papers here presented.

\subsubsection{THE ECONOMETRICA PAPERS}

Marschak's and Herstein's (joined by Milnor) Cowles discussion papers culminated in two Econometrica articles of 1950 and 1953, respectively. Herstein and Milnor (1953) had no variations in comparison to Herstein and Milnor (1952). Their path to provide

\footnotetext{
${ }^{32}$ The symbol $\mathfrak{g}^{T}$ denotes the transpose of $\mathfrak{g}$. By definition, a relation $\mathfrak{r}$ in a set $S$ is a subset of $S \times S$. Given $x, y \in S$, usually one writes $x \mathfrak{r} y$ meaning $(x, y) \in \mathfrak{r}$. The transpose of $\mathfrak{r}$ is defined as $\mathfrak{r}^{T} \doteq\{(y, x) \in S \times S:(x, y) \in \mathfrak{r}\}$.
} 
an axiomatic system implying existence and uniqueness (up to affine transformations) of an expected utility function remained stable: they employed neither new nor refined axioms, definitions, lemmas, and theorems; even proofs persevered unmodified. In contrast, Marschak (1950) was at a different stage. Since Subsection 2.2.1 already discussed Herstein and Milnor (1952), this subsection will concentrate on Marschak's research. It is important to emphasize this subsection's aim is not to track changes between Marschak's drafts and published article. Instead, it attempts to understand how his way of axiomatizing was different from that of Herstein and Milnor's in his published work because that information is essential in understanding the dissemination of Marschak (1950) and Herstein and Milnor (1953).

There is a continuity between Marschak (1948b) and Marschak (1950) concerning what is rational behavior and what roles do mathematics play in supporting economic theory. Marschak (1950, p. 111) maintained rational choice theory comprised a set of propositions of idealized behavior rules. These had a normative flavor, suggesting how people should act. Hence theoretical statements had a role of guiding people (who could not be "all fools all the time" for him) in making correct decisions. For Marschak (1950, p. 112), hypotheses should support real decision-making via "rules of logic and arithmetic". Therefore mathematics acted as a prolongation tool: it stretched common behavior facts (a set of premises) to non-obvious statements capable of governing rational behavior (theorems setting rules for rationality). To establish an axiomatic system and deduce results from it (to inform people on how they should act in the face of uncertainty) do not depend on pedagogic devices, such as using graphic representations of concepts - stating premises and proving statements are sufficient on a formalist view. Nonetheless, Marschak (1950, pp. 114-115) thought about ease of exposition when building his arguments, as he did in his working papers at Cowles or even his book review for the Theory of Games.

For example, after Marschak (1950, p. 14) defined "domain" (a subset of $\mathbb{R}^{n}$ where coordinates determined probabilities referred to mutually exclusive "histories", or simply outcomes an individual could face), Marschak visually depicted its boundary and interior (see Figure 6). While corners represented sure prospects, points expressed different probabilities determined by distances to each side of the triangle. He used curvilinear lines to illustrate a restricted subset of the points representing "all prospects that the man thinks he can achieve by his actions" (labeled "feasible set"). That way Marschak showed visually how many possible lotteries existed and how only some of them were relevant for agents making choices. Interestingly, he reflected on a footnote an easier visual model grounded on Viviani's Theorem was conceivable (as he did in reviewing von Neumann and Morgenstern's title; see Figure 4 above): "A more symmetrical but less familiar presentation would measure $a_{0}, a_{1}, a_{2}$ [respectively, the lengths of $\overline{a m}, \overline{a n}$, and $\overline{a p}]$ as the distances of a point a from each of the sides of an equilateral triangle." 
Figure 6 - Marschak's "Domain" and "Feasible Set"

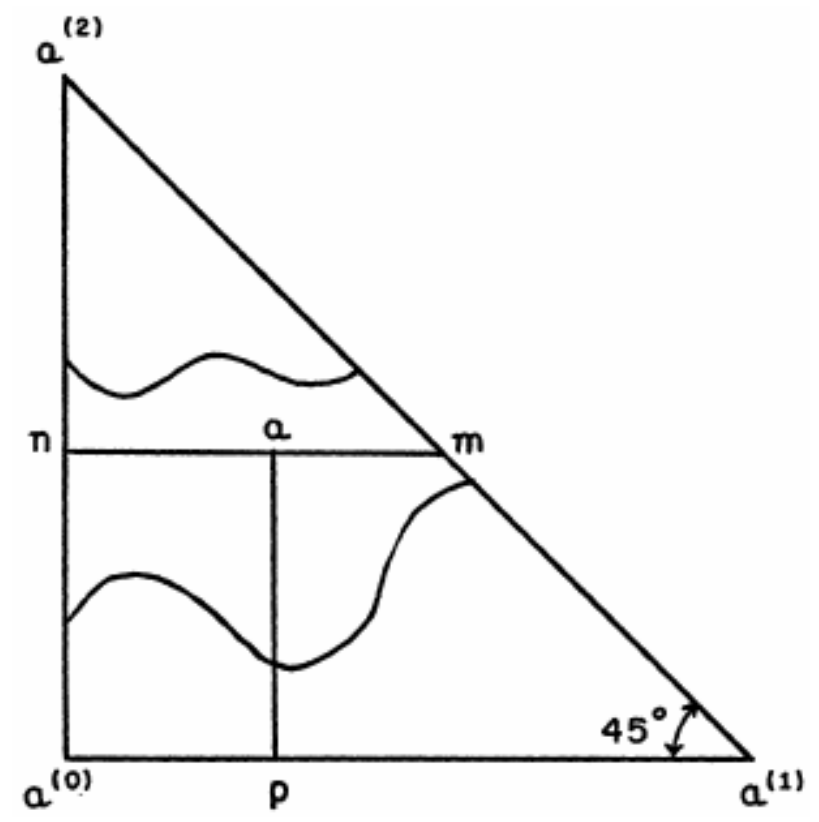

Source: Reproduction of Marschak (1950, p. 115).

Apart from supplying readers visual tools to appreciate his concepts, Marschak also made unusual choices concerning his axioms (from a standpoint valuing rigor), sacrificing generality over familiarness. It is interesting to sketch his assumptions in order to understand that point. By Postulate I, Marschak (1950, pp. 116-118) imposed a relation $\mathfrak{g}$ completely ordered his prospect space (meaning $\mathfrak{g}$ had properties of completeness and transitivity in a lottery space). Postulate II assumed continuity (as presented in Subsection 2.2.1, it instituted $\forall L_{1}, L_{2}, L_{3} \in \mathscr{L}$ such that $L_{1} \mathfrak{g} L_{2} \mathfrak{g} L_{3}, \exists \alpha \in(0,1)$ so $\left.L_{2} \mathfrak{i}\left[\alpha L_{1}+(1-\alpha) L_{3}\right]\right)$. In turn, Postulate III established that in any neighborhood of any prospect there existed another prospect which was not equivalent to it. Hence $\forall L_{1} \in$ $\mathscr{L}, \forall \alpha \in(0,1), \exists L_{2} \in \mathscr{L}$ such that $\neg\left\{L_{1} \mathfrak{i}\left[\alpha L_{1}+(1-\alpha) L_{2}\right]\right\}$. Together, Postulates I, II, and III separated Marschak's prospect space (here denoted by $\mathscr{L}$ ): every indifference surface delimited two disconnected regions of his "domain", each comprising better and worst alternatives only. Marschak (1950, p. 118) argued that "Postulate III and its implication that indifference sets are, in general, surfaces forms an interesting link with tradition", leading his reader to think of traditional indifference curves analysis. That is, in a two-dimensional case, Marschak's separation of $\mathscr{L}$ constituted of considering the areas above and below any indifference curve. However, Postulate III was stronger than needed as Marschak (1950, p. 118) showed two alternatives for it he judged to be less restrictive. First, it was sufficient to assume the existence of two prospects which were not indifferent among themselves. This assumption was a suggestion Marschak received from Wald. Second, Rubin also argued he could only presume the existence of four different 
Figure 7 - Marschak's "Postulate $\mathrm{IV}_{1}$ " and "Postulate $\mathrm{IV}_{2}$ "

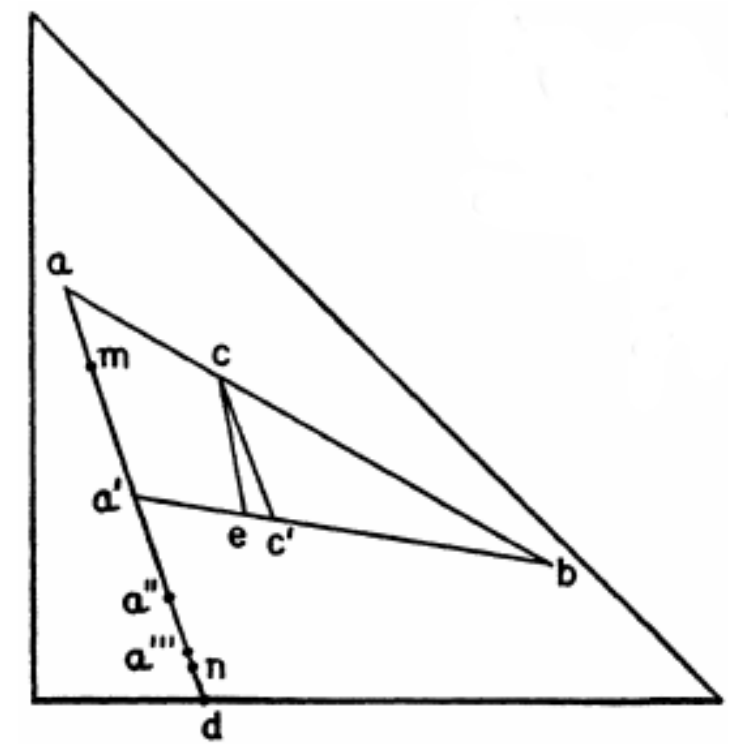

Source: Reproduction of Marschak (1950, p. 121).

indifference sets (MARSCHAK, 1950, p. 118).

There is no indication of why Marschak sticked to his Postulate III instead of a weaker alternative; the only advantage he explicitly mentioned of it was its link to indifference curve analysis, or "tradition". Still, there is another instance where he showed concern about delivering a clear, accessible text: his approach to Postulate IV. ${ }^{33}$ Before Marschak (1950, p. 120) enounced his fourth axiom, he presented two ancillary versions named Postulates $\mathrm{IV}_{1}$ and $\mathrm{IV}_{2}$. First, Postulate $\mathrm{IV}_{1}$ affirmed $\forall L_{1}, L_{2} \in \mathscr{L}$ such that $L_{1} \mathrm{i} L_{2}$, then $\forall \alpha \in(0,1) L_{1} \mathfrak{i}\left[\alpha L_{1}+(1-\alpha) L_{2}\right]$. Second, Postulate $\operatorname{IV}_{2}$ maintained given $\alpha \in(0,1)$ and $L_{1}, L_{2}, L_{3} \in \mathscr{L}$ (supposed different), then $L_{1} \mathfrak{i} L_{2} \Rightarrow\left[\alpha L_{1}+(1-\alpha) L_{3}\right] \mathfrak{i}\left[\alpha L_{2}+(1-\alpha) L_{3}\right]$. While Marschak presented $\mathrm{IV}_{1}$ and $\mathrm{IV}_{2}$ mathematically, he also afforded a geometrical representation (see Figure 7), as well as a intuitive, verbal description. These two auxiliary assumptions summarized Postulate IV, as Marschak (1950, p. 121) stated. By breaking it in particular cases, he facilitated his reader's study:

In words: If prospect a is equivalent to another prospect, $a^{\prime}$, then the prospect of obtaining either $a$ or $a^{\prime}$ with certainty is equivalent to each of them. To illustrate this postulate, we can first interpret $a, a^{\prime}$ as sure prospects (Section 4 above), that is, as two mutually exclusive future sequences of events or, still simpler, as two mutually exclusive bundles of commodities. Suppose a man is indifferent as between a car and a $\$ 1,000$

${ }^{33}$ Marschak (1950, p. 121) stated as his Postulate IV that:

$$
\forall L_{1}, L_{2}, L_{3} \in \mathscr{L}, \forall \alpha \in(0,1), \quad L_{1} \mathfrak{i} L_{2} \Rightarrow\left[\alpha L_{1}+(1-\alpha) L_{3}\right] \mathfrak{i}\left[\alpha L_{2}+(1-\alpha) L_{3}\right]
$$

Again, Postulate IV resembles what economists nowadays call the independence axiom, but it lacks the converse direction. 
bill. Then he should be also indifferent as between a car, a $\$ 1,000$ bill, and the ticket to a lottery in which the chances of winning a car or a $\$ 1,000$ bill are, respectively, .2 and .8, say. The same applies if, for a car and $\$ 1,000$, we substitute securities, or patents, or lottery tickets, etc., promising, respectively (if combined with the man's other assets), prospects such as those defined in Part I.

$[\ldots]$

In words: If two prospects $a$ and $a^{\prime}$ are equivalent, then the prospect of having $a$ or $b$ with probabilities $r, 1-r$, and the prospect of having $a^{\prime}$ or $b$ with the same respective probabilities $r, 1-r$, are equivalent. For example, suppose a $\$ 1,000$ bill and a car are equivalent. Compare two lottery tickets, one promising a $\$ 1,000$ bill or a house with probabilities .9 and .1 , the other promising a car or a house, also with probabilities .9 and .1. Then there is no reason to prefer one of the two lottery tickets to the other. (MARSCHAK, 1950, pp. 120-121)

Postulate IV condensed premises $\mathrm{IV}_{1}$ and $\mathrm{IV}_{2}$. These ancillary premises played two functions in Marschak's article. First, they facilitated his explanation: instead of addressing Postulate IV directly, he opted to display and describe two of its implications literally. Second, they also operated as a convincing device. Once readers understood two consequences of his true axiom in a simplified discussion, they could feel more compelled to accept it as a behavior postulate. This point is particularly strong since Marschak (1950) did not describe in intuitive terms his Postulate IV: its admission depended exclusively on explanations of $\mathrm{IV}_{1}$ and $\mathrm{IV}_{2}$ or on IV's obviousness (what is not very likely since Marschak had to break it down in two assumptions). Additionally, if Marschak (1950, p. 121) failed to reach his reader via verbal arguments, he would also have an extra shot by another visual representation (see Figure 7). In his notation, he supposed $a \mathfrak{i} a^{\prime}$ and that $\overline{a a^{\prime}}$ and $\overline{c c^{\prime}}$ were parallel line segments. Postulate $\mathrm{IV}_{1}$ would imply $m \mathfrak{i} a$ because it is in a line segment connecting $a$ and a prospect indifferent to it. Postulate $\mathrm{IV}_{2}$ resulted $c i c^{\prime}$ because they are averages of $b$ with two indifferent choices ( $a$ and $a^{\prime}$, respectively). By pushing his discussion to a graph, Marschak invited economists to reason in terms akin to the traditional approach of indifference surfaces.

Marschak (1950, pp. 122-126) exposed his axioms implied three significant conclusions. These also show how his way of axiomatizing had its particularities, giving significant weight to readability. First, "Theorem 1" asserted indifference sets were parallel hyperplanes. Second, "Theorem 2" posed that given any prospects on a straight line, two cases could arise: every prospect on that line was equivalent to the others, or it was strictly preferred to one of its adjacents. These two theorems had rigorous proofs, but Marschak presented them in lower type. That form of presentation de-emphasized his demonstrations' importance as mathematical arguments. In a proof-structured exposition, demonstrations would normally have primacy. Moreover, before writing his demonstration, Marschak first explored a simple case considering only three prospects existed. Again, sketching a proof of an easier problem is a concession for his reader. Third, "Theorem 3" stated that 
distances of a prospect's indifference set to a fixed (and arbitrary) origin established a set of utility indices. His presentation of it was unusual. Instead of enunciating his statement and proving it mathematically, Marschak first discussed how economists could estimate numerical values for a utility function given an indifference map (using graphical examples again) and only afterward presented "Theorem 3", as if it served to summarize his previous discussion. Hence demonstration and discussion became meshed, indistinguishable. These characteristics contrast those of Herstein and Milnor (1953), who approached proofs more technically, using fewer (almost none, actually) words and no figures.

Nonetheless, Marschak (1950) dedicated a section of his article to compare his axiomatic system and that of von Neumann and Morgenstern. Marschak (1950, p. 137) explicitly characterized his way of developing arguments was "different". He did not specify in what ways his approach differed from the Theory of Games. Still, he asserted that his contribution was not supposed to add to von Neumann and Morgenstern's "minutiousness and rigor". His point was to apply the popular indifference curves technique - fairly more familiar to economists than set theory and other tools von Neumann used-for choice under uncertainty. Moreover, both works yielded equivalent results for expected utility theory. Hence (besides some notation discrepancies), Marschak (1950, p. 135) concluded: "The difference between the presentation in this paper and in the Theory of Games thus boils down to the difference between our Postulates I-IV, and the group of axioms (3:A), (3:B), (3:C), of the Theory of Games." Assessing two different, equivalent axiomatic systems touches on second-order issues, as judging what axioms are more appealing (see quote below). Here, Marschak emphasized Postulates $\mathrm{IV}_{1}$ and $\mathrm{IV}_{2}$ role of convincing devices.

I hesitate to say which (if any) is the stronger system of axioms. I find it easier to translate Postulate IV immediately into the language of observable decisions - see the examples in Section 19 above [where Marschak presented his Postulates $\mathrm{IV}_{1}, \mathrm{IV}_{2}$, and IV, and where he provided graphic illustrations of them] - than to do so with von Neumann and Morgenstern's (3:C:b), whether stated as it is in terms of entities not susceptible to ordinary arithmetical operations, or restated in the form I have just suggested. To use a phrase of von Neumann and Morgenstern, the approach used here seems to be more "transparent", and its postulates have a more "immediate intuitive meaning by which [their] appropriateness may be judged directly". (MARSCHAK, 1950, pp. 136-137)

To conclude, while Marschak (1950) and Herstein and Milnor (1953) developed their articles at Cowles and focused on formulating an axiomatic system to support expected utility theory. However, they conveyed their arguments differently. Notwithstanding Herstein and Milnor (1953, p. 293) claiming that they endeavored to construct "a system of axioms that was simple and seemingly not too restrictive, that seemed to approximate 'economic reality,' that was transparent, and that led to the existence of a measurable utility with a minimum of mathematical difficulty or sophistication", their article yet chained theorems and proofs continuously. They supplied no comments elucidating what their 
assumptions meant economically, or made concessions so readers could understand their demonstrations more easily. These characteristics appeared before in Herstein and Milnor (1952). Marschak (1950) structured his contribution differently, yet he achieved equivalent results. He prepared several examples and graphics to illustrate his assumptions and results, securing readers several opportunities to understand his reasoning. A non-mathematically proficient economist would likely not be able to appreciate Herstein and Milnor (1953), while he could use his knowledge on traditional economics (based on indifference curves) to grasp Marschak's points. The next subsection analyzes how economists reacted to these similar in body yet discrepant in image Econometrica papers.

\subsection{HOW ECONOMISTS REACTED TO MARSCHAK AND HER- STEIN}

Marschak (1950) and Herstein and Milnor (1953) had different ways to convey arguments, what could affect how economists would react to them. This section analyzes how authors who cited these Econometrica articles applied them. In particular, it examines how economists assembled previous knowledge (that is, how they interpreted that Marschak (1950) and Herstein and Milnor (1953) fitted in economics) and how they proposed original contributions to our field by extending or modifying those texts. Subsections 2.3 .1 and 2.3.2 tackle these two types of citation, respectively. This section (and also subsections 3.1 .2 and 3.2.2) have a very particular place in the literature. On one side, research on dissemination can follow similar lines to Moscati (2016) and compose detailed narratives on how particular individuals interpreted and accepted (or rejected) expected utility theory and von Neumann and Morgenstern's axiomatics (in particular, Moscati (2016) studied Samuelson's case). Such choice provides greater insights on that individual's values (or image of knowledge). Alternatively, narratives as Doehne and Herfeld (2018) (who applied co-citation analysis to the Theory of Games) produce large networks, establishing connections among several participants in the history of axiomatic expected utility theory. This dissertation also reads dissemination as a network, as Doehne and Herfeld (2018), but it does not focus on tracking all the existent citations. Instead, it focus on some references to detail a limited area of such network (that is, working in line with Moscati (2016)).

This dissertation used Clarivate Analytics' Web of Science and Google Scholar to track citations to Marschak (1950) and Herstein and Milnor (1953). ${ }^{34}$ In general, Google Scholar is a broader dataset that has the citations contained in the Web of Science as a subset, and it includes citations from different sources. ${ }^{35}$ This section examined cita-

\footnotetext{
${ }^{34}$ Google Scholar tracked no citations to Marschak (1948b) and Herstein and Milnor (1952) (the working papers). Consequently, this section will only discuss how economists used Marschak (1950) and Herstein and Milnor (1953).

${ }^{35}$ However, Google Scholar contains mistaken citations. For instance, it suggested that von Neumann
} 
tions from each of these datasets, including journals and books of disciplines other than economics (such as applied mathematics and psychology). The period considered in this bibliographic search was from the year of publication of each article until 1954, when Savage published his The Foundations of Statistics. Such book would strengthen von Neumann and Morgenstern's approach to choice under uncertainty by a generalization (since Savage's axiomatization of expected utility allowed for subjective probabilities). Therefore considering articles published after Savage's book would cloud the analysis of the Theory of Games' dissemination. That is, The Foundations of Statistics would again impact in how economists perceived expected utility functions, non-ordinal preference representations, and axiomatics; as this dissertation focus on von Neumann and Morgenstern ([1944] 2007), citations after Savage ([1954] 1972) can capture features beyond the Theory of Games' dispersal. ${ }^{36}$

\subsubsection{ORGANIZING PREVIOUS RESULTS}

Economists have several practices of organizing previous knowledge. They classify contributions by estimating how significant they are for economics (or any of its subfields) and establishing connections between them and past research. Several articles that cited Marschak (1950) and Herstein and Milnor (1953) engaged in practices of organizing previous knowledge. However, they did so diversely: while some economists cited Marschak (1950) and Herstein and Milnor (1953) because they were in association by a mathematical equivalence (that is, because they had equal results for choice under uncertainty and ignoring any differences they bore), others did so to exemplify a statement related to expected utility theory.

The first relevant citation of Marschak (1950) came from the Cowles' ex-director himself. At the University of California, Berkeley, Marschak (1951b) presented an article a few months later his Econometrica paper went to press. That work was about developing a normative description of rational behavior paying particular attention to statistics. Marschak (1951b, p. 496) reflected on how "statistical inference has taken a remarkably 'economic' turn" since statisticians started reasoning sample design by gains and losses,

(1954) referenced both Marschak's and Herstein and Milnor's articles, but a closer look revealed he did not.

${ }^{36} \mathrm{It}$ is possible to read Savage's book as a descendant of the Theory of Games, interpreting it as yet another new axiomatization of expected utility theory inspired von Neumann and Morgenstern's contribution. Indeed, the Theory of Games had its influence upon Savage. However, The Foundation of Statistics is, in another reading, part of a different literature: that of choice under subjective uncertainty. The point here is Savage tackled expected utility using a different view of probability (see Arrow (1951a, pp. 410-411) for a discussion of different understandings of probability in problems of decision-making under uncertainty). Advancing from a objective to a subjective framework added much to expected utility's persuasion power: that step dismissed arguments against supposing individuals had perfect knowledge about every possible outcome and state of nature. Hence Savage's contribution meant a much wider contribution than a mere reshaping of von Neumann and Morgenstern's axioms and it deserves a closer inspection about its influence on economics. Unfortunately, such an study is beyond scope here. 
and attempted to attain a maximum net payoff. ${ }^{37}$ In his contribution, an individual (a statistician or a businessman) picked a strategy that determined his earnings' probability distribution. Marschak (1951b, p. 499) queried if adopting strategies of maximum expected utility constituted an optimal course of action. To answer his problem, Marschak asserted he would rely on a postulate of his Econometrica article: ${ }^{38,39}$

\begin{abstract}
Section 3 gives as a necessary condition for the precept a postulate which may be called the Postulate of Substitution between Indifferent Prospects. In an earlier paper [4], this postulate (jointly with certain other postulates) was shown to be a sufficient condition for the precept of maximizing $E u(X)$, valid for a nonempty class of utility functions, each element of which is a linear transform of any of the others. This postulate appears, thus, to be logically equivalent to the moral expectation precept (provided the other postulates are admitted). It is also possibly equivalent to certain postulates of von Neumann and Morgenstern [8]. For a comparison, see $[4$, section 7]. Finally, it is also equivalent to a postulate which Samuelson [11] recently formulated very succinctly and which he proposed to call Special Independence Assumption. (MARSCHAK, 1951b, p. 495)
\end{abstract}

Here Marschak (1951b) associated his work at Cowles on choice under uncertainty and the Theory of Games. In particular, he connected his and von Neumann and Morgenstern's axiomatic system via a mathematical equivalence (Marschak (1948b) had already proposed such link before). Still, other authors associated Marschak (1950), Herstein and Milnor (1953) and the Theory of Games under slightly different settings. For example, Debreu (1954a) cited Marschak (1950) and Herstein and Milnor (1953) as contributions to the same subject of existence and uniqueness of utility functions when reviewing a literature. Debreu (1954a, p. 159) maintained economists often assumed that when some binary relation completely ordered a finite-dimensional Euclidean space (representing a commodity space), it guaranteed they could obtain a real-valued order-preserving function on that set. However, that reasoning of economists was "easily seem to be false:" lexicographic preferences worked as a counter-example to such expectations. Debreu argued when a prospect space had "a certain algebra of combining" (regulating how probabilities can be combined), such idea of existence was legitimate. For him, this case was "rigorously and extensively studied by J. von Neumann and Morgenstern [7], J. Marschak [6], I. N. Herstein and J. Milnor [5]". Then association came not because of an alleged equivalence relation as Marschak (1951b) proposed, but by a broader similarity: all these contributions explored choice under uncertainty in a formal setting by building a non-ordinal preference representation axiomatically. Moreover, Debreu (1954a, p. 159) thought these contributions

\footnotetext{
${ }^{37}$ Wald (1945) first formulated the statistical inference problem as a two-person zero-sum game (as von Neumann and Morgenstern ([1944] 2007, pp. v-vi) acknowledged). In that approach, the statistician played against nature. His article was one of the first that outgrew from the Theory of Games.

38"Moral Expectation" referred to expected utility, following Bernoulli's language. For instance, see Bernoulli (1954, p. 26).

${ }^{39}$ Marschak (1951b, p. 495) referenced Samuelson's "Special Independence Assumption". Chapter 3 discusses that axiom.
} 
on individual decision making under uncertainty showed that something strange happened in economics. For him, it was nearly a paradox that "the general case [of choice over certain outcomes], which is more basic and simpler", had "received little attention from economists". That would lead him to his contribution (see Subsection 2.3.2).

Similarly to Debreu (1954a), Herstein (1953) cited von Neumann and Morgenstern ([1944] 2007), Marschak (1950), and Herstein and Milnor (1952) as close contributions in the literature of axiomatic choice under uncertainty. His article was a survey written for mathematical readers, as Herstein (1953, p. 249) wanted to show how the Theory of Games had been "instrumental in dispelling from the minds of many mathematicians and economists some of the false ideas about what mathematics entered, and possibly more important, what mathematics does not enter, in the problems arising in everyday mathematical economics". To illustrate how that book changed the landscape of mathematical economics, he resorted to a comparison. Herstein (1953, pp. 250-252) portrayed the economics of the 1930s by the Slutsky equation as an application of differential calculus "of the most rudimentary form". It represented how far mathematical economics could go by then. In opposition, Herstein (1953, pp. 253-254) demonstrated that some economists from the 1950s solved problems supported by modern techniques while others did not, citing Lange (1942) in this context (as another example of research based on calculus). ${ }^{40}$ Alternatively, Herstein discussed that economists could use convex set theory instead of calculus to approach welfare problems. Before finishing his comparison, Herstein (1953, p. 254) emphasized a deeper problem in Lange's argument: assuming the existence of a preference representation by a real-valued function. He cited von Neumann and Morgenstern ([1944] 2007), Marschak (1950), and Herstein and Milnor (1952) as examples of a more friendly mathematical approach that solved a subtle yet essential issue in economics:

The first of these problems [establishing conditions to guarantee orderpreserving functions exist in a certain set], important as it seems to be, has received very little attention from the economist. In fact, some economists have even gone as far as to tactily [sic] assume that every complete ordering can be so represented. (The lexicographic ordering of the unit square offers an easy counter-example to this). In case the completely ordered set is, in addition, endowed with a "probabilitymixing" operation, this problem has been thoroughly thrashed out by von Neumann-Morgenstern, Marschak [37], and Herstein-Milnor [25]. (HERSTEIN, 1953, p. 254)

Despite minor differences, citations by Marschak (1951b), Herstein (1953), and Debreu (1954a) identified a mathematical connection between the Theory of Games, Marschak (1950) and Herstein and Milnor (1953). The basis for such link was that they tackled choice under uncertainty axiomatically and afforded answers about the existence

\footnotetext{
${ }^{40}$ Lange (1942) studied welfare economics by assuming a real-valued function could represent any individual's preferences and wrote first-order conditions for a maximum solution through marginal utility ratios. That is, his approach used calculus extensively.
} 
and uniqueness of expected utility functions. It was also significant that they not only used modern techniques (as set theory in opposition to calculus) but structured formal, rigorous arguments. Nevertheless, references erased any differences among von Neumann and Morgenstern ([1944] 2007), Marschak (1950) and Herstein and Milnor (1953): for instance, they overlook Marschak's less technical presentation, or Herstein and Milnor's greater generality by working on a generic mixture space instead of $\mathbb{R}^{n}$. This does not mean Marschak (1951b), Herstein (1953), and Debreu (1954a) were unaware of any particularities - instead, what matters for dissemination is that they portrayed those contributions homogeneously for their readers. If these had no contact with the originals, they would not become informed about special points each contribution had. ${ }^{41}$

In contrast to citing articles as representatives of a research area, there is another way by which economists cited Marschak (1950). They mentioned him as an example of particular features of the non-ordinal approach to preference representation. These references appeared in Strotz (1953) and Leontief (1954). It is essential to reconstruct Strotz's arguments to understand how he made use of Marschak (1950) to illustrate a point of the Theory of Games. Before doing so, a little background will prove itself useful. When von Neumann and Morgenstern ([1944] 2007) presented economists with a nonordinal preference representation, they reopened a finished debate (that of ordinal versus non-ordinal utility functions). Strotz (1953, pp. 384-385) recollected: "Initially we accepted the concept of utility as measurable, then we rejected it, and now we are in the process of accepting it again", reinterpreting measurability not as a property to be "discovered" out of utility (as an intrinsic characteristic), but to be "invented" for prediction purposes. ${ }^{42}$ Thus Strotz (1953, p. 388) alleged that von Neumann and Morgenstern planned to discover a "helpful" measure suited for their objective, that "would make possible the use of a simple formula to describe an individual's choices among various risks".

However, Strotz (1953, p. 390) questioned if von Neumann and Morgenstern's expected utility represented real behavior: "Is it self-evident that people who are not

\footnotetext{
${ }^{41}$ Roy (1952) is another example supporting that claim. There was only one exception among citations: Baumol (1951, p. 61) claimed that von Neumann and Morgenstern's volume promoted that "a more or less unique numerical index of utility (i.e., the true measure) can be deduced from a sufficient amount of information obtainable from the observed behavior of an individual". For him, several contributions followed the Theory of Games' lead on expected utility, as Marschak (1950). However, he maintained that his critics toward expected utility theory applied only to von Neumann and Morgenstern ([1944] 2007), as if Marschak (1950) was not an equivalent (in terms of results).

${ }^{42}$ Generally speaking, Strotz (1953) believed that economists were in the process of accepting nonordinal utility functions. His view was not consensual. For example, Baumol (1951, pp. 61-62) was on the side against expected utility, seeing only two possible interpretations for von Neumann and Morgenstern's results on the uniqueness of preference representation. First, it could be "an arbitrary but effective procedure" to determine one among many functions compatible with individual preferences. Second, it could as well signify "the only true" behavior description. In a footnote, Baumol appended "what is meant by the term [utility] in most economic discussions" differed from what the Theory of Games advised. Hence how people interpreted utility was a potential source of "misapprehension" in debating it. In particular, he felt economists debated utility as something attainable via possession, disregarding dimensions of substitution and complementarity.
} 
pathological will order their preferences among gambles so that the existence of a NeumannMorgenstern function will be assured? I am afraid my intuition tells me very little. It is not self-evident to me that this function either does exist or does not exist." To resolve this issue, Strotz (1953, pp. 390-391) proposed to "replace the hypothesis that there exists a Neumann-Morgenstern utility function with an axiomatic system that implies this statement as a theorem". Naturally, he remarked that the Theory of Games itself had one such solution. However, he also indicated that "several other authors" accomplished such substitution. In a footnote, he acknowledged Marschak (1950) and Herstein and Milnor (1953) (still forthcoming then). Aside from indicating that the Theory of Games had an axiomatic system grounding expected utility and that reinterpretations of it existed, Strotz (1953, pp. 390-391) decided to show his reader one such set of axioms. Instead of displaying von Neumann and Morgenstern's original, he opted for that of Marschak (1950):

[...] Von Neumann and Morgenstern have provided us with an axiomatic system for their utility measure as have several other writers. Let me sketch one of these systems, that of Professor Marschak, in a rather carefree fashion to indicate the main idea.

Marschak's axioms or postulates are as follows:

$[\ldots]$

These axioms have strong intuitive appeal. It would seem that every normal person would clearly accept them as precepts of behavior. Now, Marschak shows that these axioms are just another way of saying that a Neumann-Morgenstern utility function exists. If you accept the axioms you are then logically required to accept the Neumann-Morgenstern theorem which can be derived from them. (STROTZ, 1953, p. 391)

Strotz (1953) cited Marschak (1950) due to his less complicated and more intuitive premises (compared to those from the Theory of Games). His goal was to exemplify how common facts of choice could ground unappealing, mathematical behavior rules (as a curious note, he rewrote Marschak's axioms verbally and left any mathematics aside). Similarly to Strotz (1953), Wassily W. Leontief cited Marschak (1950) to exemplify a point in a survey examining how economist's toolbox was shifting in favor of more advanced mathematics. ${ }^{43}$ Leontief (1954, p. 217) asserted: "Differential calculus and elementary algebra - the two traditional tools of the mathematical economist - are being thus replaced or at least supplemented by those of topology and matrix algebra" in optimal behavior problems. To compose his survey, Leontief (1954, p. 218) argued that for past economists "cardinal measurement turned out to be neither necessary for formulation and solution of the maximum problem at hand nor, essentially for that very reason, operational in terms of actual experience". This widespread belief persisted until "the recently revived interest

\footnotetext{
${ }^{43}$ Leontief (1954, p. 215) acknowledged that his viewpoint was not consensual in our field: "The views to be presented are, of course, not necessarily shared by other economists. Even leaving out those who feel with Lord Keynes that mathematical economics is 'mere concoctions', theoretical disagreements and methodological controversies keep us from sinking into the state of complacent unanimity."
} 
in the old eighteenth century problem of choice under conditions of uncertainty led to renewed attempts to rehabilitate the cardinal utility function". While Leontief (1954) did not explicitly list any "renewed attempts", he maintained they depended on a statement brought by Marschak (1950):

The argument hinges on the assertion [6] [Marschak's article] that from the point of view of "rational" behavior, if,

(a) $U\left(X_{1}\right)$ and $U\left(X_{2}\right)$ are the utility levels associated in the mind of a decision-making consumer with certain but alternative possession of the two specific commodity combinations, $X_{1}$ and $X_{2}$ and

(b) $p$ is a true positive fraction such that

(c) this consumer, when offered the choice between the "chance with the probability $p$ of possessing $X_{1}$ " and "the chance with the probability $(1-p)$ of possessing $X_{2}$ " will find both these offers to be equally desirable, then,

$$
\frac{U\left(X_{1}\right)}{U\left(X_{2}\right)}=\frac{(1-p)}{p}
$$

Once this is admitted, a cardinal comparison of utilities must obviously be accepted as operationally feasible. (LEONTIEF, 1954, p. 218)

Therefore Marschak (1950) delivered a condition to support non-ordinal utility functions in Leontief's account as if it synthesized that approach to preference representation (that is, if someone would accept non-ordinal utilities, he would have to comply with Marschak's statement). Leontief (1954, p. 219) argued that economists could test Marschak's proposition for any given individual; if he behaved in discordance with it, the theory should declare him irrational. However, Leontief's ratio above did not come directly from Marschak (1950). To obtain it, it would be necessary so assume outcomes that are not $X_{1}$ and $X_{2}$ (in Leontief's notation) yielded a utility of 0 (see Marschak (1950, p. 34), particularly "Theorem 5"). That is a mild premise since he could freely apply positive affine transformations on any expected utility functions. Still, Leontief's choices are curious: that ratio was not necessary for his discussion of individual-decision making that came afterwards in his exposition, nor did it genuinely embody expected utility theory (since no expositor of it used such condition as the main result; a more straightforward alternative would be to state that agents maximize an expected utility function).

To conclude, economists who read Marschak (1950) and Herstein and Milnor (1953) depicted them as representatives of a literature on choice under uncertainty that the Theory of Games inspired. What connected them was a mathematical relation: they had produced equivalent axiomatic systems for expected utility theory. There was another type of citation Marschak (1950) received. Some economists referenced him to typify particular aspects of expected utility - or by reproducing his axioms, or by labeling one of his results as a synthesis to that approach to individual-decision making over risky outcomes. Furthermore, von Neumann and Morgenstern ([1944] 2007), Marschak (1950), 
and Herstein and Milnor (1953) seemed homogeneous according to references they received. While Marschak (1950) and Herstein and Milnor (1953) had distinct ways to axiomatize, such particularity did not appear in citations they received by economists who used them to organize previous knowledge. The differences Marschak (1950) and Herstein and Milnor (1953) bore would appear more clearly in citations that used them to pursue new research possibilities.

\subsubsection{NEW RESEARCH POSSIBILITIES}

Besides engaging in practices of knowledge organization, economists also employed Marschak (1950) and Herstein and Milnor (1953) as references to tackle new questions. For instance, backed by past contributions providing non-ordinal preference representations a formal foundation, an economist could straightforwardly study welfare economics using such mappings disregarding issues of existence and uniqueness. Naturally, to adhere or not to the axiomatic approach was optional: economists could use results from Marschak (1950) and Herstein and Milnor (1953) and apply them in a non-rigorous or literary approach. This subsection analyzes how economists employed Marschak (1950) and Herstein and Milnor (1953) to formulate new, original research. In particular, it emphasizes different uses economists made of Marschak (1950) and Herstein and Milnor (1953) (for example, discussing if such usages were mathematical or not, axiomatic or not) as a way to investigate how von Neumann and Morgenstern's influence traveled trough Marschak (1950) and Herstein and Milnor (1953) and reached a wider audience.

As observed in Subsection 2.3.1, Marschak (1951b) cited his axiomatic system by associating it with the Theory of Games as corresponding contributions to choice under uncertainty. However, Marschak (1951b) also built on Marschak (1950) and explored another foundation for expected utility theory. In particular, his purpose was to verify if his Postulate IV was tantamount to supposing individuals maximize expected utility functions (that is, keeping Postulates I, II, and III, assuming Postulate IV or that agents maximize expected utility functions would produce no divergent results of existence and uniqueness). More than a simple mathematical proof, that result attempted to strengthen his Postulate IV's acceptability among economists. While he kept Postulates I and II unchanged (that together assumed a binary, continuous relation completely ordered a lottery space), Marschak (1951b, p. 500) substituted Postulate III for a weaker form. His new Postulate III was already present in Marschak (1950, p. 118) as a suggestion from Wald. ${ }^{44}$ While Marschak (1951b, p. 502) did not justify his change, he argued I, II, and III were "weak enough as a description of reasonable behavior" (before, he believed his original Postulate III was more intuitive; see Subsection 2.3.1). By using appealing axioms

\footnotetext{
${ }^{44}$ Denote by int $\mathscr{L}$ the interior of $\mathscr{L}$ and let $\mathfrak{p}$ be a binary relation standing for "is preferred to", as usual. Wald suggested that him Marschak (1951b, p. 118) could suppose $\exists L_{1}, L_{2} \in \operatorname{int} \mathscr{L}$ such that either $L_{1} \mathfrak{p} L_{2}$ or $L_{2} \mathfrak{p} L_{1}$.
} 
and showing how different assumptions implied equal results of existence and uniqueness in expected utility theory, Marschak (1951b) had a point that boiled down to his readers' preferences: if some economist felt more comfortable assuming IV or that individuals are expected utility maximizers, it made no difference:

\begin{abstract}
In [4] [Marschak (1950)], a certain set of behavior postulates, numbered I-IV, was shown by the author to imply the proposition that there exists a class of utility functions, linear transforms of each other, and such that for every utility function the expected value of utility is maximized. We shall presently restate these postulates and show that, if postulates I-III (which appear rather mild) are accepted, then postulate IV follows from the condition that $E u(X)$ [the expected utility] is maximized. A joint result of the two papers is, then, that under certain weak conditions, postulate IV and the rule of maximizing moral expectation are equivalent. Postulate IV will be called the "rule of substitution between indifferent prospects". (MARSCHAK, 1951b, p. 500)
\end{abstract}

Therefore Marschak (1951b) reused three assumptions from Marschak (1950) to raise another foundation for expected utility theory. His argument was technical: he provided readers with a proof of an equivalence relation between his axioms and expected utility maximization. Similarly to him, Debreu borrowed an axiom from Herstein and Milnor (1953) to apply it rigorously in individual-decision making over certain alternatives. Debreu (1954a, p. 159) considered a "more basic and simpler" problem of decision-making among certain outcomes, a query that had "received little attention from economists". He demonstrated two representation theorems. In particular, he showed that a continuous real-valued order-preserving function existed in sets under two different collections of hypotheses. First, if preferences were continuous, it sufficed to suppose they completely ordered a separable and connected commodity space. Second, the existence of that function also followed if such space was simply completely ordered and perfectly separated. ${ }^{45}$ Debreu (1954a, p. 162) referenced Herstein and Milnor (1953) in a footnote stating: "The closedness assumptions have already been used in a similar context by I. N. Herstein in an earlier unpublished version of [5]." "Closedness" referred to their axiom of preference continuity. ${ }^{46}$ Debreu (1954b, p. 160) also gave his reader an alternative definition of continuity hypothesis using sequences. Still, that was not Debreu's only article on decision-making relying on that axiom from Herstein and Milnor (1953).

Debreu had a second article summoning Herstein and Milnor (1953) and their continuity axiom. His work was about valuation equilibria and Pareto optima. Differently from a Pareto optimum where "no consumer can be made better off without making

\footnotetext{
${ }^{45}$ Using $\mathbb{R}^{n}$ is separable and connected, modern textbooks present a less general version of Debreu's theorem. See Mas-Colell, Whinston and Green (1995, p. 47).

${ }^{46}$ To remember, Herstein and Milnor (1953, p. 292) assumed that for any $L_{1}, L_{2}, L_{3} \in \mathscr{L},\{\alpha$ : $\left.\alpha L_{1}+(1-\alpha) L_{2} \mathfrak{g} L_{3}\right\}$ and $\left\{\alpha: \alpha L_{1}+(1-\alpha) L_{2} \mathfrak{g}^{T} L_{3}\right\}$ are closed. Instead, Debreu (1954a, p. 162) postulated given any $L_{1}$ the sets $\left\{L \in \mathscr{L}: L \mathfrak{g} L_{1}\right\}$ and $\left\{L \in \mathscr{L}: L \mathfrak{g}^{T} L_{1}\right\}$ are closed. That was an equivalent version to that of Herstein and Milnor (1953) presented by Herstein (1951a).
} 
another consumer worse off", Debreu (1954b, p. 588) explained that a valuation equilibrium is a state where "no consumer can make himself better off without spending more, and no producer can make a larger profit". He intended to formulate and demonstrate two theorems formalizing "old beliefs in economics:" put simply, to determine under what conditions a valuation equilibrium is Pareto optimum and vice versa. Although alongside Arrow he had already addressed this point "with techniques permitting proofs", Debreu managed to weaken previous assumptions. In particular, he extended his analysis to encompass infinite-dimensional real vector spaces. To prove any valuation equilibrium is Pareto optimum, Debreu (1954b, p. 589) had to adopt two hypotheses regarding convexity of consumption-sets and preferences, both already "used by Arrow and Debreu in a different context". Similarly, to prove the converse statement, Debreu (1954b, p. 590) needed three additional assumptions. Besides two premises regarding the aggregate production set, he needed a continuity axiom for individual preferences, about which he maintained: "This weak axiom of continuity for preferences has been introduced by Herstein and Milnor in another context."

Similarly to Marschak (1951b) and Debreu (1954a, 1954b), Hildreth (1953) also borrowed axioms to apply them in a rigorous setting, but from von Neumann and Morgenstern ([1944] 2007). Concerned by welfare economics Hildreth (1953, p. 81) rivaled Arrow (1951b) (who discussed methods for obtaining group preferences given individual preferences). To sketch rules governing collective behavior, he needed to proceed as Arrow (1951b) and lay down a system describing individual choices. His way was to rehash the Theory of Games' axiomatic system - Hildreth (1953, p. 84) stated: "Assumptions 1-3 restate the axioms of von Neumann and Morgenstern." Aside from referencing von Neumann and Morgenstern ([1944] 2007), Hildreth also cited Marschak (1950). To enter the realm of uncertainty, Hildreth (1953, p. 84) organized his discussion in terms of prospects (defined by him as "either a specification of amounts of commodities to be received and furnished by an individual over a given period of time or a probability combination of such specification"). As his consideration for how agents chose among uncertain prospects was not exhaustive, he cited Marschak (1950) as a reference for a fuller discussion about prospects. Similarly to Hildreth (1953), Marschak (1951b) and Debreu (1954b, 1954a) had a particular way to apply contributions from Marschak (1950) and Herstein and Milnor (1953): they adopted axioms and definitions to develop new axiomatic systems both in and out of individual choice under uncertainty. These applications had proof-driven structures, that is, they grounded their claims by using a formal mathematical reasoning. This characteristic was not a rule: among other citations to Marschak (1950) and Herstein and Milnor (1953), several appropriated some results of expected utility theory instead of its axioms.

For instance, Herman Chernoff relied on von Neumann and Morgenstern's proof of the existence of a measurable utility function to build an article. Chernoff (1954, p. 423) 
considered statisticians' game theoretical approach to inference problems. ${ }^{47}$ His model had four premises. In particular, Chernoff (1954, p. 423) admitted a measurable utility function represented any gains a statistician could obtain by adopting a strategy. His citation to the Theory of Games and Marschak (1950) came in a footnote: "Von Neumann and Morgenstern [10] have shown that under relatively mild conditions, one may attach a utility $u$ to a prospect, (the term prospect was used by Marschak [6])." Although he presented nonmathematical discussions, his article is everywhere full of formal demonstrations - indeed, it includes an appendix to house some of them. By structuring his article in premises, statements, and proofs, Chernoff (1954) resembles Marschak (1951b), Hildreth (1953), and Debreu (1954b, 1954a). However, his use of von Neumann and Morgenstern ([1944] 2007) and Marschak (1950) was distinct: while he operated an expected utility function in his model, he did not reveal what hypotheses could ground its existence, uniqueness, or linearity properties. The application of established results of expected utility theory would appear in several articles of verbal or less-sophisticated mathematical reasoning.

In a big picture, Chernoff's case is an exception: most readers of Marschak (1950) and Herstein and Milnor (1953) who applied results instead of assumptions did it so in verbal or less-sophisticated mathematical ways. To illustrate, consider Morishima (1952, pp. 223-224), who claimed: "we have no established theory of consumer's behavior in a monetary economy." Then he modeled behavior as if people made choices envisioning to achieve a better living standard in a time to come - that is, one dimension of what economists call commodity space referred to different living standards. By hypothesis, people's preferences were a relation that completely ordered his space of goods and probabilities of future living standards. Marschak (1950) was essential for Morishima in providing him a basis to develop that assumption, as he described in a footnote: "In his excellent paper, Professor Marschak [5] postulated complete ordering of probability space. Our postulate is the one of complete ordering of commodity-probability space." However, Morishima (1952, p. 225) did not show formally his adaptation from Marschak (1950) yielded a non-ordinal representation of preferences. Instead, he assumed a utility function existed and represented his ordering. His general goal was to analyze first- and second-order conditions to achieve a maximum, the effects of change in prices and the interest rate, and monetary shocks; it was not to explore rigorous demonstrations for his assumptions.

Similarly, Marschak and Mickey (1954) used earlier foundational articles to advance an application of expected utility, relying on the existence result of one such function. In particular, their problem was to describe optimal behavior of an army choosing among

\footnotetext{
${ }^{47}$ Following Wald (1945), Chernoff (1954) interpreted statistical inference as a two-person game played by a statistician and nature. Curiously, Chernoff (1954, p. 436-437) had a result that opposed to von Neumann and Morgenstern ([1944] 2007): for him, mixed strategies were absolutely unessential in solving games of statistical inference.
} 
Figure 8 - The "Theorem of Mixtures"

\section{B}

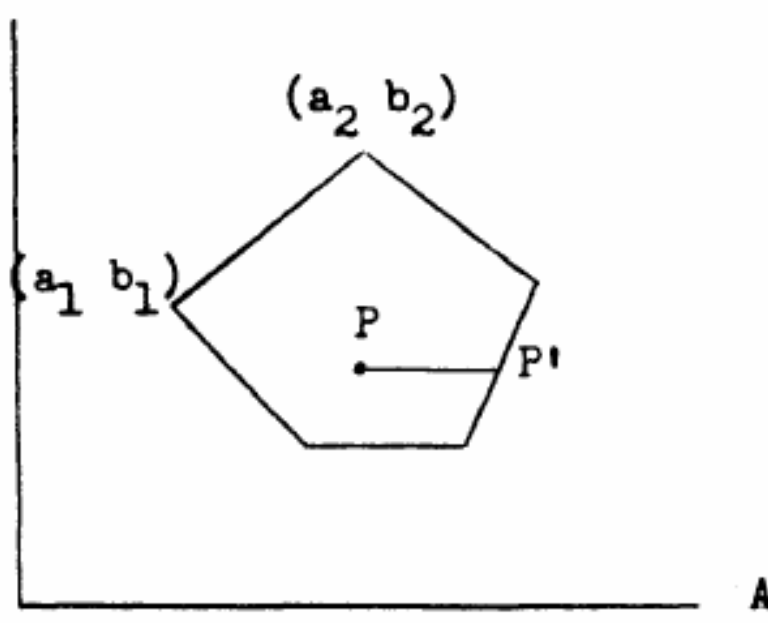

Source: Reproduction of Marschak and Mickey (1954, p. 126).

single-target weapons. Marschak and Mickey (1954, pp. 116-117) asserted that an "expected military utility" function existed given some "innocently looking postulates on rational behavior". In a footnote, they referenced their readers to von Neumann and Morgenstern ([1944] 2007), Marschak (1950), and Herstein and Milnor (1953). These citations justified such existence for Marschak and Mickey (1954). Still, Marschak and Mickey (1954) did not focus on demonstrating mathematical claims even if they spoke in typical terms of who works on a formal setting. For instance, Marschak and Mickey (1954, p. 125) declared that a "Theorem of Mixtures" (emphasis added) was "briefly stated and loosely proved later". They justified that theorem's validity graphically instead of formally (see Figure 8). They instructed readers to draw a horizontal line starting from $P$ to show them how any solution for their problem would happen at the polygon's right-hand boundary. That graphical argument was their "loose" proof. It shows Marschak and Mickey (1954) focused not on formally justifying results, but only giving a sufficiently convincing argument to proceed to applications and estimations (subsequently, Marschak and Mickey (1954, pp. 131-137) computed several maxima of expected military utilities given specific values of "kill probability" and weapon costs). ${ }^{48}$

\footnotetext{
${ }^{48} \mathrm{~A}$ last and unique case of use of Marschak (1950) was that of Roy (1952), who instead of adapting premises or directly borrowing results from Marschak (1950), used him as a benchmark of choice under uncertainty. His point of citing Marschak (1950) was to build a comparison to show how his model had a better fit with real behavior. Instead of applying expected utility maximization, Roy (1952, p. 432) contested von Neumann and Morgenstern ([1944] 2007) and Marschak (1950) because "real people" cannot have (and do not consider to have) full knowledge. For him, agents form expectations in a "much more vague manner" than simple computing all available probabilities or potential surprises. Roy (1952) resorted to visual arguments and had a numerical exercise illustrating his approach to uncertainty as Marschak and Mickey (1954) did — his goal was not propose and rigorously demonstrate statements.
} 
To conclude, economists used Marschak (1950) and Herstein and Milnor (1953) to pursue their research agendas in axiomatic and non-axiomatic ways. In particular, those Econometrica articles served for borrowing axioms (adapted or directly), definitions, and results. The analysis of citations Marschak (1950) and Herstein and Milnor (1953) received shows that appropriation of axioms is closely related to authors who worked axiomatically and that provided arguments in form of rigorous demonstrations, whereas studies that applied results of expected utility theory (mainly of existence and uniqueness) were not proof-driven. These employed less mathematically sophisticated tools (mostly calculus) and resorted to graphical and verbal arguments. Regarding the dissemination of the Theory of Games by secondary sources, the analysis of citations from Marschak (1950) and Herstein and Milnor (1953) show von Neumann and Morgenstern's approach indirectly inspired both non-axiomatic and axiomatic research, in and out of choice of uncertainty.

\subsection{CONCLUDING REMARKS}

The Theory of Games practiced a type of mathematics above what economists usually employed around the 1940s and 1950s, as its book reviews emphasized. That book would depend on secondary sources to translate its contents in a less technical, more verbal fashion to reach a broader audience. These translators necessarily should be mathematically skilled. Since Marschak's and Hurwicz's book reviews already tried to decipher some of von Neumann and Morgenstern's concepts and results in terms economists could follow, and they had a connection with Cowles when they composed their assessments, it would only be natural to look for such translations in Cowles' research output. Indeed, Marschak (1950) and Herstein and Milnor (1953) were two articles that originated at the Commission that followed leads left by the Theory of Games. This chapter analyzed them and citations they received.

In particular, Marschak (1950) and Herstein and Milnor (1953) reworked von Neumann and Morgenstern's axiomatic system providing alternative foundations for expected utility theory. They strived for a simplification of demonstrations and broader generality of assumptions. Additionally, Marschak and Herstein's researches overlapped, as Herstein read and corrected one of Marschak's work (showing his trial to obtain preference continuity as a result instead as of an axiom was not possible). Nonetheless, they conveyed arguments differently. Herstein and Milnor provided rigorous demonstrations to their claims and left no concessions for their readers. To follow their reasoning it would be necessary some familiarity with higher mathematics. In contrast, Marschak also had formal demonstrations to back up his points, but he made use of several devices to make his exposition easier and accessible for economists not so well-acquainted with mathematics. He extensively used visual representations of concepts and spared no words when it came to explaining his points verbally. 
Different ways to structure articles can correlate with how economists reacted to these. At first sight, economists interpreted von Neumann and Morgenstern ([1944] 2007), Marschak (1950) and Herstein and Milnor (1953) as very similar contributions to choice under uncertainty, erasing meaningful differences they bore. This feature appeared from analyzing practices of organizing previous knowledge by citations these works received. However, a closer look on how economists applied Marschak (1950) and Herstein and Milnor (1953) shows that two approaches emerged from the new axiomatizations inspired by the Theory of Games: economists borrowed and adapted axioms singly or in a bundle to build new formal systems for problems of choice over certain and risky outcomes, as well as collective decision-making. In turn, economists also used results of existence and uniqueness of expected utility theory to applied exercises of varied topics, such as military queries of how optimally choose weapon systems. These uses came into sight by examining practices of pursuing new research possibilities after the contributions of Marschak (1950) and Herstein and Milnor (1953). Therefore the Theory of Games reached economists working in different terms than those of von Neumann and Morgenstern via secondary sources as Marschak (1950) and Herstein and Milnor (1953), as it also inspired new axiomatic exercises. 



\section{THE TWISTED HISTORY OF INDEPEN- DENCE}

Chapter 2 analyzed citations that Marschak (1950) and Herstein and Milnor (1953) received. Marschak (1950) received another reference that Chapter 2 omitted because it touched on a particularly important subject absent in other citations. That reference's authors were the economist Alan S. Manne (Harvard University) and the mathematician Abraham Charnes (Carnegie Institute of Technology). Before presenting it, a concept needs clarification. Octane rating is a measure of fuel performance. The blending of two different types of gasoline results in a mix of a new grade. An important question about combining fuels is how to mix different varieties to maximize the mixture's performance degree. Manne and Charnes (1952, pp. 665-666) investigated an alleged association between applying linear programming methods in the gasoline blending problem with von Neumann and Morgenstern's axioms grounding expected utility theory. In particular, Manne and Charnes (1952, p. 666) showed that Marschak's "Theorem 1" (which stated that indifference sets were parallel hyperplanes; see Marschak (1950, p. 122)) did not hold for gasoline blending problems. They concluded that since Paul A. Samuelson had found an axiom necessary for expected utility theory - called "Strong Independence Assumption" - that did not hold for experiments measuring octane ratings. Specifically, averaging elements' grades in a mixture did not result in the blend's actual rating. Manne and Charnes (1952, p. 666) concluded: "If the independence condition actually held, linear programming (in terms of blending indices) would constitute a sound, logical procedure for gasoline output scheduling." Since it did not, applying a linear programming model would result in inefficient combinations.

Marschak (1950) and Herstein and Milnor (1952) reformulated von Neumann and Morgenstern's axiomatic system for choice under uncertainty using versions of what economists understand as the independence axiom (called above "Strong Independence Assumption"). ${ }^{1,2}$ It is important to stress that condition is necessary for a system of hypothesis to imply expected utility theory. Curiously, it was apparently absent in von Neumann and Morgenstern ([1944] 2007) — since the Theory of Games implied expected

\footnotetext{
${ }^{1}$ The independence axiom postulates that individually mixing two lotteries with a third preserves the preference ranking of those two gambles regardless of the third or the probabilities used (keeping odds fixed). Following Mas-Colell, Whinston and Green (1995, p. 171),

$$
\forall L_{1}, L_{2}, L_{3} \in \mathscr{L}, \forall \alpha \in(0,1) \quad L_{1} \mathfrak{g} L_{2} \Leftrightarrow\left[\alpha L_{1}+(1-\alpha) L_{3}\right] \mathfrak{g}\left[\alpha L_{2}+(1-\alpha) L_{3}\right]
$$

${ }^{2}$ Curiously, Mas-Colell, Whinston and Green (1995, p. 171) affirmed on a footnote "The independence axiom was first proposed by von Neumann and Morgenstern ([1944] 2007) as an incidental result in the theory of games."
} 
utility theory, it necessarily was there, but hidden. Additionally, Marschak (1950) did not claim to be its creator, nor did he establish a link between his Postulate IV (independence) and any of the Theory of Games assumptions. Indeed, Manne and Charnes (1952, p. 667) claimed that independence was "self-evident and hardly worth discussing" for those who accepted von Neumann and Morgenstern's approach. ${ }^{3}$ Historians of economics interpret that the independence axiom was born after the Theory of Games. ${ }^{4}$ Usually, they identify Savage and Samuelson as key-players in that step. Discussing how von Neumann and Morgenstern ([1944] 2007) grounded expected utility theory relying on no independence condition was a question that made the Theory of Games' authors to spend a few words defending themselves on a preface (for the third edition, of 1953):

\begin{abstract}
In connection with the methodological critique exercised by some of the contributors to the last-mentioned symposium, we would like to mention that we applied the axiomatic method in the customary way with the customary precautions. Thus the strict, axiomatic treatment of the concept of utility (in Section 3.6. and in the Appendix) is complemented by an heuristic preparation (in Sections 3.1.-3.5.). The latter's function is to convey to the reader the viewpoints to evaluate and to circumscribe the validity of the subsequent axiomatic procedure. In particular, our discussion and selection of "natural operations" in those sections covers what seems to us the relevant substrate of the Samuelson-Malinvaud "independence axiom". (VON NEUMANN; MORGENSTERN, [1944] 2007, p. viii)
\end{abstract}

"The last-mentioned symposium" marks when economists discovered the independence axiom. Some of its papers appeared in a number of Econometrica. ${ }^{5}$ There, Samuelson (1952) formally presented independence and discussed it was implicit in the Theory of Games. In turn, Malinvaud (1952) showed where it was. However, Fishburn and Wakker (1995) identified that independence was already stated two years before that symposium, in contributions of Marschak (1950) and Nash (1950a) (also published in Econometrica). ${ }^{6}$ Fishburn and Wakker (1995, p. 1133) observed Marschak did not emphasize such axiom, suggesting that "the condition's necessity was common knowledge among Marschak and his colleagues". Nash's article had it the same way: he cited no source for his independence condition nor claimed its crafting. Bleichrodt et al. (2016) wrote a short argument claiming Nash's discovery happened independently and simultaneously to Marschak. As for Nash,

\footnotetext{
${ }^{3}$ As usual, let $L_{1}, L_{2} \in \mathscr{L}$ be lotteries, $\alpha \in(0,1)$ a real number, and $\mathfrak{i}$ be a binary relation standing for "indifferent to". For ease of comparison, Marschak (1950, p. 121) stated $L_{1}$ i $L_{2}$ implied $\forall L_{3} \in \mathscr{L}\left[\alpha L_{1}+\right.$ $\left.(1-\alpha) L_{3}\right] \mathfrak{i}\left[\alpha L_{2}+(1-\alpha) L_{3}\right]$. In turn, Herstein and Milnor (1953, p. 293) assumed $L_{1} \mathfrak{i} L_{2}$ implied $\forall L_{3} \in \mathscr{L}\left[1 / 2 L_{1}+1 / 2 L_{3}\right] \mathfrak{i}\left[1 / 2 L_{2}+1 /{ }_{2} L_{3}\right]$ (that is, Herstein and Milnor (1953, p. 293) stated Marschak's axiom specifying $\alpha=1 / 2$ ).

${ }^{4}$ See Fishburn and Wakker (1995) and Moscati (2016).

${ }^{5}$ See Wold, Shackle and Savage (1952), Manne and Charnes (1952), Samuelson (1952), and Malinvaud (1952).

${ }^{6}$ Fishburn and Wakker (1995, p. 1134) believe Norman C. Dalkey's "A Numerical Scale for Partially Ordered Utilities", a working paper of RAND Corporation's "Research Memorandum" series (dated of December 1949), was the first written document stating the independence axiom. Dalkey never had his paper published.
} 
Bleichrodt et al. (2016, p. 2) claimed he "simply needed expected utility and just wrote it [the independence axiom] down, apparently unaware that it was new and that he was correcting von Neumann and Morgenstern".

Besides Marschak's unawareness of his accomplishment, none among those who cited him until 1954 paid special attention to his version of independence, except by Manne and Charnes (1952). Since independence is an essential ingredient to expected utility theory and given citations to Marschak (1950) were silent about it, this chapter explores the dissemination of Nash (1950a) and Samuelson (1952) (as historians of economics identify these articles as key actors in the independence axiom's history). In particular, this chapter focuses on which use - or non-use - economists made of that assumption, paying special attention to its possible participation in the dissemination of the Theory of Games. Methodologically, Chapter 3 follows Chapter 2 closely: it tracks citations Nash (1950a) and Samuelson (1952) until 1954 and analyzes them sticking to Stapleford (2017) (that is, it replicates the exercise done previously with Marschak (1950) and Herstein and Milnor (1952) but considering Nash (1950a) and Samuelson (1952)).

This chapter has two sections besides a conclusion. Section 3.1 presents a background for Nash's article in bargaining theory and studies its dissemination among economists, but focusing on his contribution to individual-decision making under uncertainty. Section 3.2 presents a similar analysis for Samuelson's contribution. It uses proceedings from a conference ("The last-mentioned symposium" partially published in Econometrica) to discuss its dispersal among economists since Samuelson received no citations related to his independence condition until 1954.

\subsection{NASH'S CONTROVERSIAL DEBUT IN ECONOMICS}

Nash's contribution to game theory was a historical landmark; in a sequence of four articles, Nash $(1953,1950 b, 1950 a, 1951)$ established a boundary between cooperative and non-cooperative games. However, his accomplishments were far greater than establishing definitions. Bargaining had captured economists' interest way before Nash (1950a). For example, Serrano (2018) highlighted Edgeworth ([1881] 1967) and Hicks ([1932] 1935) as essential readings on that subject for economists before Nash. However, until Nash's solution concept emerged economists supposed and accepted bargaining problems as inherently indeterminate. For Serrano (2018, p. 718), any agreements respecting individual and collective rationality were far too numerous and "theorists were inclined to believe that theoretical arguments could go no further than this in obtaining a prediction". 7 To narrow down specific solutions, they presumed it was necessary to make use of "extra-economic variables". Nash changed that view. Watson (2018, pp. 9280) argued that Nash (1950a)

\footnotetext{
${ }^{7}$ For Serrano (2018, p. 718), collective rationality meant no party would agree with an inefficient outcome.
} 
initiated "the axiomatic method for the analysis of bargaining (where theorists explore how different axioms characterize various functional solutions), starting a literature that thrived for several decades. The Nash bargaining solution is still the dominant solution in applied economic models".

Differentiating non-cooperative from cooperative games and reshaping economists' views on equilibrium interested in bargaining problems are achievements particular to game theory. Still, Nash (1950a) had his part in the Theory of Games' history of dissemination by formulating an independence condition for preferences. The objective of this section is to understand if and how Nash (1950a) participated in the dissemination of (axiomatic) expected utility theory. Since Nash's paper was not about choice under uncertainty (although he formulated an axiomatic system for expected utility), it is important to understand Nash's reception in a broader context (that is, considering what features of his article attracted economist's attention and what questions it raised). Subsection 3.1.1 presents and discusses how Nash (1950a) axiomatized choice and uncertainty. Subsection 3.1.2 tracks and analyzes citations to Nash (1950a) (as Chapter 2 did for Marschak (1950) and Herstein and Milnor (1953)).

\subsubsection{EXPECTED UTILITY IN NASH'S BARGAINING MODEL}

"The Bargaining Problem", Nash's first paper, has a widely known history. He drafted it as a requirement for the only economy class he's ever taken, an undergraduate international trade course at the Carnegie Institute of Technology, and published it in Econometrica when he was a mathematics Ph.D. student at Princeton University. Remarkably, Nasar (1998, p. 90) claimed that Nash (1950a) developed its content before any exposure to game theory that he would have at Princeton, or even reading the Theory of Games. Although, its only cited reference is von Neumann and Morgenstern's book: he probably benefited from interaction with them between his first sketch and the final version since Nash (1950a, p. 155) decided to credit them in his published text: "The author wishes to acknowledge the assistance of Professors von Neumann and Morgenstern who read the original form of the paper and gave helpful advice as to the presentation." Even if he cultivated his ideas independently, in his Econometrica publication, Nash (1950a, p. 157) identified a link between his model and von Neumann and Morgenstern's theory, categorizing his contribution as a generalization that flourished from their treatment of zero-sum two-person games.

While Nash's ultimate objective was to discuss bargaining, he took time to discuss individual decision-making before presenting arguments for his main subject. Nash (1950a) structured his points around two main sections entitled "Utility Theory of the Individual" and "Two Person Theory". Since describing individual-decision making was not his final goal, he approached preference representation as von Neumann and Morgenstern did in 
their book's first edition: he stated sufficient assumptions to warrant preferences were amenable to description in terms of an expected utility function. In particular, Nash (1950a, p. 156) presented five axioms to "develop the utility theory of a single individual". He called "anticipation" any circumstance in which an individual expects to receive (or lose) something, such as "a Buick or a Cadillac". "Anticipations" are equivalent to Marschak's "prospects", or current economists' "lotteries". His first three premises stated that any individual could rank any pair of anticipations in terms of desirability respecting transitivity and, if they mixed two equivalent states, that operation would produce an option equally desirable as its components. For his fourth axiom, he picked "an assumption of continuity:" given three anticipations $L_{1}, L_{2}, L_{3} \in \mathscr{L}$ such that $L_{1} \mathfrak{g} L_{2}$ and $L_{2} \mathfrak{g} L_{3}$, then there would exist a probability $\alpha \in(0,1)$ such that a mix of $L_{1}$ and $L_{2}$ with odds $\alpha$ and $1-\alpha$ would be as desirable as $L_{3} \cdot{ }^{8}$ Nash's last axiom is a version of what economists today call independence axiom (uppercase Latin letters were anticipations in Nash's notation): ${ }^{9}$

If $0<p<1$ and $A$ and $B$ are equally desirable, then $p A+(1-p) C$ and $p B+(1-p) C$ are equally desirable. Also, if $A$ and $B$ are equally desirable, $A$ may be substituted for $B$ in any desirability ordering relationship satisfied by $B$. (NASH, 1950a, p. 156)

Although Nash (1950a, p. 157) decided to present an axiomatic system grounding expected utility theory, he gave his claims of existence, uniqueness, and linearity no proof (formal or not), only mentioning they "suffice to show the existence of a satisfactory utility function, assigning a real number to each anticipation of an individual". Such an absence of demonstrations records that Nash was not committed to contributing to individual decision-making under uncertainty, but simply needed some assumptions under which advantageous properties of uniqueness and linearity would follow logically. Another evidence for his soft take on individual choice comes from his reference to von Neumann and Morgenstern. When he formally cited them in his "Introduction", he specified the Theory of Games' pages 15 to 31, that covered only a subsection of von Neumann and Morgenstern ([1944] 2007) entitled "The Notion of Utility" - that also handed out axioms, but no demonstrations (as previously mentioned, proofs about expected utility would come in its second edition in an appendix).

Three additional assumptions were necessary for Nash (1950a) to proceed from individual choice to bargaining. Two points here are important to understand the dissemination of Nash's article. First, among his premises Nash (1950a, p. 159) postulated people had "equality of bargaining skill". Consequently, utility levels for each player should be

\footnotetext{
${ }^{8}$ As usual, $\mathfrak{g}$ is a relation meaning "at least as good as". Nash (1950a, p. 156) has a typo in his fourth axiom. He assumed $\forall L_{1}, L_{2}, L_{3} \in \mathscr{L}$ such that $L_{1} \mathfrak{g} L_{2} \mathfrak{g} L_{3}$, then $\exists \alpha \in(0,1)$ such that $\left[\alpha L_{1}+(1-\alpha) L_{3}\right] \mathfrak{i} L_{3}$. Certainly he meant $\left[\alpha L_{1}+(1-\alpha) L_{3}\right] \mathfrak{i} L_{2}$.

${ }^{9}$ As for Marschak (1950), Nash's version of independence lacks the converse direction, that is, one can presume ordering preferences for two lotteries by observing predilections for particular mixings.
} 
equal in any solution. This assumption would receive severe criticism. ${ }^{10}$ Second, Nash's way of axiomatizing behavior under bargain was different from his approach to expected utility. For individual-decision making, Nash's hypotheses characterized a preference relation that would imply individuals made choices as to maximize an expected utility function. However, when it came to bargaining, Nash's axioms characterized equilibria directly (that is, he listed desirable properties an equilibrium should have). That way of modeling avoided answering how people behave when they face bargain situations (for example, it left it unanswered how individuals picked strategies, or how they threatened each other).

To conclude, Nash (1950a) showed two approaches to axiomatics when he developed his bargaining model. In individual-decision making, his premises characterized agents' preference relations. As a conclusion, they would act as expected utility maximizers. Concerning bargaining, Nash let axioms describe equilibria instead. Consequently, Nash could not detail how individuals behaved in bargaining situations. While subtle, that contrast is crucial to understand how economists received Nash (1950a). Nowadays some points in such dissemination history are still unclear. If Innocenti (2008) provided an account of how economists responded to Nash (1950a) and his symmetry assumption, how they reacted to his system axiomatizing expected utility theory remains unexplored. Subsection 3.1.2 analyzes that aspect of Nash's dissemination: similarly to Marschak (1950) and Herstein and Milnor (1953), it is possible his article helped to spread the Theory of Games' approach to preference representation over risky outcomes.

\subsubsection{HOW ECONOMISTS REACTED TO NASH}

An analysis to citations of Nash (1950a) up to 1954 shows that its usefulness for economists remained restricted. Two references Nash (1950a) received came from Marschak. Since Marschak himself appeared unaware of his accomplishment of making it explicit a version of the independence axiom, it is reasonable to expect he would not emphasize that achievement of Nash (1950a). Likewise, nor would he discuss an axiomatization that was equivalent to his (yet less extensive since Nash (1950a) did not write down proofs for his statements about individual choice). Indeed, Radner and Marschak (1954, pp. 61-63) wanted to scrutinize two alternative decision criteria to von Neumann and Morgenstern's minimax principle proposed by Hurwicz and Savage. They cited Nash (1950a) once to suggest a parallel between a Cowles Discussion Paper of Chernoff and Nash's approach to equilibrium. Their point was that Nash's axiom regulating equilibria depended only on a small portion of the boundary of the set of possibilities. That property seemed to have an

\footnotetext{
${ }^{10}$ See Innocenti (2008) for a history of the reception of Nash (1950a) focused on his contribution to game theory.
} 
analog in Chernoff's research. ${ }^{11,12}$ In turn, Marschak (1954, pp. 188-190) devised different ways to model individual and group preferences (and depending on which ways these preferences overlapped, he defined different forms of organization: coalitions, foundations, and teams). Here he cited Nash's first Econometrica article only to remark that "A theory of bargaining has been presented by J. Nash" referring to Nash (1950a) and Nash (1953) that is, acknowledging his contribution in a generic manner, without being specific about what were Nash's main achievements or how it fitted the literature of bargaining.

Only Nash (1953) found in his earlier article some use to explore new research possibilities. There is a clear continuity between both of Nash's articles. Their axiomatic system had a close connection, as Nash (1953, pp. 138-139) observed that his newer work had only two "really new" assumptions (out of seven). There was more to it: by keeping his old premises, Nash could greatly facilitate his demonstrations if he managed to reduce his new problem to that of Nash (1950a). In his model of 1953, individuals could threat each other (and those threats would result in a game end if individuals failed to come to terms). Nash observed that if players had but one possible threat, his present problem would fall into his bargaining question. This adaption permitted Nash (1953, p. 139) to prove his statements: he appended the new axioms "to reduce the problem of games where each player may have a non-trivial space of strategies (threats)", guaranteeing a return to his old bargaining model.

If Nash (1953) preserved his old axioms characterizing equilibria in his article from 1953, he distanced himself from his past axiomatization of individual decision-making under uncertainty. As it happened on Nash (1950a), he needed to model individual behavior in terms of an expected utility function. He could have used his past axioms, but Nash (1953, p. 129) preferred to borrow von Neumann and Morgenstern's results instead. Not only he mentioned the Theory of Games thoroughly discussed properties of expected utility functions (redirecting an interested reader to von Neumann and Morgenstern's book), but Nash (1953, p. 136) stated that "Order preserving linear transformations of the utilities $[\ldots]$ do not change the solution" as an axiom instead of as a logical consequence.

While Nash (1950a) was not a reference on individual decision-making for himself, nor it was for economists in general. Consider someone cited Nash and he needed to develop

\footnotetext{
${ }^{11}$ See Chernoff (1949). He had a point against Savage's criterion complaining that it was sensitive to enlargements of the strategy space. In comparison, Nash's assumption on bargaining equilibria was not.

${ }^{12}$ Hurwicz (1953, p. 400) (who cited Nash (1950a)) also touched this subject more broadly, making a review of recent developments on alternatives to the minimax criterion: "None of these uncertainty behavior principles commands universal acceptance, since they all exhibit certain unsatisfactory properties. Just to what extent that is inevitable is not yet completely known. In the opinion of the present writer, one should not expect unanimous acceptance of some particular one among these principles, since it seems reasonable that some individuals might, say, find the regret principle a natural one, while others would feel inclined to maximax. In any case, however, if an individual is to have any consistent behavior pattern in nonprobabilistic uncertainty situations, he must (implicitly or explicitly) follow some uncertainty behavior principle, whether it be minimax or something else."
} 
some form of representation of individual behavior, as mapping preferences through a real-valued function. Given he had contact with Nash (1950a), three possibilities would follow. He could cite Nash and use his axiomatic system to dodge any pains of constructing an argument. Instead, he could give Nash a reference (acknowledging his contribution of stating assumptions) and use a system from someone else (as von Neumann and Morgenstern ([1944] 2007) or Marschak (1950)). Lastly, he could skip Nash's system —in that case, he would cite him only for other purposes. Citations Nash (1950a) received between 1950 and 1954 show all the economists who used it fell on that last category: other references everywhere superseded his systematization of individual behavior. Two authors (disregarding Nash (1953)) developed models requiring addressing of how individuals behave in an uncertain environment. They were Hildreth (1953) and Pen (1952). In those cases, Nash drew attention by his way to treat bargaining only. ${ }^{13}$

Hildreth (1953) (who Chapter 2 already discussed due to his citation to Marschak (1950)) was interested in collective decision-making. He suggested axioms to ground individual behavior, being largely inspired by Marschak (1950) and Arrow (1951b). Instead of facing Nash's system as on par with Marschak's, Hildreth (1953, pp. 86-87) summoned Nash (1950a) only when discussing desirable properties for social orders. For him, supposing a collective ranking of alternatives was complete could imply a conflict with "the realization of strongly held ethical values". Hildreth (1953, p. 87) only hinted a way out would be Nash's "method for making a choice from any of a suitably general class of achievable sets". In turn, Jan Pen, then an economist at the Ministry of Economic Affairs in the Netherlands, was developing his bargaining model and, similarly to Nash (1950a), required some device to represent individual preferences. Since he knew Nash's article, a way out was to rely on it. However, Pen (1952, p. 27) decided to use "ophelimity functions", resurrecting for unexplained reasons a terminology dating back to Pareto ([1909] 1971), that economists broadly used before ordinal representations became dominant. Because he cited no other references on that point, be it of ordinal or non-ordinal nature, and dispensed properties of uniqueness (which would reveal more of his approach or nomenclature picking), it is not immediately clear what he intended. ${ }^{14}$ However, it is explicit that he rejected expected utility theory as a valid approach to uncertainty.

Similarly to Hildreth (1953), Pen also cited Nash (1950a) for his way out of the problem of modeling a bargaining process. However, Pen (1952, p. 24) referenced it in a critical tone, claiming: "Until recently, economic science did not include a theory of

\footnotetext{
${ }^{13}$ Naturally Nash (1950a) would find use in problems of bargaining more easily as his axiomatization of individual-decision making was not completed by a proof. However, consider von Neumann and Morgenstern's case: albeit they focused on building economics a new foundation through game theory, what captivated economists was its escape from non-ordinal utility functions. Not necessarily because individual choice under uncertainty was a secondary point for Nash it would be so for those who read his text.

${ }^{14}$ Pen $(1952$, p. 27$)$ mentioned he could use profits instead of ophemilities, which gives a hint he had a non-ordinal representation in mind.
} 
bargaining." For him, economists failed to obtain determinate solutions for equilibrium prices in a bargaining process. Further, he argued: "This indeterminateness is not a characteristic of the price in itself (as is conceded by some of the economists listed above), but is a consequence of the inadequate theories of bilateral monopoly", and accepting it as part of economic science was similar to "submit to agnosticism". For him, reasoning by arguments borrowed from other fields (such as psychology) to obtain solution determination was an unfair approach since "the tasks of economics is to elucidate the relation between the price and the psychological factors (the latter being known as data)". Pen (1952, p. 25) felt theories backed by "special premises" to model behavior were of "minor importance". Among these, he cited von Neumann and Morgenstern ([1944] 2007) because of their use of "rational conduct, neutral risk valuation, perfect insights". In a footnote, he added Nash (1950a) to the bundle of unimportant works, claiming: "This author also presupposes equal bargaining skill, whereby interesting aspects of the problem are left out of the picture."

Even if Nash's axiomatic system grounding choice under uncertainty found no immediate use among economists, they perceived Nash (1950a) as part of economics although its bargaining model left no room for actual bargaining. Regardless that Nash (1950a) had not described how bargainings occur, economists considered his approach to be traditional because it was a constrained maximization problem. Therefore views of how Nash (1950a) could be in conflict. For instance, Henderson (1954, pp. 566-567) argued by mid-1950s there were two "modern lines of solution" of duopoly models leading to profit maximization: theorists could describe imperfect competition via game theory, which had "provided the stimulus to a re-examination of duopoly without contributing directly to the solution", or stick to "the traditional approach to the problem", what meant stating a maximization problem disregarding coalition formation. If an economist wanted definite results, there was no choice: he should go for traditional approaches. In Henderson's argument, Nash (1950a) belonged to tradition even if his symmetry axiom heavily circumscribed his results. In turn, Hurwicz (1953, pp. 403-404) felt games where players could communicate constituted a field with many unexplored results due to its "complexity;" here is were he fitted Nash (1950a) as a typical example. Therefore economists immediately interpreted Nash (1950a) as simultaneously part of a traditional approach to economics and the frontier of game theory. That ambiguous view follows from how Nash misfitted in the traditional image of economics, as he fundamentally departed from how economists modeled the equilibrium concept.

Treating problems of decision-making by axiomatically building a solution was not a stabilized practice among economists at mid-1950s. Therefore, there was no consensual view of how should economists carry out axiomatizations. This circumstance is related to Nash (1950a). In particular, Hurwicz (1953) discusses such subject (although he did not target Nash specifically). Hurwicz (1953, p. 401) interpreted von Neumann and Morgenstern ([1944] 2007) enriched imperfect competition theory by considering "the possibility of 
coalitions, threats, and compensations" outside two-person games. An outgrowth of the Theory of Games would focus on a class of simpler games, where players had no intercommunication possibilities: for Hurwicz (1953, p. 401), Nash (1950b) and Nash (1951) were examples of such type of inquiry. In these, Nash studied non-zero-sum two-person and n-person games. Hurwicz (1953, p. 401) criticized them because they lacked a feature von Neumann's zero-sum two-person games had: "two minimax strategies 'meet' at a 'saddlepoint,' the important implication being that when one of the players uses his minimax strategy, the other player cannot do any better than to use his minimax strategy." The Theory of Games had a good mesh of rationality (understood as specifying some behavior rule for agents) and solution stability (interpreted as once reached, individuals would not find rational reasons to search for another equilibrium) for Hurwicz. In contrast, Hurwicz (1953, pp. 401-402) interpreted Nash's approach required "sacrifice at least one of these two features:" in particular, Nash favored stability over rationality. Hurwicz positioned himself against that choice. Clearly, Nash (1950a) was subject to similar criticism. His way of finding an equilibrium did not go in line with von Neumann and Morgenstern ([1944] 2007), letting agents meet at a solution. Instead, Nash (1950a) postulated desirable equilibrium properties and disregarded any interactions needed to achieve such solutions. ${ }^{15}$

The present writer's inclination is to question the advisability of seeking solutions possessing the required equilibrium properties but sacrificing the rationality of behavior. To see the disadvantage of the equilibrium approach one only has to visualize an individual who is inclined to follow the maximin principle when faced by uncertainty situations. Such an individual (let us call him $A$ ) would be disinclined to count on the likelihood of his opponent $B$ adopting (or retaining) his Nash strategy, since he $(A)$ might suffer considerable losses were $B$ (for whatever reasons) to follow some strategy other than that corresponding to the Nash equilibrium point.

One might, therefore, argue that in a two-person (or many-person) game without communication (Nash's nonco-operative game) each player should simply follow his usual uncertainty behavior principle (whether it be maximin, maximax, or anything else), subject to taking into account such information as he believes to have about his opponent's probable behavior. [...] Of course this would not, in general, result in a Nash equilibrium point. However, the situation obtained would be one of equilibrium nature if the players are genuinely attached to the uncertainty behavior principle being followed. Hurwicz (1953, p. 402)

To conclude, Nash (1950a) provided yet another reformulation of the Theory of Games' axiomatics for expected utility theory. Unlike Marschak (1950) and Hurwicz (1953), Nash abstained himself from writing down proofs; he only stated a set of premises

\footnotetext{
${ }^{15}$ Henderson (1954) also cited Nash (1951) to criticize his solution concept. Henderson (1954, p. 571572 ) understood it as emerging when any agent "maximize his profit for any given policy of the other". Furthermore, he argued: "The difficulty is that both parties can do much better, and there is no reason to doubt that they will realize this". His critique opposed to that of Hurwicz's. It is more about Nash's choice to rule out communication than how he opted to solve his problem.
} 
needed to imply existence and uniqueness of expected utility functions. Citations he received up to 1954 focused on his arguments concerning bargaining theory: economists did not perceive Nash (1950a) as a reference in expected utility theory, nor was his formulation of the independence axiom acknowledged. However, while Nash (1950a) did not act as to disseminate the Theory of Games' approach to choice under uncertainty, he certainly had brought burning questions concerning axiomatics. In particular, his way of reaching an equilibrium disregarding a fuller description of how agents end in a solution raised a controversy among economists. Turning to Samuelson's contribution can help understanding how the independence axiom passed unnoticed in Marschak (1950) and Nash (1950a). This is what Section 3.2 does.

\subsection{SAMUELSON BETWEEN REJECTION AND AFFINITY}

Marschak (1950) and Nash (1950a) first stated that an independence condition for preferences, but they did not emphasize its importance for expected utility theory, nor they pointed out that the Theory of Games lacked such an assumption. Because Samuelson (1952) criticized von Neumann and Morgenstern ([1944] 2007) for not showing that hypothesis explicitly and trying to put a magnifier on their axioms, it is reasonable to interpret that he discovered the independence axiom. In 1965, Samuelson ([1950] 1966a, p. 124) argued that most economists would agree with him that: "von Neumann and Morgenstern inadvertently slipped the important Independence Axiom into their 'zeroth axiom' by which the entities of their system are defined." ${ }^{16}$ In opposition, von Neumann and Morgenstern ([1944] 2007, p. viii) defended their axiomatic system was flawless. If historians of economics had already studied such tale (inquiring how Samuelson became aware of that problem and eventually came to solve it; see Fishburn and Wakker (1995) and Moscati (2016)), it is not clear how such a contribution was useful for economics and how it participated in disseminating the Theory of Games' approach to choice under uncertainty. ${ }^{17}$

That controversy between von Neumann and Morgenstern ([1944] 2007) and Samuelson is the main topic of this section. While other contributions this dissertation discussed so far-Marschak (1950), Nash (1950a), and Herstein and Milnor (1953)-reshaped the Theory of Games' system and produced equivalent results and simpler proofs, they did not explain how their assumptions related to those of the Theory of Games. Subsection 3.2.1 will put Samuelson (1952) in context, explaining how he became aware of a missing

\footnotetext{
${ }^{16}$ To clear any confusions, Samuelson had his article of 1950 reprinted in a book dated of 1966 . In turn, that new issue had a postscript that Samuelson wrote in 1965.

${ }^{17}$ The history of the independence axiom have more interesting and unexplored details. For instance, there is no account explaining how the versions proposed by Marschak (1950), Nash (1950a), and Samuelson (1952) came to assume the form we study today in textbooks. Unfortunately, such a point is out of the scope of this dissertation.
} 
axiom in von Neumann and Morgenstern ([1944] 2007) and how he formulated his answer to that. This is important to understand how different his contribution was compared to Marschak (1950), Nash (1950a), and Herstein and Milnor (1953), and how it could act as a dispersal instrument for the Theory of Games. Subsection 3.2.2 investigates how economists reacted to Samuelson's contribution. As it will show, his Econometrica article received no significant citations. However, other materials can help explain how such an important argument passed unnoticed by economists. ${ }^{18}$

\subsubsection{SAMUELSON'S PUZZLE: WHERE IS INDEPENDENCE?}

Samuelson's journey in attacking and accepting expected utility theory started in a paper published in Keizai Kenkyu (The Economic Review-Japanese), where he rebuffered non-ordinal representations of preferences (as that offered by the Theory of Games). Samuelson ([1950] 1966a, p. 117) sustained: "To the modern theorist cardinal utility is irrelevant both for the positive explanation of demand behavior and for normative welfare economics." Non-ordinal utility functions antedated to Daniel Bernoulli and Alfred Marshall, yet Samuelson remarked its modern references were Friedman and Savage (1948) and von Neumann and Morgenstern ([1944] 2007) (commended for giving "the theory a rigorous axiomatic basis"). To demonstrate such inappropriateness, Samuelson ([1950] 1966a, p. 118) tried to show theories as the Theory of Games's had "arbitrariness at the logical level". Furthermore, he felt resurrecting cardinal utility could undesirably reshape economists' conception of rationality by "completely tautological semantic results", that is, by claiming an individual is rational because, by definition, to be rational is to behave in accordance to expected utility theory.

Samuelson ([1950] 1966a, pp. 119-120) considered a set of complete and transitive preferences entailing a set of ordinal indexes subject to comparison through standard, ordinal utility functions to build his argument. Transitioning from choice over certain bundles to that over risky alternatives would require additional hypotheses. A reasonable assumption in such field would be, for example, that individuals get better if monetary lottery prizes increase or if likelihoods change as to favor outcomes of greater gains. As Moscati (2016, p. 228) discussed, such an assumption resembles first-order stochastic dominance. ${ }^{19}$ However, Samuelson's intention was not to construct an adequate (by his

\footnotetext{
${ }^{18}$ Again, see Moscati (2016) for a narrative on Samuelson's rejection and acceptance of von Neumann and Morgenstern's axiomatic expected utility theory. The focus here is on how other economists reacted to Samuelson's participation in spreading the Theory of Games' approach to decision-making under uncertainty.

${ }^{19}$ Following Mas-Colell, Whinston and Green (1995, p. 195), a probability distribution (of monetary gains) $F$ first-order stochastically dominates $G$ if, for every increasing function $u: \mathbb{R} \rightarrow \mathbb{R}$,
}

$$
\int_{\mathbb{R}} u(x) \mathrm{d} F(x) \geq \int_{\mathbb{R}} u(x) \mathrm{d} G(x)
$$


standards) axiomatic system governing decision-making under uncertainty. Instead, his suggested axiom was an example of a reasonable postulate compared to others proposed by defenders of non-ordinal utility functions. In special, Samuelson ([1950] 1966a, p. 119) was concerned that von Neumann and Morgenstern ([1944] 2007) had a "not-easily-recognized special arbitrary assumption"-Samuelson was not sure of how their axioms, seemingly in accordance to his view of how economists should understand utility, lead to a non-ordinal representation. Since their assumptions were still obscure for him, he opted to attack their results. What particularly called his attention was that, in expected utility theory, "all of the [indifference] surfaces everywhere can be determined by heroic extrapolation, from the behavior of their partial derivatives upon an arbitrary curve in space". As Marschak (1950) discussed, utility functions under an expected utility framework were unique up to positive affine transformations. Hence given two arbitrary constants of intercept and slope, its functional form could be completely pinned down. Further, individuals could decide among any lotteries, regardless of their complexity, if they knew how to rank certain outcomes. Such powerful claims were far too much to request from individuals; and for Samuelson, implications sufficed to show the theory's so-called arbitrariness:

In my judgment this is nonsense. The most rational man I ever met,
whom I shall call Ysidro, determined his own ordinal preference pattern.
$[\ldots .$.
$[\ldots]$ When told that he [Ysidro] did not satisfy all of the v. Neumann-
Morgenstern axioms, he replied that he thought it more rational to satisfy
his preferences and let the axioms satisfy themselves. Once the empirical
implications of the v. Neumann-Morgenstern axioms are understood,
their arbitrariness and that of the Bernoulli-Marshall theory stands
revealed. (SAMUELSON, [1950] 1966a, pp. 118-119)

Although Samuelson ([1950] 1966a) opposed to von Neumann and Morgenstern's approach to preference representation based on its derived properties, he felt no clear uneasiness against their axioms. Samuelson ([1950] 1966a, pp. 121-122) rightfully sensed Friedman and Savage (1948) was not truly equivalent to the Theory of Games. However, building a formal argument showing so was out of his reach due to his puzzlement over the Theory of Games' axioms and proofs - indeed, instead of firmly stating that Friedman and Savage (1948) made a mistake, Samuelson ([1950] 1966a, p. 121) declared himself "confused" since "so many eminent mathematicians and economists rarely go wrong in the field of pure deduction". Nonetheless, his intuition was right. Friedman and Savage (1948, pp. 287-288) supposed a "consumer unit" behaved "as if (a) it had a consistent set of preferences; (b) these preferences could be completely described by a function attaching a numerical value - to be designated 'utility' - to alternatives each of which is regarded as certain; (c) its objective were [sic] to make its expected utility as large as possible". For them, these hypotheses were tantamount to the Theory of Games' axioms. Supported by Samuelson's correspondence (mainly with Savage), Moscati (2016, p. 224) showed Savage 
would recognize his mistake already in 1950: his and Friedman's system was not equivalent to von Neumann and Morgenstern's, nor it implied expected utility theory. Samuelson's clue to detect a possible false equivalence was his personal view of what configures an acceptable way to hypothesize rational behavior: for Samuelson ([1950] 1966a, p. 122), Friedman and Savage's axioms seemed "completely arbitrary and inadmissible" whereas von Neumann and Morgenstern's appeared to be "quite acceptable and rather harmless". Consequently, they could not be equivalent.

Apart from Friedman and Savage's mistake, another query remained: Samuelson ([1950] 1966a, p. 122) was stroked by how the Theory of Games' axioms, seemingly acceptable because they appeared in accordance to ordinal preference representations, resulted in a utility function unique up to positive affine transformations only; it was widespread knowledge among economists ordinal utilities should be invariant to any increasing monotonic transformation. That fact led him to another guess, as Samuelson ([1950] 1966a, p. 122) stated that: "the authors of the Theory of Games deceived themselves as to the inevitability of their demonstration of the measurability of utility". Possibilities were twofold: either von Neumann and Morgenstern committed a logical misstep in their reasoning or they "implicitly added a hidden and unacceptable premise to their axioms". Samuelson's answer, although partial, would come quickly: Moscati (2016, pp. 222-223) showed by May 5, 1950 he completed a RAND Research Memorandum entitled "Measurement of Utility Reformulated" where he revealed such hidden premise and christened it "Special Independence Assumption", where the adjective "Special" had an intentional belittling interpretation as he was a staunch defender of ordinalism. ${ }^{20}$ By then, Samuelson was unaware of previous, equivalent formulations, as Marschak (1950) and Nash (1950a), but would soon come to know them. However, formulating a version of independence condition was not enough for his argument: to demonstrate von Neumann and Morgenstern had slipped in the "Special Independence Assumption", Samuelson still needed to find where they did so.

Still having an open question to address, Samuelson would bring his query in his luggage to Paris, where he attended to a conference held on 12-17 May 1992, entitled "Fondements et Applications de la Théorie du Risque en Économétrie". ${ }^{21}$ There Samuelson presented a working paper entitled "Utilité, Préferénce et Probabilité", later translated to English. ${ }^{22}$ It served as the basis for a Econometrica article of 1952, published alongside contributions of other authors who also discussed independence at Paris. There are no

\footnotetext{
${ }^{20}$ Unfortunately, this dissertation did not have access to Samuelson's memorandum. Moscati (2016, pp. 223) stated he formulated his axiom in terms of indifference, affirming for $L_{1}, L_{2} \in \mathscr{L}$ such that $L_{1}$ i $L_{2}$, then for any $L_{3} \in \mathscr{L}$ and any $\alpha \in(0,1)$ it would be true that $\left[\alpha L_{1}+(1-\alpha) L_{3}\right] \mathfrak{i}\left[\alpha L_{2}+(1-\alpha) L_{3}\right]$ (that is, as Marschak (1950) did).

${ }^{21}$ The Centre National de la Recherche Scientifique organized the conference Fondements et Applications de la Théorie du Risque en Économétrie.

${ }^{22}$ The reference this dissertation uses is the translation.
} 
substantial differences among his Paris and Econometrica texts. Samuelson ([1950] 1966b, pp. 128-129) claimed that "through the patient good offices of Savage" his opposition presented in his Japanese paper had changed, but not vanished altogether: "Even since I have become sympathetic toward the theory, I have not been able to find any confirmation of the theory's aspects that are special and (therefore) interesting." ${ }^{23}$ Besides a natural skepticism toward empirical usability (since it had not undergone extensive testing by then), his apprehension was not restricted to an empiric issue: "as yet, I have not seen any demonstration of the theory's normative properties." Samuelson ([1950] 1966b, pp. 128-129) felt any normative arguments in favor of expected utility theory fell under petitio principii, unreasonably forcing people to be immensely "consistent" or "elegant", or had their backs on limiting theorems. On its deductive side, where "good mathematical analysis should remove all disagreements", Samuelson still had his main puzzle since it seemed "to remain something of a shroud of mystery about the interpretation of the NeumannMorgenstern axiomatic system". ${ }^{24}$ In his words, it was a "scandal:" while Marschak (1950), Nash (1950a), and Samuelson (1952) himself rewrote all the axiomatics resorting to a "strong independence assumption", no one could pinpoint an equivalent hypothesis in the Theory of Games' system. Samuelson hinted for other members at the conference he believed von Neumann hid something in his "preliminary entities and concepts". That guess was correct, as Malinvaud (1952) would formally show at Paris (see Subsection $3.2 \cdot 2)$.

Once stripped of any empirical, normative, or deductive value for economics, Samuelson ([1950] 1966b, p. 130) remarked what made him sympathetic toward expected utility was its significance "of an aesthetic and semantic character". Albeit not clear, his surrender came by his acceptance of independence as a "natural if not inevitable" axiom in the realm of stochastic choice regardless of its implications for decision-making over certain alternatives. Moscati (2016, pp. 221-222) showed his yield followed an argument posed by Savage in letters they exchanged from May to September on 1950. A crucial point here is how Samuelson dissociated independence from non-risky choices, as his precedent arguments usually took ordinal representations as a benchmark to compare against von Neumann and Morgenstern ([1944] 2007) (and similar works standing for a non-ordinal preference representation). His opinion changed as he modified his rule for determining what is acceptable in choice under uncertainty. Indeed, in his Econometrica article of 1952 he presented an argument defending it in terms of reasonableness, the same value he used

\footnotetext{
${ }^{23}$ Samuelson ([1950] 1966b, p. 128) added: "In saying this I am not using the perfectionist standards by which we could easily discredit any part of economic theory - such as the theory of nonstochastic indifference curves, or the maximization of profits. I am making all the generous allowances and abstractions that are needed to leave those theories with a residue of explanatory interest."

${ }^{24}$ Moscati (2016) showed how Friedman, Savage, and Samuelson accepted expected utility theory for their particular reasons. For instance, he argued that Friedman accepted it because he thought it was empirically valid, while Marschak accepted it because of its underlying axiomatic system was normative appealing. Moscati's point focus on Samuelson's path to accepting it.
} 
to attack it before.

Samuelson ([1950] 1966b, pp. 132-134) proposed an axiomatic system assuming a preference relation completely ordered an agent's lottery space (plus unstated "minimum continuity assumptions") and his independence condition. He explained it literary: "using the same probability to combine each of two prizes with a third prize should not have 'contaminating' effects upon the ordering of those two original prizes." Consider $L_{1}, L_{2}, L_{3} \in$ $\mathscr{L}$ such that $L_{1} \mathfrak{g} L_{2}$ and some $\alpha \in(0,1) .{ }^{25}$ He intuitively argued a mix $\left[\alpha L_{1}+(1-\alpha) L_{3}\right]$ should be preferred to $\left[\alpha L_{2}+(1-\alpha) L_{3}\right]$ by differentiating two scenarios. First, suppose the event of probability $\alpha$ occurred. Then because $L_{1}$ is preferred, the first mix would be more desirable among both. Second, if the event of likelihood $1-\alpha$ occurred, then the individual would get $L_{3}$ in both mixes, so what $L_{3}$ was chosen specifically did not matter for ranking preferences over combinations of lotteries. Hence $\left[\alpha L_{1}+(1-\alpha) L_{3}\right] \mathfrak{g}\left[\alpha L_{2}+(1-\alpha) L_{3}\right]$ because the first mix would offer some advantage in at least one state of nature and be equivalent in others. Although Samuelson was not the first to develop the independence axiom - as seem before, Marschak (1950) and Nash (1950a) previously accomplished it-, his article was the first to emphasize it in discussing decision-making under uncertainty as a crucial ingredient of expected utility theory. However, his contribution would not (at least immediately) become a standard reference for economists, as Subsection 3.2.2 shows.

To conclude, previous contributions (such as Marschak (1950) and Nash (1950a)) that outgrew of von Neumann and Morgenstern ([1944] 2007) overlooked an important point of expected utility theory that: the independence axiom is a necessary condition to establish it, even if they formulated a version of that assumption. More importantly, the Theory of Games had no such a hypothesis in explicit form in its axiomatic system for choice under uncertainty. Samuelson queried where von Neumann and Morgenstern ([1944] 2007) hid it, although he lacked means to properly investigate that matter (not only Samuelson had difficulties with von Neumann's premises and proofs, but the subject was overly technical for most economists). While Malinvaud (1952) would present a solution for that puzzle, it remains unexplored in the history of economics how independence played through Samuelson (1952) and Malinvaud (1952) a role of dispersing the Theory of Games' approach to choice under uncertainty. Subsection 3.2.2 investigates that.

\subsubsection{HOW ECONOMISTS REACTED TO SAMUELSON}

Economists found no immediate use (until 1954) for Samuelson (1952). Its received citations were fairly general, having no sign of in-depth discussion or practical uses of independence as formulated by him. For instance, a representative of such references is Edwards (1954, p. 392) who stated in a survey of decision theory: "a number of axiom systems, differing from von Neumann and Morgenstern's but leading to the same result, have been

\footnotetext{
${ }^{25}$ As usual, $\mathfrak{g}$ is a binary relation standing for "at least as good as" and $\mathscr{L}$ is a lottery space.
} 
developed." Among these, he included Marschak (1950) and Herstein and Milnor (1953), but not Nash (1950a). Additionally, he also commented other complex discussions that followed such reshaping of the Theory of Games' axiomatics, even if an in-depth analysis of them was out of scope for his survey. He cited Samuelson (1952) among these, alongside Malinvaud (1952) and every other contribution in that Econometrica number related to the conference "Fondements et Applications de la Théorie du Risque en Économétrie". ${ }^{26}$ An extended analysis of Samuelson's citations until 1960 showed only Harvey M. Wagner, then a Ph.D. student at the Massachusetts Institute of Technology mentioned the independence axiom in particular. ${ }^{27}$ It is important to refresh Herstein and Milnor (1953) appeared in Econometrica six months later than Samuelson (1952) and had citations until 1954 applying it in the development of new, original research. Therefore Samuelson's scarcity of meaningful citations does not follow from this dissertation's methodological restrictions (particularly, of tracking citations until 1954). The proceedings from Économétrie XL, the before mentioned Paris conference, can base an account explaining how his contribution remained unused during the $1950 \mathrm{~s}^{28,29}$

After Maurice Allais presented a working paper entitled "Fondements d'une Théorie Positive des Choix Comportant un Risque" and Samuelson his "Utilité, Préférence et Probabilité", Économétrie XL's participants started an intense and rather erratic debate. ${ }^{30}$ For example, Pierre B. D. Massé argued that "Le Point Essentiel des théories développées jusqu'à présent est le caractère d'additivité ou de linéarité des formules obtenues: on se sert de l'espérance mathématique de quelque chose", ${ }^{31}$ with no explicit discussion of Samuelson's main point: the independence axiom's adequacy in economic theory and its counterpart in von Neumann and Morgentern's version. Any critical appraisal of expected utility theory could seize its underlying axioms or conclusions. However, what was a definition, a theorem, or a premise varied in different interpretations and formulations. For instance, Massé noted von Neumann and Morgenstern ([1944] 2007) started from axioms and reached a

\footnotetext{
${ }^{26}$ Alchian (1953, p. 32) used Malinvaud (1952) and Samuelson (1952) (and all articles on Econometrica 52 which touched on the colloquium) in a footnote after commenting utility is a "numerical magnitude" attached to "entities", which could be "any specifiable object, action, event, or set or pattern of such items or actions". Another example of how lightly citations to Samuelson (1952) were is Coombs and Beardslee (1954, pp. 255-256), who referenced it on a list of recent works on "The problem of the measurement of utilities and psychological probabilities" without discussing it any further.

${ }^{27}$ See Wagner $(1957,1958)$.

${ }^{28}$ These comments on Samuelson's reception also apply to Malinvaud (1952).

${ }^{29}$ Unfortunately, the proceedings from Économétrie $X L$ are available only in French. Every quote from the Centre National de la Recherche Scientifique (1952) will have a free translation for expository purposes.

${ }^{30}$ This section will not cover Allais' working paper nor particular critiques it received at Économétrie $X L$ since it does not have a direct connection with Samuelson's problem. His point was to challenge expected utility in empirical grounds. For a discussion of how that dimension of the dissemination of expected utility theory's dissemination in economics, see Moscati (2017) (who argues that economists accumulated evidences against expected utility up to 1985, yet it remained a core component of economic theory).

31"The essential point of the theories developed so far is the additive or linear characteristics of the obtained formulas: we use the mathematical expectation of something".
} 
real-valued function representing preferences. In turn, Allais's approach commenced from the existence of an expected utility function to discuss, based on it, if its fundamental axioms held empirically. ${ }^{32}$ While Massé himself did not develop further this point, he felt linearity was, as a property, "excessivement restrictif:"33 "Il est extraordinaire que le comportement d'un individu en toute circonstance convenable se déduise d'un aussi petit nombre d'observations." 34 This point likely referred to how expected utility required only an individual evaluation of certain outcomes to resolve decision over any gambles, no matter how complex they were, or how only two numerical assignments were sufficient to pin down the utility function (each referring to the utility function's intercept and slope). ${ }^{35}$

Massé's speak brought up an interesting point: economists had different ways to assess an axiomatic contribution to economic theory. Discussions of Samuelson's paper show how such practices were not stabilized yet among economists. In particular, interventions from Marschak, Allais, and Guilbaud ${ }^{36}$ demonstrated how complicated it was to weight positive and normative arguments, and how economists diverged in judging if a system should have its value measured by single, isolated axioms or by what they could produce as a whole. Marschak started his commentary by expressing that he felt some people - without naming any of his peers - confounded mixing goods and mixing lotteries: the linearity in the expected utility function was not related to an additive separable utility function defined over certain outcomes of goods and services, which economists associated with cardinalism before they stabilized preference representation as an ordinal property. Even corrected any misconceptions, he added: "on doit reconnaître que certains des axiomes de Neumann ou Savage peuvent apparaître trop forts." 37

To illustrate, Marschak presented a piece of anecdotal evidence. Robert Thrall, an economist from the University of Michigan, refused to accept preference continuity as an axiom. He grounded his refusal on an example. Consider three particular outcomes arranged in ascending preferability: be hanged, receive one match, or receive two matches. Thrall questioned if any individual would find a probability specifying a gamble resulting in either hanging or receiving two matches that would be equally desirable as a certain prize of just one match. For him, no rational person would agree to such a risk for such an insignificant award. In particular, that argument amounted to stating under certain situations, preferences mimic a dictionary, like the case of lexicographic preferences (since a chance of death would always be worse than no chance at all). Marschak questioned if economic theory truly needed such generalizations. In a view favoring a descriptive

\footnotetext{
${ }^{32}$ See Allais (1953) for a similar approach.

33 "Excessively restrictive".

34 "It is extraordinary that one individual's behavior is, in any circumstances, conveniently deduced from a small number of observations".

${ }^{35}$ See Centre National de la Recherche Scientifique (1952, pp. 150-151).

${ }^{36}$ See Centre National de la Recherche Scientifique (1952, pp. 151-153).

37 "We must recognize that some of the axioms of Neumann or Savage may appear too strong."
} 
theory, answering Thrall's question would be desirable because theory should fit observed behavior under any circumstances. However, facing expected utility theory as a set of normative statements, Marschak felt that Thrall's case was irrelevant: expected utility theory was too "naturel et simple" 38 for economists to abandon due to such arguments, especially considering how its mathematics for analyzing stocks, games and organizations were already far too complicated (and satisfying Thrall's demand of dismissing preference continuity would likely render them even more convoluted). Therefore, in Marschak's view, economists should not reject expected utility based on extreme examples because of its normative significance and mathematical tractability outweighed any such problems as Thrall's.

In turn, Allais retorted the fundamental problem in the axiomatics of expected utility was not continuity, as if Marschak was attacking a straw man, or merely avoiding its real issues - indeed, Samuelson's reasoning had no complaints about continuity. Until Allais' intervention, no discussant spoke specifically of the independence axiom, of which he remarked: "A mon avis, d'un point de vue rationnel, ils doivent précisément être rejetés." He argued that a real person would not fit expected utility's axioms, and hence they should be rejected. Allais also applied this critique to Marschak's utility, that for him had "un inconvénient considérable: c'est, en général, de ne pas exister" 40 since its existence, sustained only upon a logical reasoning over a set of axioms, relied on "éminemment discutable" 41 premises unjustified by heuristic or empiric facts. This commitment of sticking to reality ensued from Allais' view of science, which should always aim at prediction: the subject matter of choice under uncertainty was to analyze the behavior of real individuals and normative value or mathematical simplicity could under no circumstances overrule data fit. Guilbaud entered the discussion by questioning if it was right to focus arguments on one isolated axiom, debating if it was reasonable or not, instead of its consequences and usefulness for practical scientific research. Allais had a harsh reaction, responding his point was simple, and economists should ask themselves if truly rational men behave under expected utility. Additionally, he argued such question had only two possible answers-yes or no: "Se refuser à donner une réponse ne me paraît pas une position scientifiquement acceptable." 42,43

Regardless of personal understandings of what is fundamental and subsidiary in explaining behavior under uncertainty, Bruno de Finetti argued expected utility theory's path to move forward its criticism was twofold: economists could modify its foundations

\footnotetext{
38"Natural and simple".

39 "In my opinion, from a rational point of view, they must precisely be rejected". Allais spoke in the plural because he was referencing "les axiomes fondamentaux de substitution, ou d'indépendance" ("the fundamental axioms of substitution, or independence"). His rejection particularly aimed it.

40 "A considerable inconvenience: that of, in general, not existing".

41 "Eminently disputable".

42 "Refusing to answer does not seem to me to be a scientifically acceptable position".

${ }^{43}$ See Centre National de la Recherche Scientifique (1952, pp. 153-155).
} 
or try to adjoin complementary explanations as to overcome problematic cases, as Thrall's argument against continuity. In response, Allais clarified he was not troubled by any possible logical inconsistency axiomatic systems for expected utility could have, but how they seemed to be stealthily reshaping what rationality was. For him, to argue that a rational individual should conform to one axiom because it is the definition of rationality seemed a tautology devoid of any scientific value: if expected utility is to redefine such an elementary concept as rationality, it was a task (still unaccomplished) of its defenders to demonstrate how rational their axioms were. Further, if only coherence served as a rule to demonstrate rationality, then he felt the independence axiom was not a proper premise since it appeared to contain something beyond than just coherent behavior. Here it is possible Allais referred to Samuelson's suspicions thrown over the Theory of Games' axiomatics. The discussions at Paris seemed to put Samuelson's main question - to find where von Neumann and Morgenstern hid their independence assumption-aside; several theoretical and empirical problems, perhaps more urgent, overrode it. Was it not the case, participants would have shown at least a minimal attention to Samuelson's particular problem of identifying the independence version of von Neumann and Morgenstern ([1944] 2007). Only one discussant tackled that query directly. He was the last to join the debate. ${ }^{44}$

Edmond Malinvaud, a French economist who was a guest at Cowles during 1950-51, found an answer to Samuelson's puzzle. His argument, later published in Econometrica alongside Samuelson's published version of his Paris working paper, showed where the Theory of Games hid the independence axiom. Malinvaud (1952, p. 679) observed from von Neumann's "heuristic comments" that his operation of mixing "entities" was written in terms of "equivalence classes". That is, in the Theory of Games' notation, $u, v, w \ldots$ were sets comprising indifferent lotteries. So writing $\alpha u+(1-\alpha) v$ denoted not a lottery emerging from a combination of other two, but a subset of $\mathscr{L}$ comprising all lotteries equivalent to such mix. Once interpreted like Malinvaud (1952, p. 679) suggested, independence followed as a consequence: given two equivalent lotteries, mixing them with a third (keeping probabilities fixed) would produce two lotteries in the same equivalence class (indifferent to each other by definition). The widespread confusion happened because von Neumann and Morgenstern ([1944] 2007, p. 26) used "+" and "=" to sum vectors and to combine equivalence sets, although these are different operations. In their words, "We consider a system $U$ of entites $u, v, w, \ldots$ In $U$ a relation is given, $u>v$, and for any number $\alpha$, $(0<\alpha<1)$, an operation

$$
\alpha u+(a-\alpha) v=w^{\prime \prime}
$$

When von Neumann and Morgenstern ([1944] 2007) reused symbols "+" and "=" to mix lotteries, they engaged a practice that is harmless in several contexts. For instance,

\footnotetext{
${ }^{44}$ See Centre National de la Recherche Scientifique (1952, pp. 159-162).
} 
many textbooks in linear algebra use "+" and "=" to sum scalars in a field and to sum vectors in a vector space, even if they are different operations. However, how harmless was such a notation abuse in the Theory of Games is debatable. At any rate, Allais, awarded the Nobel Prize for Economics in 1988, was no regular economist, having meaningfully contributed to "general equilibrium and optimal allocation of resources ('rendement social' or 'efficacité maximale' in Allais' terminology), capital and growth, money and business cycle, and risky choices" (BELLOC; MOREAUX, 2018, pp. 253-256). Still he and other leading names in economic theory - such as Samuelson, Marschak, and Savage - also struggled to understand how von Neumann and Morgenstern ([1944] 2007) used the independence condition for preferences. That problem was not trivial and coexisted with several other competing open questions in theoretical economics (as seen in "Économétrie $X L$ ", there was no consensus on how to judge an axiom, or if axioms should stand scrutiny alone or in group). To understand how Samuelson's Econometrica paper found such a small immediate utility among economists, it is important to recognize the state of mathematical economics in mid-1950s and how well-equipped an "average economist" would be to participate in the discussing of the independence axiom.

Evidence found on Chapter 1 suggested economists could not go so deep into von Neumann and Morgenstern's axiomatics. Indeed, departments in economists had not yet by the mid-1950s adopted training in higher mathematics as a standard part of graduate education. ${ }^{45}$ To give yet another example of how most economists felt uncomfortable reading mathematical research by the mid-1950s, consider a note published in The Economic Journal. This example is interesting because it illustrates how journal editors felt about publishing mathematical articles in economics, focusing on dissemination issues. Harrod, Robinson and Matthews (1954, pp. 1-2) (its editors) observed that after World War II the research output in economics had grown substantially. ${ }^{46}$ Consequently, it required authors to be more concise (apart from the editor's effort in increasing volumes and publishing more articles in each issue). They believed "not more than fifteen pages $[\ldots]$ will enable the author to present his ideas to our readers in as full detail as is necessary". In addressing such problem, Harrod, Robinson and Matthews (1954, pp. 1-2) added a note on mathematical economics, observing an increasing number of economists wished to rely on "the added precision that mathematical argument affords". That posed for them a dissemination issue.

They felt that mathematical tools imposed a barrier for many of their readers. Being journal editors, they argued they had the duty of selecting articles in accordance to the capabilities of the majority their readers: "We suggest that authors should aim at avoiding the use of advanced mathematics, except where it is necessary for supplying a rigorous

\footnotetext{
${ }^{45}$ Again, see Bowen (1953).

${ }^{46}$ The editors who signed that note were Roy F. Harrod and Austin Robinson, editors, besides R. C. O. Matthews (the assistant editor).
} 
proof, or where the nature of the subject inevitably requires." Moreover, mathematicallyskilled authors should state assumptions and conclusions in "ordinary economic language" as well. Therefore central papers in disseminating von Neumann and Morgenstern's book, as Marschak (1950), Nash (1950a), Samuelson (1952), and Herstein and Milnor (1953), would find a hard way publishing their works at the Economic Journal. Furthermore, if they did, they would reach a majority of mathematically unskilled economists. Given such a public, it is hard to argue that many economists would be able to understand Samuelson's issue with independence (and even less would have the expertise to attempt a solution).

To conclude, evidence from Chapter 1 and The Economic Journal show using mathematics in economics was not a stabilized practice - economists had strong disagreements, seeing their field divided into two opposed fields. Besides, even within the small group discussing Samuelson's working paper at Économétrie XL, they disagreed concerning how to weight positive and normative arguments, as well as how to appraise an axiomatic work (for example, as Guilbaud asked if it should focus on single axioms or systems). That turmoil can account for Samuelson's lack of citations. Unlike Marschak (1950) or Nash (1950a), who were relatively more well-cited until mid 1950s, Samuelson's query dug too deep into axiomatics. His interest in how the independence axiom had no explicit counterpart in von Neumann and Morgenstern's system required skilled economists to understand the Theory of Games' section and appendix about utility and be able to map Samuelson's formula to it. While Marschak's and Nash's articles also were full of technical details, their discussions were more accessible. For example, a literary economist could skip Marschak's proofs and study his verbal statements on how utility was unique up to positive affine transformations. The subject Marschak covered would likely remind economists of earlier discussions in the 1920s and 1930s - that had many verbal contributions - on how preference representation needed only to be ordinal. So he would have a background and tools to think over what Marschak was affirming, even if he missed some of his points due to his mathematics. For Nash's article, the same applies as he did not dive in complex mathematics and his topic of choice related to imperfect competition, another familiar topic for literary economists. Readers of Samuelson (1952) would not have that possibility: his subject was altogether technical and consequently left many economists aside.

\subsection{CONCLUDING REMARKS}

The independence axiom is a fundamental ingredient of expected utility theory. Because it is a necessary condition for that approach to choice under uncertainty, it was unavoidable for von Neumann and Morgenstern ([1944] 2007): they needed it in the Theory of Games. However, how they did so was unclear, as Samuelson (1952) pointed out, even if past axiomatic works had stated it explicitly and claimed themselves to follow 
von Neumann and Morgenstern's book. Marschak (1950) and Nash (1950a) were the first who explicitly published versions of the condition that Samuelson (1952) identified. Given that Chapter 2 studied Marschak's reception and found only one mention to its independence condition, Chapter 3 analyzed how economists used other contributions related to it-namely, Nash (1950a) and Samuelson (1952).

Although Nash (1950a) was a pioneer for formulating an independence condition for preferences, such part of his article passed unnoticed by economists interested in individual decision-making over risky alternatives. Nash was the only one who cited his bargaining model for exploring new research possibilities. While it received many citations, they focused on his contributions to bargaining theory despite his formulation of a set of assumptions grounding expected utility. In particular, they questioned his way of axiomatizing how agents interacted in his model. His approach consisted of establishing desirable properties an equilibrium should possess, and neglecting any discussion of how individuals bargained in practice. Consequently, it would be hard to argue that Nash participated in disseminating the Theory of Games' approach to choice under uncertainty among economists until 1954, even if he touched on a critical point in how economists do axiomatic theories.

In turn, Samuelson (1952) certainly acted as a disseminator of von Neumann and Morgenstern ([1944] 2007) by raising a fundamental problem in expected utility theorythat of pinpointing in the Theory of Games an independence assumption. Marschak's and Nash's contribution of enunciating versions of independence remained unacknowledged by economists until 1954. Probably such lack of recognition follows from a simple chronological fact: the lack of an explicit axiom of independence was not a problem until Samuelson made it a problem. Regardless of how essential Samuelson's role was, his contribution passed unnoticed as well. That happened as economics was yet in the transformation to a more mathematical-oriented form. Economists lacked the tools to work over such highly technical issues (as Samuelson's point of finding for each axiom in equivalent systems developed by Nash, Marschak, and others a counterpart in the Theory of Games). Besides, several points in axiomatics lacked stabilization: economists did not have a generally accepted way to appraise an axiomatic contribution, nor have they decided if expected utility theory was an adequate approach to choice under uncertainty. Consequently, other (probably more urgent) issues competed for their attention. 



\section{CONCLUSION}

This dissertation analyzed how economists reacted to the Theory of Games' axiomatic contribution to choice under uncertainty, both directly and indirectly, until 1954. On a first approximation, that narrative relied on book reviews von Neumann and Morgenstern's volume received. Regarding historiography, such assessments are a valuable source for historians to study dissemination. Historians of economics have much to learn about them yet, especially about how economists read and write them. Besides a lack of discussion of such material, there are many different frameworks for historians to analyze book reviews. This dissertation proposed to mesh Corry's images of knowledge and Stapleford's practices to not blindly accept everything economists wrote and to be aware of possible values underlying any statements left in their texts. A first conclusion book reviews enable is that the Theory of Games set up many discussions about what proper definitions of equilibrium are, and how should economists use mathematics in theoretical endeavors.

Concerning axiomatics and expected utility theory, book reviews showed that it is crucial to consider how mathematically-skilled economists used that book in more didactic, less heavy on mathematics, narrower in subject articles to understand the history around von Neumann and Morgenstern's influence on economics. Translations were necessary because most economists lacked tools to fully appreciate von Neumann and Morgenstern's reasoning by the end of the 1940s and mid-1950s. They would help to disperse the Theory of Games approach by verbally and visually reshaping arguments of it, or by focusing on a single subject (such as choice under uncertainty) instead of developing a full, 600-page long new foundation for economics. Apart from book reviews that acted as translators, secondary sources would assume an equal role. In the Cowles Commission, Marschak (1950) and Herstein and Milnor (1953) reformulated von Neumann and Morgenstern's axiomatic system for expected utility theory striving for more straightforward premises and demonstrations.

An analysis of citations that Marschak (1950) and Herstein and Milnor (1953) received until 1954 shows axiomatic expected utility found its way into different areas of economics (such as individual choice among risk-free outcomes and collective decisionmaking). In such unfoldings, using an axiomatic approach was not a rule: many economists cited Marschak (1950) and developed non-mathematically rigorous models. However, clear patterns appeared. Economists who cited Marschak (1950) and Herstein and Milnor (1953) for borrowing or modifying hypotheses worked axiomatically, whereas those who cited them for applying results of existence and uniqueness of expected utility functions adopted less-sophisticated tools and were not proof-driven. Curiously, neither Marschak 
(1950) nor Herstein and Milnor (1953) emphasized the independence axiom's role in their systems. That would be a natural highlight since independence is a necessary premise for expected utility theory. To understand how independence made its way into economics, this dissertation studied the reception of Nash (1950a) and Samuelson (1952).

Nash (1950a) provided yet another formulation for expected utility theory and historians of economics acknowledge him as who discovered the independence axiom alongside Marschak. However, no citation he received until 1954 recognized him as a contribution to choice under uncertainty. Whenever someone who cited Nash needed an approach to individual decision over risky alternatives, other references (such as von Neumann and Morgenstern ([1944] 2007) and Marschak (1950)) always superseded him. Still, Nash had important (and more general) points on axiomatization that deserve further inquiry. As for Samuelson (1952), his primary role was to perceive the Theory of Games had no explicit version of the independence axiom and question (being it a necessary hypothesis) where von Neumann and Morgenstern hid it. That problem would receive an answer at Économetrie $X L$, but proceedings from that conference demonstrate how many other problems economists had with axiomatics and expected utility theory. In particular, economists were not yet comfortable in assessing axioms (questioning, for instance, if they should appraise them individually or only in whole systems), and expected utility's usefulness and validity received much criticism as an accurate description of rationality. An additional conclusion is that economists did not find useful applications for independence once Samuelson's puzzle was over.

This dissertation emphasized how personal values and views of how economics should be as a scientific field acted in economists' reception of the Theory of Games and its approach to individual choice under uncertainty. By the mid-1950s, axiomatic expected utility theory was yet not a stabilized, standard approach to choice under uncertainty among economists; many problems remained open. However, it had already taken its first steps on that journey by 1954 . 


\section{BIBLIOGRAPHY}

ALCHIAN, Armen A. The meaning of utility measurement. The American Economic Review, v. 43, n. 1, p. 26-50, 1953.

ALLAIS, Maurice F. C. Le comportement de l'homme rationnel devant le risque: Critique des postulats et axiomes de l'école américaine. Econometrica, p. 503-546, 1953.

ARROW, Kenneth J. Alternative approaches to the theory of choice in rrisk-taking situations. Econometrica, p. 404-437, 1951.

ARROW, Kenneth J. Social Choice and Individual Values (Monograph No. 12). Chicago, 1951.

ARROW, Kenneth J. Cowles in the history of economic thought. Avaiable at <https://cowles.yale.edu/50th-anniversary-celebration>. Accessed in 29 March, 2019. 1983.

ARROW, Kenneth J.; DEBREU, Gérard. Existence of an equilibrium for a competitive economy. Cowles Commission Discussion Papers, Econ 2082. 1953.

BARNA, Tibor. Review. Economica, v. 13, n. 50, p. 136-138, 1946.

BAUMOL, William J. The Neumann-Morgenstern utility index-an ordinalist view. Journal of Political Economy, v. 59, n. 1, p. 61-66, 1951.

BELLOC, Bernard; MOREAUX, Michel. Allais, Maurice (born 1911). In: MACMILLAN, Palgrave (Ed.). The New Palgrave Dictionary of Economics. London: Palgrave Macmillan, 2018. p. 253-256.

BERNOULLI, Daniel. Exposition of a new theory on the measurement of risk (translated by Louise Sommer). Econometrica, v. 22, n. 1, p. 23-36, 1954.

BLEICHRODT, Han; LI, Chen; MOSCATI, Ivan; WAKKER, Peter P. Nash was a first to axiomatize expected utility. Theory and Decision, v. 3, n. 81, p. 309-312, 2016.

BOUMANS, Marcel; DUPONT-KIEFFER, Ariane. A history of the histories of econometrics. History of Political Economy, v. 43 (Supplement), p. 5-31, 2011.

BOWEN, Howard R. Graduate education in economics. The American Economic Review, v. 43, n. 4, Supplement, p. 1-223, 1953.

Centre National de la Recherche Scientifique. Économetrie XL: Fondements et Applications de la Théorie du Risque en Économétrie. Paris, 1952.

CHERNOFF, Herman. Remarks on a rational selection of a decision function. Cowles Commission Discussion Papers, Sta 326. 1949.

CHERNOFF, Herman. Rational selection of decision functions. Econometrica, v. 22, n. 4, p. $422-443,1954$. 
CHERRIER, Béatrice. Rationalizing human organization in an uncertain world: Jacob Marschak, from ukrainian prisons to behavioral science laboratories. History of Political Economy, v. 42, n. 3, p. 443-467, 2010.

CHRIST, Carl F. History of the Cowles Commission 1932-1952. In: Cowles Commission for Research in Economics (Ed.). A Twenty-Year Research Report, 1932-1952: Economic Theory and Measurement. Maryland: Waverly Press, 1952. p. 3-65.

CHRIST, Carl F.; HURWICZ, Leonid. Koopmans, Tjalling Charles (1910-1985). In:

MACMILLAN, Palgrave (Ed.). The New Palgrave Dictionary of Economics. London:

Palgrave Macmillan, 2018. p. 7346-7354.

COOMBS, Clyde H.; BEARDSLEE, David. On decision making under uncertainty. In: THRALL, Robert M.; COOMBS, Clyde H.; DAVIS, Robert L. (Ed.). Decision Processes. New York: John Wiley \& Sons, 1954. p. 255-286.

COPELAND, Arthur H. Review. Bulletin of the American Mathematical Society, v. 51, n. 7, p. 498-504, 1945.

CORRY, Leo. Linearity and reflexivity in the growth of mathematical knowledge. Science in Context, v. 3, n. 2, p. 409-440, 1989.

CORRY, Leo. Modern Algebra and the Rise of Mathematical Structures. Basel: Springer, [1996] 2004.

Cowles Commission for Research in Economics. Five-Year Report, 1942-1946. Chicago, 1946.

Cowles Commission for Research in Economics. Report for Period January 1, 1948-June 30, 1949. Chicago, 1949.

Cowles Commission for Research in Economics. 19th annual Report, 1950-1951: Rational Decision-Making and Economic Behavior. Chicago, 1951.

Cowles Commission for Research in Economics. A Twenty-Year Research Report, 1932-1952: Economic Theory and Measurement. Chicago, 1952.

DEBREU, Gérard. An economic equilibrium existence theorem. Cowles Commission Discussion Papers, Econ 2032. 1952.

DEBREU, Gérard. Representation of a preference ordering by a numerical function. In: THRALL, Robert M.; COOMBS, Clyde H.; DAVIS, Robert L. (Ed.). Decision Processes. New York: John Wiley \& Sons, 1954. p. 159-165.

DEBREU, Gérard. Valuation equilibrium and pareto optimum. Proceedings of the National Academy of Sciences of the United States of America, v. 40, n. 7, p. 588-592, 1954.

DEBREU, Gérard. Mathematical economics at Cowles. Avaiable at $<$ https://cowles.yale.edu/50th-anniversary-celebration>. Accessed in 29 March, 2019. 1983.

DEMING, William E. Review. Journal of the American Statistical Association, v. 40, n. 230, p. 263-265, 1945. 
DIMAND, Robert W.; DIMAND, Mary A. Von Neumann and Morgenstern in historical perspective. Revue d'économie Politique, v. 105, n. 4, p. 539-557, 1995.

DOEHNE, Malte; HERFELD, Catherine. The diffusion of scientific innovations: A role typology. Studies in History and Philosophy of Science: Part A, p. 1-18, 2018.

EDGEWORTH, Francis Y. Mathematical Psychics: An Essay on the Application of Mathematics to the Moral Sciences. New York: A. M. Kelley, [1881] 1967.

EDWARDS, Ward. The theory of decision making. Psychological Bulletin, v. 51, n. 4, p. 380-417, 1954.

FISHBURN, Peter C.; WAKKER, Peter. The invention of the independence condition for preferences. Management Science, v. 41, n. 7, p. 1130-1144, 1995.

FRIEDMAN, Milton; SAVAGE, Leonard J. The utility analysis of choices involving risk. The Journal of Political Economy, v. 56, n. 4, p. 279-304, 1948.

GIOCOLI, Nicola. Modeling Rational Agents: From Interwar Economics to Early Modem Game Theory. Cheltenham: Edward Elgar Publishing, 2003.

GUILBAUD, Georges-Théodule. The Theory of Games. In: PEACOCK, Alan T. (Ed.). International Economic Papers: Translations Prepared for the International Economic Association. 1. ed. London: Macmillan, [1949] 1951. p. 37-65.

GUMBEL, Emil J. Review. The Annals of the American Academy of Political and Social Science, v. 239, p. 209-210, 1945.

HARRISON, Robert W. Review. v. 27, n. 3, p. 725-726, 1945.

HARROD, Roy F.; ROBINSON, Austin; MATTHEWS, R. C. O. Notice by the editors. The Economic Journal, v. 253, n. 64, p. 1-2, 1954.

HARTLEY, James. Reading and writing book reviews across the disciplines. Journal of the American Society for Information Science and Technology, v. 57, n. 9, p. 1194-1207, 2006.

HAWKINS, David. Review. Philosophy of Science, v. 12, n. 3, p. 221-227, 1945.

HENDERSON, Alexander. The theory of duopoly. The Quarterly Journal of Economics, v. 68, n. 4, p. 565-584, 1954.

HERFELD, Catherine. Between mathematical formalism, normative choice rules, and the behavioural sciences: The emergence of rational choice theories in the late 1940s and early 1950s. The European Journal of the History of Economic Thought, v. 24, n. 6, p. 1277-1317, 2017.

HERFELD, Catherine. From theories of human behavior to rules of rational choice: Tracing a normative turn at the Cowles Commission, 1943-54. History of Political Economy, v. 50, n. 1, p. 1-48, 2018.

HERSTEIN, Israel N. An axiomatic approach to measurable utility. Cowles Commission Discussion Papers, Econ 2024. 1951. 
HERSTEIN, Israel N. A comment of Marschak's paper: A simplification of the axiomatics of measurable utility, c.c.d.p. economics 2012. Cowles Commission Discussion Papers, Econ 2021. 1951.

HERSTEIN, Israel N. Some mathematical methods and techniques in economics. Quarterly of Applied Mathematics, v. 11, n. 3, p. 249-262, 101953.

HERSTEIN, Israel N.; MILNOR, John. An axiomatic approach to measurable utility. Cowles Commission Discussion Papers, Econ 2039. 1952.

HERSTEIN, Israel N.; MILNOR, John. An axiomatic approach to measurable utility. Econometrica, v. 21, n. 2, p. 291-297, 41953.

HICKS, John. Value and Capital. Oxford: Clarendon Press, [1939] 1975.

HICKS, John R. The Theory of Wages. London: Macmillan, [1932] 1935.

HILDRETH, Clifford. The Cowles Commission in Chicago, 1939-1955. Heidelberg: Springer-Verlag Berlin Heidelberg, [1986] 2012.

HILDRETH, Clifford G. Alternative conditions for social orderings. Econometrica, v. 21, n. 1, p. 81-94, 1953.

HURWICZ, Leonid. The theory of economic behavior. The American Economic Review, v. 35, n. 5, p. 909-925, 1945.

HURWICZ, Leonid. Theory of the firm and of investment. Econometrica, v. 14, n. 2, p. 109-136, 1946.

HURWICZ, Leonid. Review. The Annals of Mathematical Statistics, v. 19, n. 3, p. 436-437, 1948.

HURWICZ, Leonid. What has happened to the Theory of Games. The American Economic Review, v. 43, n. 2, p. 398-405, 1953.

INNOCENTI, Alessandro. Linking strategic interaction and bargaining theory: The Harsanyi-Schelling debate on the axiom of symmetry. History of Political Economy, v. 40, n. 1, p. 111-132, 2008.

KATTSOFF, Louis O. Review. Social Forces, v. 24, n. 2, p. 245-246, 1945.

KAYSEN, Carl. A revolution in economic theory? The Review of Economic Studies, v. 14, n. 1 , p. $1-15,1946-1947$.

KENDALL, Maurice George. Review. Journal of the Royal Statistical Society, v. 107, n. 3/4, p. 293, 1944.

KLEIN, Lawrence R. Macroeconomics and the theory of rational behavior. Econometrica, v. 14, n. 2, p. 93-108, 1946.

KLEIN, Lawrence R. Remarks on the theory of aggregation. Econometrica, v. 14, n. 4, p. 303-312, 1946.

KUHN, Harold A. Introduction. In: Theory of Games and Economic Behavior. Princeton: Princeton University Press, 2007. p. vii-xiv. 
LANGE, Oscar. The foundations of welfare economics. Econometrica, v. 10, p. 215-228, 1942 .

LEONARD, Robert. Von Neumann, Morgenstern, and the Creation of Game Theory: From Chess to Social Science, 1900-1960. New York: Cambridge University Press, 2010.

LEONTIEF, Wassily W. Mathematics in economics. Bulletin of the American Mathematical Society, v. 60, n. 3, p. 215-233, 1954.

MALINVAUD, Edmond. Note on von Neumann-Morgenstern's strong independence axiom. Econometrica, v. 20, n. 4, p. 679, 1952.

MALINVAUD, Edmond. Econometric methodology at the Cowles Commission: rise and maturity. Avaiable at <https://cowles.yale.edu/50th-anniversary-celebration $>$. Accessed in 29 March, 2019. 1983.

MANNE, Alan S.; CHARNES, Abraham. The strong independence assumption-gasoline blends and probability mixtures. Econometrica, v. 20, n. 4, p. 665-669, 1952.

MARSCHAK, Jacob. Review. Journal of Political Economy, v. 54, n. 2, p. 97-115, 1946.

MARSCHAK, Jacob. Abstract: Measurable utility and the theory of assets. Cowles Commission Discussion Papers, Abbreviated and Revised Version of Econ 226. 1948.

MARSCHAK, Jacob. Measurable utility and the theory of assets. Cowles Commission Discussion Papers, Econ 226. 1948.

MARSCHAK, Jacob. Rational behavior, uncertain prospects, and measurable utility. Econometrica, v. 18, n. 2, p. 111-141, 41950.

MARSCHAK, Jacob. A simplification of the axiomatics of measurable utility. Cowles Commission Discussion Papers, Econ 2012. 1951.

MARSCHAK, Jacob. Why "should" statisticians and businessmen maximize "moral expectation"? In: NEYMAN, Jerzy (Ed.). Proceedings Of The Second Berkeley Symposium On Mathematical Statistics And Probability. Berkeley and Los Angeles: University of California Press, 1951. p. 493-506.

MARSCHAK, Jacob. Towards an economic theory of organization and information. In: THRALL, Robert M.; COOMBS, Clyde H.; DAVIS, Robert L. (Ed.). Decision Processes. New York: John Wiley \& Sons, 1954. p. 61-68.

MARSCHAK, Jacob; MICKEY, M. R. Optimal weapon systems. Naval Research Logistics Quarterly, v. 1, n. 2, p. 116-140, 1954.

MAS-COLELL, Andreu; WHINSTON, Michael D.; GREEN, Jerry R. Microeconomic Theory. New York: Oxford University Press, 1995.

MORISHIMA, Michio. Consumer's behavior and liquidity preference. Econometrica, v. 20, n. 2, p. 223-246, 1952.

MOSCATI, Ivan. How cardinal utility entered economic analysis: 1909-1944. The European Journal of the History of Economic Thought, v. 20, n. 6, p. 906-939, 2013. 
MOSCATI, Ivan. How economists came to accept expected utility theory: the case of Samuelson and Savage. Journal of Economic Perspectives, v. 30, n. 2, p. 219-36, 2016.

MOSCATI, Ivan. Expected utility theory and experimental utility measurement, 1950-1985. From confidence to scepticism. The European Journal of the History of Economic Thought, v. 24, n. 6, p. 1318-1354, 2017.

NAGEL, Ernest. Review. The Journal of Philosophy, v. 42, n. 20, p. 550-554, 1945.

NASAR, Sylvia. A Beautiful Mind. New York: Simon \& Schuster, 1998.

NASH, John F. The bargaining problem. Econometrica, v. 18, n. 2, p. 155-162, 1950.

NASH, John F. Equilibrium points in n-person games. Proceedings of the National Academy of Sciences of the United States of America, v. 36, n. 1, p. 48-49, 1950.

NASH, John F. Non-cooperative games. Annals of Mathematics (Second Series), v. 54, n. 2, p. 286-295, 1951.

NASH, John F. Two-person cooperative games. Econometrica, v. 21, n. 1, p. 128-140, 1953.

PARETO, Vilfredo D. Manual of Political Economy. New York: Macmillan, [1909] 1971.

PEN, Jan. A general theory of bargaining. The American Economic Review, v. 42, n. 1, p. 24-42, 1952.

RADNER, Roy. Marschak, Jacob (1898-1977). In: MACMILLAN, Palgrave (Ed.). The New Palgrave Dictionary of Economics. London: Palgrave Macmillan, 2018. p. 8343-8347.

RADNER, Roy; MARSCHAK, Jacob. Note on some proposed decision criteria. In: THRALL, Robert M.; COOMBS, Clyde H.; DAVIS, Robert L. (Ed.). Decision Processes. New York: John Wiley \& Sons, 1954. p. 61-68.

RILEY, Lawrence E.; SPREITZER, Elmer A. Book reviewing in the social sciences. The American Sociologist, v. 5, n. 4, p. 358-363, 1970.

ROY, Andrew D. Safety first and the holding of assets. Econometrica, v. 20, n. 3, p. 431-449, 71952.

RUBIN, Herman. The existence of measurable utility and psychological probability. Cowles Commission Discussion Papers, Stat 331. 1949.

SAMUELSON, Paul A. Probability, utility, and the independence axiom. Econometrica, v. 20, n. 4, p. 670-678, 1952.

SAMUELSON, Paul A. Probability and the attempts to measure utility. In: STIGLITZ, Joseph E. (Ed.). The Collected Scientific Papers of Paul A. Samuelson. New York: Oxford \& I.B.H. Publishing Co., [1950] 1966. p. 117-126.

SAMUELSON, Paul A. Utility, preference, and probability. In: STIGLITZ, Joseph E. (Ed.). The Collected Scientific Papers of Paul A. Samuelson. New York: Oxford \& I.B.H. Publishing Co., [1950] 1966. p. 127-136. 
SAVAGE, Leonard Jimmie. The Foundations of Statistics. New York: Dover Publications, [1954] 1972.

SCHMIDT, Torsten; WEBER, Christian E. On the origins of ordinal utility: Andreas Heinrich Voigt and the mathematicians. History of Political Economy, v. 40, n. 3, p. 481-510, 2008.

SERRANO, Roberto. Bargaining. In: MACMILLAN, Palgrave (Ed.). The New Palgrave Dictionary of Economics. London: Palgrave Macmillan, 2018. p. 717-731.

SIMON, Herbert A. Review. American Journal of Sociology, v. 50, n. 6, p. 558-560, 1945.

SMITH, Cedric A. B. Review. The Mathematical Gazette, v. 29, n. 285, p. 131-133, 1945.

STAPLEFORD, Thomas A. Historical epistemology and the history of economics: Views through the lens of practice. Research in the History of Economic Thought and Methodology, v. 35A, p. 113-145, 2017.

STONE, John R. N. Review. The Economic Journal, v. 58, n. 230, p. 185-201, 1948.

STROTZ, Robert H. Cardinal utility. The American Economic Review, v. 43, n. 2, p. 384-397, 1953.

VON NEUMANN, John. A numerical method to determine optimum strategy. Naval Research Logistics Quarterly, v. 1, n. 2, p. 109-115, 1954.

VON NEUMANN, John; MORGENSTERN, Oskar. Theory of Games and Economic Behavior. Princeton: Princeton University Press, [1944] 2007.

WAGNER, Harvey M. A unified treatment of bargaining theory. Southern Economic Journal, v. 23, n. 4, p. 380, 1957.

WAGNER, Harvey M. Advances in game theory. The American Economic Review, v. 48, n. 3 , p. $368-387,1958$.

WALD, Abraham. Statistical decision functions which minimize the maximum risk. Annals of Mathematics, p. 265-280, 1945.

WALD, Abraham. Review. The Review of Economics and Statistics, v. 29, n. 1, p. 47-52, 1947.

WATSON, Joel. Nash, John Forbes (born 1928). In: MACMILLAN, Palgrave (Ed.). The New Palgrave Dictionary of Economics. London: Palgrave Macmillan, 2018. p. 9276-9283.

WEINTRAUB, E. Roy. How Economics Became a Mathematical Science. Durham: Duke University Press, 2002.

WEINTRAUB, E. Roy; MIROWSKI, Philip. The pure and the applied: Bourbakism comes to mathematical economics. Science in Context, v. 7, n. 2, p. 245-272, 1994.

WOLD, Herman O. A.; SHACKLE, George L. S.; SAVAGE, Leonard J. Ordinal preferences or cardinal utility? Econometrica, v. 20, n. 4, p. 661-664, 1952. 